\title{
WESF Cesium Capsule Behavior at High Temperature or During Thermal Cycling
}

\author{
G. L. Tingey \\ W. J. Gray \\ R. J. Shippell \\ Y. B. Katayama
}

June 1985

Prepared for the U.S. Department of Energy under Contract DE-AC06-76RLO 1830

Pacific Northwest Laboratory Operated for the U.S. Department of Energy by Battelle Memorial Institute 


\title{
DISCLAIMER
}

This report was prepared as an account of work sponsored by an agency of the United States Government. Neither the United States Government nor any agency thereof, nor any of their employees, makes any warranty, express or implied, or assumes any legal liability or responsibility for the accuracy, cornpleteness, or usefulness of any information, apparatus, product, or process disclosed, or represents that its use would not infringe privately owned rights. Reference herein to any specific commercial product, process, or service by trade name, trademark, manufacturer, or otherwise, does not necessarily constitute or imply its endorsement, recommendation, or favoring by the United States Government or any agency thereof. The views and opinions of authors expressed herein do not necessarily state or reflect those of the United States Government or any agency thereof.

\author{
PACIFIC NORTHWEST LABORATORY \\ operated by \\ BATTELLE \\ for the \\ UNITED STATES DEPARTMENT OF ENERGY \\ under Contract DE-AC06-76RLO 1830
}

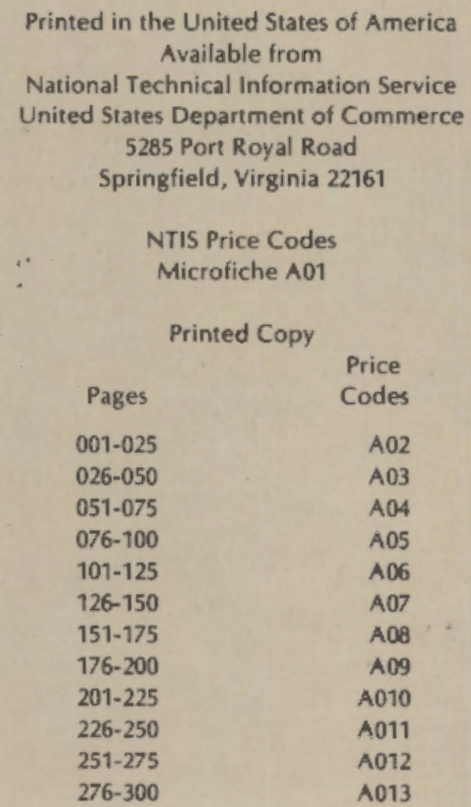




\section{0}

WESF CESIUM CAPSULE BEHAVIOR

AT HIGH TEMPERATLRE OR OURING

THERMAL CYCLING

\section{G. L. Tingey \\ W. J. Gray \\ R. 3. Shippell \\ Y. B. Katayama}

June 1985

Prepared for the U.S. Department of Energy under Contract DE-AC06-76RLO 1830

Pacific Northwest Laboratory Richland, Washington 99352 


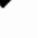




\section{SUMMARY}

A Yanford Waste Encapsulation and Storage Facility (WESF) capsute was filled with a nonradioactive salt mixture to simulate cesium chloride that had decayed for 1 half-life ( 30 years). The impurities found in the radioactive HESF capsules were also included in the salt mixture. This capsule, which was filled to a loading factor of $3.11 \mathrm{~g}$ of $s a l \mathrm{t} / \mathrm{cm}^{3}$ of inner capsule volume, was heated in an $800^{\circ} \mathrm{C}$ furnace for 90 min to examine the possible effects from an accidental fire. The end cap weld of the inner capsule failed, opening a small crack and allowing the molten salt mixture to flow into the annulus between the inner and outer capsules. The salt, however, was contained in the outer capsule, which has the same wall thickness as the inner capsule. Corrosion of the inner capsule wall by the salt was quite high $(0.005$ to $0.010 \mathrm{in.} / \mathrm{h})$, as expected at this temperature; however, corrosion should not be of consequence in a short-duration fire.

Based on the results of this test, WESF capsules can be used safely even in the unlikely event of a short-duration $800^{\circ} \mathrm{C}$ temperature excursion. Capsules with loading factors equal to or less than $2.71 \mathrm{~g} / \mathrm{cm}^{3}$ are not expected to be stressed on either the inner or outer capsule walls, thus assuring capsule integrity. About $40 \%$ of the capsules in the WESF pool have loading factors higher than $2.71 \mathrm{~g} / \mathrm{cm}^{3}$ and could potentially have inner capsule weld failures under the conditions of this test, but none of the capsules planned for irradiator use has a loading factor high enough to produce stress from salt expansion on the outer capsule. Since the most highly loaded capsules may have inner end cap weld failure when subjected to a fire, consideration should be given to removing them from service if they are ever subjected to such high temperatures.

In a wet storage/dry operation irradiator, capsules are thermally cycled as they are transferred from the water storage pool to the air environment. The results of a finite-element analysis of themal cycling indicate that the most severe thermal stresses are placed on the outer capsule bottom end cap weld. This weld is subjected to temperature differences up to $36^{\circ} \mathrm{C}$ across the weld when the capsules are lowered into the water. The stresses generated by 
such temperature differences are projected to produce a crack growth rate of $2.9 \times 10^{-9} \mathrm{in./cycle.} \mathrm{Thus,} \mathrm{a} \mathrm{weld} \mathrm{crack} \mathrm{of} \mathrm{only} 0.0001$ in. would be expected from a capsute after $3.5 \times 10^{4}$ cycles (94 years if cycled once each day).

An experiment was conducted to verify the theoretical calculations using WESF capsules filled with radioactive cesium chloride. After 3845 cycles, no evidence of cracking or thermal stress was observed on either of the outer capsule welds during high-resolution metallographic examination. Although this short-term test does not quantitatively verify the projection, it does indicate that no unanticipated, observable thermal effects occur in the first 3800 cycles. The test simulates the stresses expected during 10.5 years of operation with the capsules cycled once each day during irradiator operation. 
CONTENTS

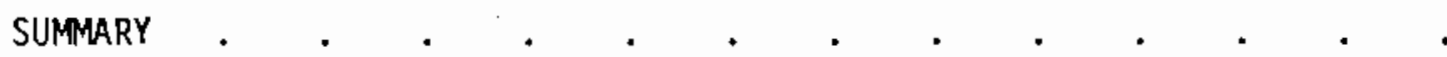

INTRODUCTION

CAPSULE SWELLING DUE TO THERMAL EXPANSION OF CESIUM CHLORIDE AT $800^{\circ} \mathrm{C}$.

TEST PROCEDURE AND RESULTS . . . . . . . . . . . . . . . 4

Salt Preparation and Characterization . . . . . $\quad . \quad 4$

Capsule Characterization and Loading Factor . . . . 7

Capsule Closure and Heat Treatment . . . . . 11

Post-Heat-Treatment Analyses . . . . . . . . 12

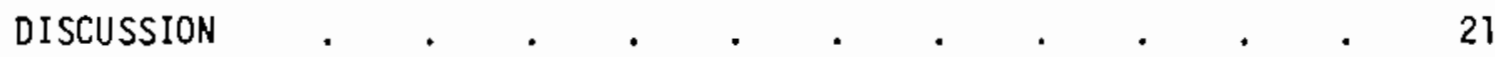

THERMAL STRESS DURING THERMAL CYCLING . . . . . . . . . . . . . 25

METHOO OF ANALYSIS . . . . . . . . . . . . . 25

Assumptions . . . . . . . . . . . 26

Geometry . . . . . . . . . . . . 27

Boundary Conditions . $\quad . \quad$. $\quad . \quad$. . . . 27

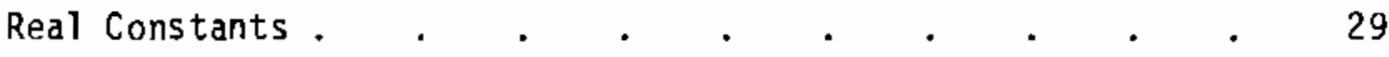

Material Properties. . . . . . . . . . . . 30

Loads $\quad . \quad . \quad . \quad . \quad . \quad . \quad . \quad . \quad . \quad . \quad . \quad . \quad . \quad . \quad 30$

RESULTS . $\quad . \quad$. $\quad . \quad$. . . . . . . . . . . 30

One-Dimensional Thermal Model . . . . . . . . 30

Two-Dimensional Thermal Model . $\quad . \quad . \quad . \quad . \quad . \quad . \quad . \quad 37$

Two-Dimensional Mechanical Model . . . . . . . . 46

EXPERIMENTAL VERIFICATION OF THERMAL STRESS PROJECTIONS • • 50

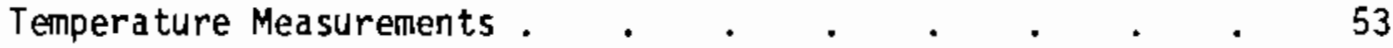

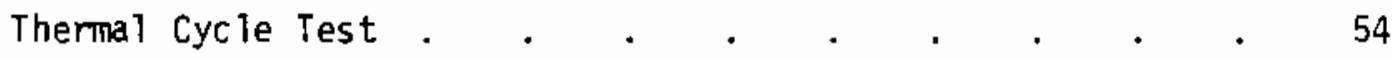




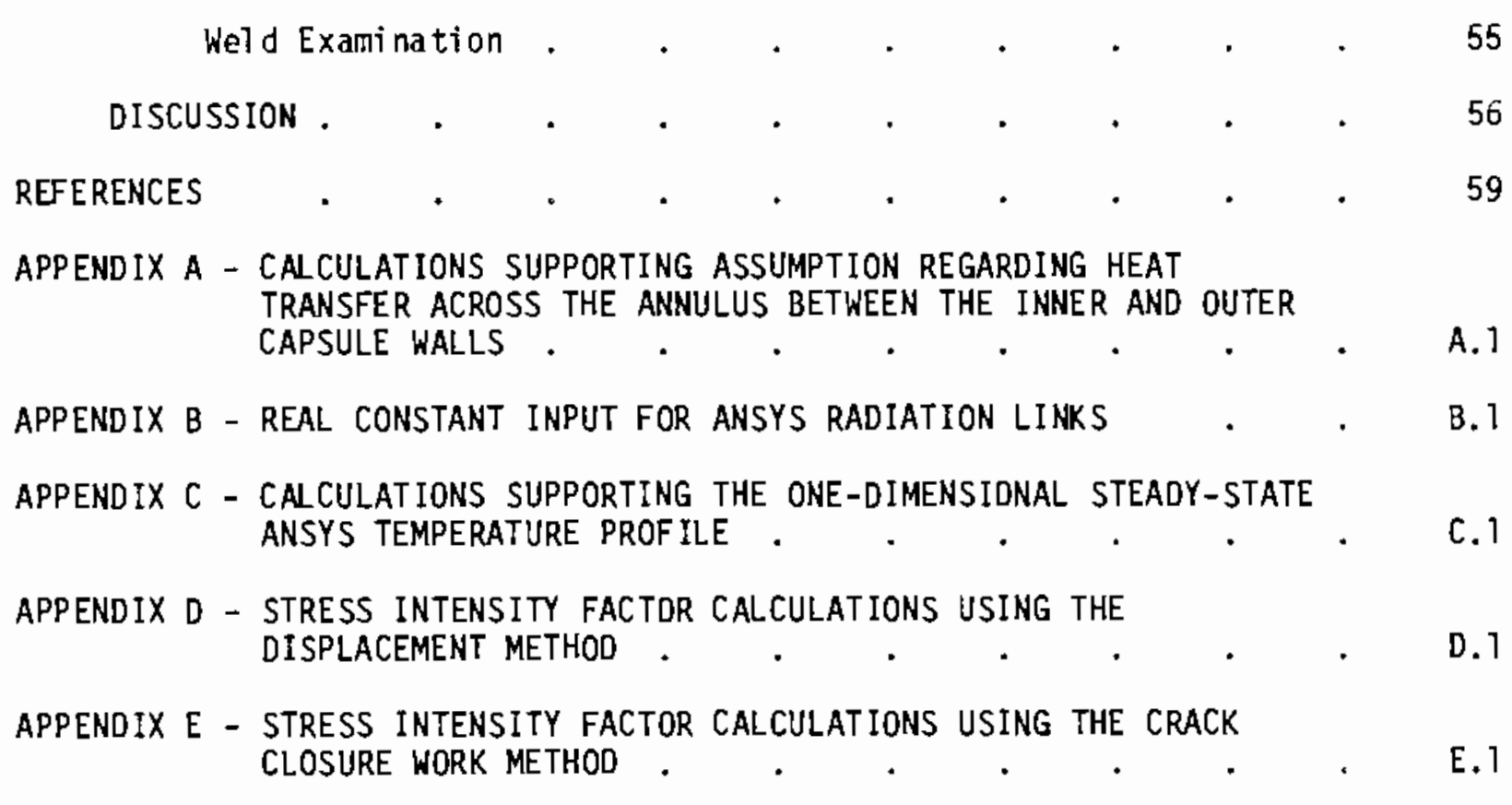




\section{FIGURES}

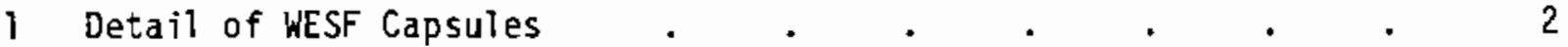

2 WESF Capsules Showing Measurement Locations and Other Parameters . 10

3 Inner Capsule Showing Bulged End, Failed Weld Area, and Salt Incrustation $. \quad . \quad . \quad . \quad . \quad . \quad . \quad 13$

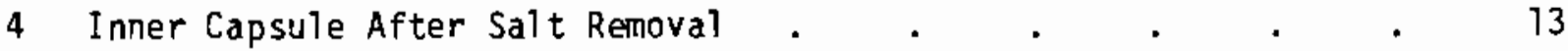

5 Macrographic Cross Section of Inner Capsule in Vicinity of Failed Weld . . . . . . . . . . . . 15

6 Micrograph of Failed Weld . . . . . . . . . . . . . 15

7 Macrographic Cross Section of Inner Capsule Opposite the Failed Weld Area. . . . . . . . . . . . 16

8 Micrographs of Weld Area Opposite the Failed Area . . . 16

9 Failed Weld Area After Repolishing and Etching. . . . 17

10 Weld Area Opposite the Failed Area After Repolishing and Etching

11 Micrograph of Center Region of Inner Capsule Showing the Salt/Stainless Steel Boundary $. \quad . \quad . \quad . \quad . \quad 18$

12 Magnification of the Stainless Steel Region in Figure 11 . . 18

13 Micrograph of Sintered Disk . . . . . . . . . . . . $\quad$. 19

14 Finite-Element Mesh of the One-Dimensional Thermal Model . . 28

15 Finite-Element Mesh of the Upper Weld Region - Two-Dimensional Model

16 Finite-Element Mesh of the Lower Weld Region - Two-Dimensional

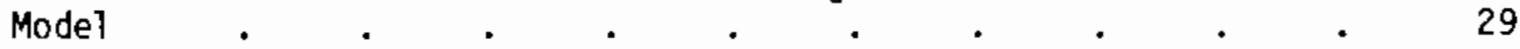

17 One-Dimensional Radial Temperature Profiles at Steady-State In-Air Condition.

18 One-Dimensional Radial Temperature Profiles at Steady-State In-Water Condition

19 One-Dimensional Radial Temperature Profiles at Steady-State In-Air Condition with Varying Annulus Gap 
20 One-Dimensional Radial Temperature Profiles at Steady-State In-Water Condition with Varying Annulus Gap

21 One-Dimensional Radial Temperature Profiles at Steady-State In-Air Condition with Distributed Thermal Power

22 One-Dimensional Radial Temperature Profiles at Steady-State In-Water Condition with Distributed Thermal Power.

23 Two-Dimensional Maximum Radial Temperature Profiles at SteadyState In-Air and In-Water Conditions

24 Two-Dimensional Salt/Wall Interface Axial Temperature Profiles at Steady-State In-Air and In-Water Conditions .

25 Two-Dimensional Maximum CsCl Axial Temperature Profiles at Steady-State In-Air and In-Water Conditions

26 Two-Dimensional Temperature Profiles of Upper Weld Area Response to Water Quench.

27 Two-Dimensional Temperature Profiles of Lower Weld Area Response to Water Quench.

28 Two-Dimensional Temperature Differences in Upper Weld Area as Result of Water Quench.

29 Two-Dimensionat Temperature Differences in Lower Weld Area as Result of Water Quench.

30 Two-Dimensional Temperature Profiles of Upper Weld Area Response to Air Heatup.

31 Two-Dimensional Temperature Profiles of Lower Weld Area Response to Air Heatup.

32 Two-Dimensional Temperature Differences in Upper Weld Area as Result of Air Heatup

33 Two-Dimensional Temperature Differences in Lower Weld Area as Result of Air Heatup

34 Effect of Crack Growth on the Relative Change in Stress Intensity Factor for the Upper Weid

35 Effect of Crack Growth on the Relative Change in Stress Intensity Factor for the Lower Weld

36 Fatigue Crack Growth Rate Data for Stainless Steels - Conditions of Low and High Stress Ratio, Laboratory Air, and Simulated PWR Environment 
37 Location of Thermocouples on the Thermocycled Cesium Capsules . 52

38 Temperature Cycles of Thermocycled Capsules at Two Points, One on Each Side of Weld

39 Micrographs of the Etched Weld Section of a WESF Cesium Capsule After Thermal Cycling for 3845 Cycles . . . . . 


\section{TABLES}

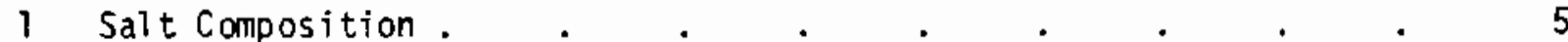

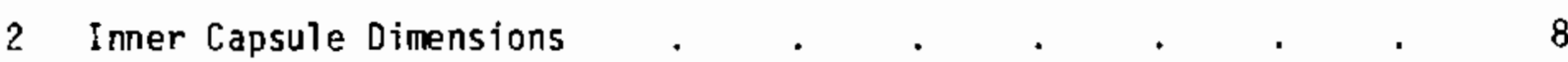

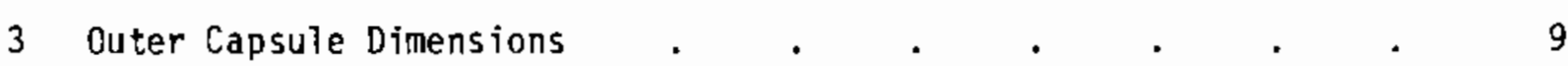

4 Additional Capsule Parameters . . . . . . . . . . 11

5 Composition of Salt in Capsule After Heat Treatment . . . . 20

6 CsCl Capsule ANSYS Thermal Properties . . . . . . . . . . 31

7 CsCl Capsule ANSYS Mechanical Properties . . . . . . . 31

8 Description of WESF Cesium Capsules $\quad$. $\quad . \quad \ldots \quad$. . . 52

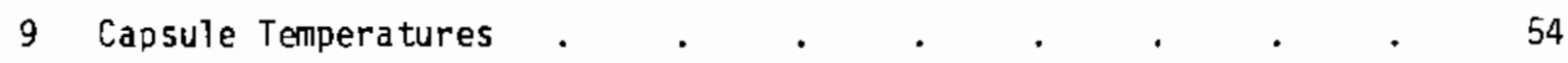




\section{INTROOUCTION}

Double-walled stainless steel (SS) capsules prepared for storage of radioactive ${ }^{137} \mathrm{Cs}$ from defense waste are now being considered for use as sources for commercial. irradiation. Cesium was recovered at B-plant from the highlevel radioactive waste generated during processing of defense nuclear fuel. It was then purified, converted to the chloride form, and encapsulated at the Hanford Waste Encapsulation and Storage Facility (WESF). The molten cesium chloride salt was encapsulated by pouring it into the inner of two concentric SS cylinders. Each cylinder was fitted with a SS end cap that was welded in place by inert gas-tungsten arc welding. The capsule configuration and dimensions are shown in Figure 1.

In a recent review of the safety of these capsules, Tingey, Wheelwright, and Lytle (1984) indicated that experimental studies were continuing to produce long-term corrosion data, to reaffirm capsule integrity during a 90-min fire where capsule temperatures reached $800^{\circ} \mathrm{C}$, to monitor mechanical properties as a function of time, and to assess the effects of thermal cycling due to periodic transfer of the capsules from a water storage pool to the air environment. of an irradiator facility.

This report covers results from tests that simulated the effects of the 90-min fire and from thermal cycling actual WESF cesium capsules for 3845 cycles over a period of six months. This work was conducted by Pacific Northwest Laboratory (PNL) ${ }^{(a)}$ under the Defense Byproducts Production and Utilization Program.

(a) Operated for the U.S. Department of Energy (DOE) by Battelle Memorial Institute under Contract DE-AC06-76RLO 1830. 


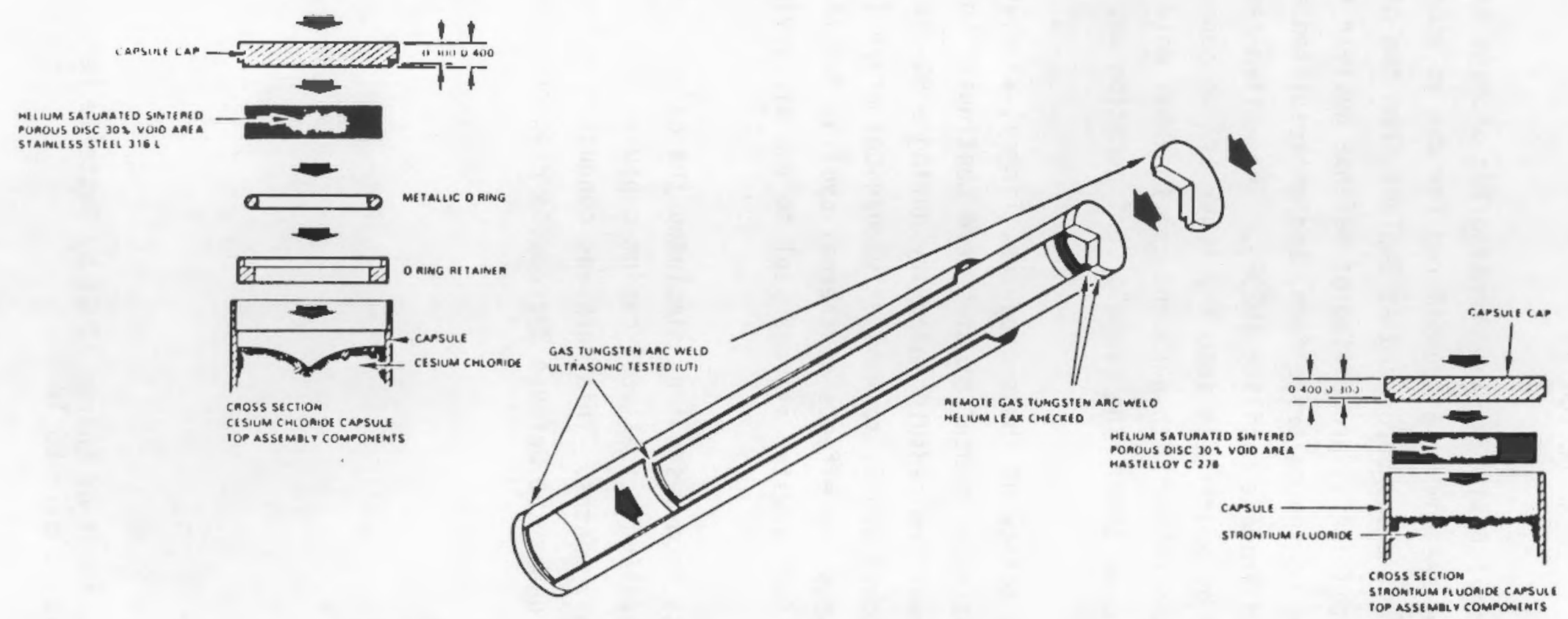

\begin{tabular}{|c|c|c|c|c|c|c|c|c|c|c|}
\hline & \multicolumn{10}{|c|}{ CAPSULE } \\
\hline & & & INMEn & & & & & outin & & \\
\hline & MAIEMIAL & $\begin{array}{l}\text { WALL } \\
\text { Thickents: }\end{array}$ & 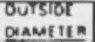 & $\begin{array}{l}\text { Toral } \\
\text { IEMGTH }\end{array}$ & 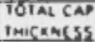 & Matemial & $\begin{array}{l}\text { WALL } \\
\text { IMICKNESS }\end{array}$ & 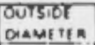 & $\begin{array}{l}\text { rorki } \\
\text { if }\end{array}$ & $\begin{array}{l}\text { Tolke } \\
\text { twickiss }\end{array}$ \\
\hline $\begin{array}{l}\text { Sthomilium } \\
\text { fluoniot }\end{array}$ & $\begin{array}{l}\text { massiftion } \\
\text { C 210 }\end{array}$ & 0136 & 2250 & 10000 & 0400 & $\begin{array}{l}\text { Shaintess } \\
\text { s1:EL }\end{array}$ & 0136 & 2025 & 20100 & 04000 \\
\hline $\begin{array}{l}\text { CESIUM } \\
\text { CHLOAIOE }\end{array}$ & $\begin{array}{l}\text { Stainuss } \\
\text { stef } \\
3161\end{array}$ & שנום & 2350 & ל5 12 & 0400 & $\begin{array}{l}\text { SIAIMLESS } \\
\text { s1Ek } \\
3162\end{array}$ & 0136 & 2023 & $20 \mathrm{~ms}$ & 0400 \\
\hline
\end{tabular}

FIGURE 1. Detail of WESF Capsules 


\section{CAPSULE SWELLING OUE TO THERMAL EXPANSION OF CESIUM CHLORIOE AT $800^{\circ} \mathrm{C}$}

Pure cesium chloride expands to about 1.5 times its initial volume when heated from 25 to $800^{\circ} \mathrm{C}$. Components of this expansion include thermal expansion of the solid and liquid phases, an $18 \%$ expansion during the crystalline phase transition from body-centered cubic to the face-centered cubic structure that occurs at $469^{\circ} \mathrm{C}$, and a $10 \%$ expansion during the solid-to-liquid transition at $645^{\circ} \mathrm{C}$. In the event of a fire, which could increase the temperature of the capsule and its contents to $800^{\circ} \mathrm{C}$, volume expansion has the potential for stressing the WESF capsules.

The radioactive WESF capsules were filled with salt by pouring mol ten cesium chloride into the inner container at a salt temperature of 700 to $750^{\circ} \mathrm{C}$. During cooling to its steady-state temperature, the salt shrinks, leaving a substantial void volume at the top. This void volume would normally be sufficient to accommodate any expansion occurring at salt temperatures up to $750^{\circ} \mathrm{C}$. In some cases, however, additional molten cesium chloride was added after cooling to "top off" those capsules that had been only partially filled. Additional molten cesium chloride may have been allowed to flow into the capsule during cooldown. Thus, the high-temperature salt volume may be greater than the inner capsule internal volume, which would cause the inner capsule to swell or even rupture if it were subjected to high temperatures after closure.

Capsule loading factors (salt weight/capsule volume at $25^{\circ} \mathrm{C}$ ) were determined for WESF capsules using the measured salt mass and the nominal capsule volume. Using these data, the extent of swelling required to accommodate the salt volume at any temperature (if the salt were pure cesium chloride) can be estimated. However, since there is $10 \%$ to $20 \%$ impurity in the salt initially and since ${ }^{137} \mathrm{Cs}$ decays to ${ }^{137} \mathrm{Ba}$, the specific volume of the salt mixture at temperature cannot be calculated directly. An experiment was conducted to measure the potential for swelling of the capsules using a nonradioactive salt mixture to simulate the WESF salt after 1 half-1ife (30 years) of decay time. The following paragraphs describe the test and the results of the study. 


\section{TEST PROCEOURE ANO RESULTS}

Test procedures (including the salt preparation and characterization), capsule characterization, loading factor, closure, heat treatment, and postheat-treatment analysis are described in this section. Test results are also presented.

\section{Salt Preparation and Characterization}

The salt composition was chosen to be representative of the WESF salt after 1 half-life ( 30 years) of ${ }^{137} \mathrm{Cs}$ decay. Thus, barium was added assuming that $33 \%$ of the original $\mathrm{Cs}$ was ${ }^{137} \mathrm{Cs}$ (Tingey, Wheelwright, and Lytle 1984, p. 17). In addition, the salt mixture included impurities based on the most likely composition from previous analyses (Tingey, Wheelwright, and Lytle 1984, p. 15). Table 1 gives the nominal and analyzed compositions of the salt that was prepared and lists the actual compounds that went into the mixture.

When ${ }^{137} \mathrm{Cs}_{s}$ decays to ${ }^{137} \mathrm{Ba}$, a di sproportionation reaction such as the following is postulated:

$$
\mathrm{CsCl}+\mathrm{BaCl} \rightarrow \frac{3}{2} \mathrm{Ba}+\frac{1}{2} \mathrm{BaCl}_{2}
$$

Therefore, half the $\mathrm{Ba}$ was included in metallic form and half in chloride form. The metallic Ba was a solid rod that was cut into roughly $1 \mathrm{~mm} \times 3 \mathrm{~mm} \times 3 \mathrm{~mm}$ chunks in an argon glove box; the oxygen concentration was maintained below $10 \mathrm{ppm}$. All the chemicals were in anhydrous form, either purchased or dried in a laboratory oven before use. Approximately $4 \mathrm{~kg}$ of the mixture and some $\mathrm{Al}_{2} \mathrm{O}_{3}$ balls were sealed in a large polyethylene bottle in the argon glove box. The bottle was then removed from the glove box and rolled on a ball mill for $\sim \mathrm{h}$ to thoroughly mix the chemicals.

After mixing, the chemicals were returned to the argon glove box, melted, and poured into the inner capsule. Each melt consisted of about $500 \mathrm{~g}$ of salt that was placed in a SS crucible and then in a furnace preheated to $800^{\circ} \mathrm{C}$. As the mixture began to melt, the Ba metal chunks lying near the surface were observed to undergo some type of rather violent reaction that caused some material to splatter from the crucible. Bubbling and frothing also occurred, indicating gas release. However, these reactions were of short duration and little 
TABLE 1. Salt Composition

Nominal

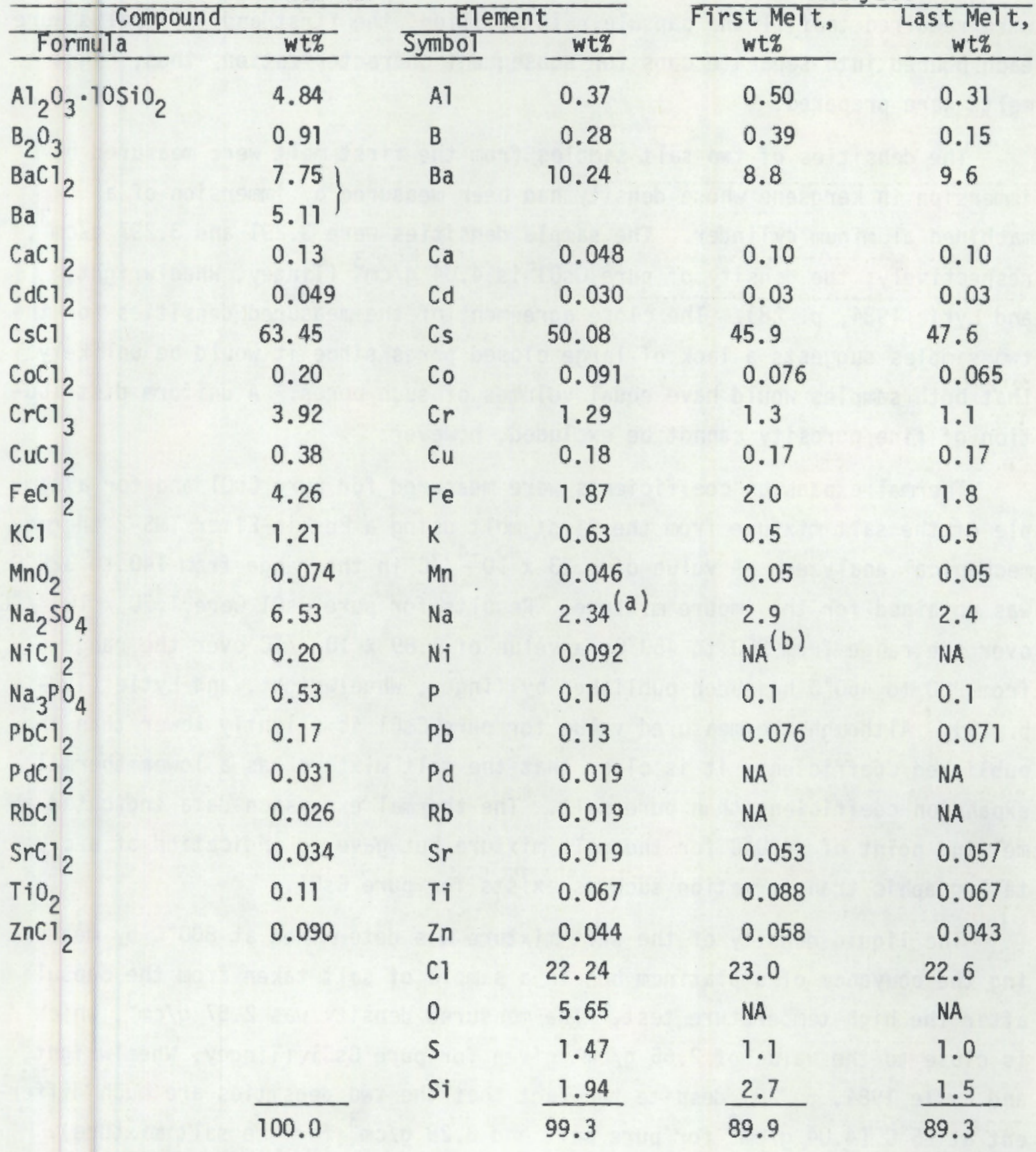

(a) Includes $\mathrm{Na}$ from $\mathrm{Na}_{3} \mathrm{PO}_{4}$.

(b) NA = not analyzed. 
material was lost from the crucible. After melting appeared to be complete, the mixture was maintained at $800^{\circ} \mathrm{C}$ for 20 to 30 min before pouring. Six melts were required to fill the capsule. In addition, the first and last melts were each poured into separate cans for subsequent characterization; thus, eight melts were prepared.

The densities of two salt samples from the first melt were measured by immersion in kerosene whose density had been measured by immersion of a machined aluminum cylinder. The sample densities were 3.291 and $3.297 \mathrm{~g} / \mathrm{cm}^{3}$, respectively; the density of pure $\mathrm{CsCl}$ is $4.04 \mathrm{~g} / \mathrm{cm}^{3}$ (Tingey, Wheelwright, and Lytle 1984, p. 28). The close agreement of the measured densities for the two samples suggests a lack of large closed pores since it would be unlikely that both samples would have equal volumes of such pores. A uniform distribution of fine porosity cannot be excluded, however.

Thermal expansion coefficients were measured for pure $\mathrm{CsCl}$ and for a sample of the salt mixture from the first melt using a Perkin-Elmer TMS-2 thermomechanical analyzer. A value of $1.23 \times 10^{-4} /{ }^{\circ} \mathrm{C}$ in the range from 140 to $325^{\circ} \mathrm{C}$ was obtained for the impure mixture. Results for pure $\mathrm{CsCl}$ were $1.70 \times 10^{-4} /{ }^{\circ} \mathrm{C}$ over the range from 200 to $450^{\circ} \mathrm{C}$; a value of $1.89 \times 10^{-4} /{ }^{\circ} \mathrm{C}$ over the range from 200 to $460^{\circ} \mathrm{C}$ has been published by Tingey, Wheelwright, and Lytle (1984, p. 28). Although the measured value for pure $\mathrm{CsCl}$ is slightly lower than the published coefficient, it is clear that the salt mixture has a lower thermal expansion coefficient than pure salt. The thermal expansion data indicated a melting point of $\sim 430^{\circ} \mathrm{C}$ for the salt mixture but gave no indication of a crystallographic transformation such as exists for pure $\mathrm{CsCl}$.

The liquid density of the salt mixture was determined at $800^{\circ} \mathrm{C}$ by measuring the bouyancy of a platinum bob in a sample of salt taken from the capsule after the high-temperature test. The measured density was $2.57 \mathrm{~g} / \mathrm{cm}^{3}$, which is close to the value of $2.65 \mathrm{~g} / \mathrm{cm}^{3}$ given for pure $\mathrm{CsCl}$ (Tingey, Wheelwright, and Lytle 1984, p. 28) despite the fact that the two densities are much different at $25^{\circ} \mathrm{C}\left(4.04 \mathrm{~g} / \mathrm{cm}^{3}\right.$ for pure salt and $3.29 \mathrm{~g} / \mathrm{cm}^{3}$ for the salt mixture).

Both the first and last melts were chemically analyzed for all but a few constituents, the most notable exception being oxygen. The composition of the two samples was essentially the same and in good agreement with that 
calculated from the compounds added in the preparation (Table 1). The lower fraction of cesium was expected due to vaporization losses during melting. Barium may also have vaporized somewhat, and some may have been lost due to splattering that occurred during the violent reaction during initial mel ting. If the nominal values for $\mathrm{O}, \mathrm{Ni}, \mathrm{Pd}$, and $\mathrm{Rb}$ are added to the total analyzed constituents, the sum is greater than $95 \%$ of the sample weight, indicating a reasonably complete mass balance.

\section{Capsule Characterization and Loading Factor}

Tables 2 and 3 list the measured dimensions for the inner and outer capsules used in this study. The locations of the dimensional measurements, the end caps, the sintered disk, and the 0-ring and retainer that are placed in the ends of the capsules are shown in Figure 2. The inner wall at the ends of the capsules was machined from 0.14 to $0.08 \mathrm{in}$. to accommodate the 0 -ring and retainer. Additional capsule dimensions are given in Table 4.

The capsule loading factor is defined as the weight of the salt divided by the capsule volume at $25^{\circ} \mathrm{C}$. The loading factor selected for this test was calculated to cause the inner capsule diameter to swell just enough at $800^{\circ} \mathrm{C}$ to fill the annulus between the inner and outer capsules. Since the density and thermal expansion of the salt mixture were not known, the values for pure CsCl were used even though it was recognized that this might lead to considerable error. The volume of the inner capsule available to the salt was assumed to be the total free volume excluding the porosity in the sintered metal disk. To this volume, the volume of the annulus between the inner and outer capsules over the inside length of the inner capsule was added. After adjusting for thermal expansion, this volume at $800^{\circ} \mathrm{C}$ was determined to be $1120 \mathrm{~cm}^{3}$. Since the density of $\mathrm{CsCl}$ at $800^{\circ} \mathrm{C}$ is $2.65 \mathrm{~g} / \mathrm{cm}^{3}$ (Tingey, Wheelwright, and Lytle 1984 , p. 28), the desired weight of the salt was taken to be $2967 \mathrm{~g}$. The room temperature volume of the inner capsule up to the bottom of the sintered metal disk (see Table 4) was $918 \mathrm{~cm}^{3}$. Thus, the desired loading factor was $2967 / 918=3.23 \mathrm{~g} / \mathrm{cm}^{3}$. 
TABLE 2. Inner Capsule Dimensions

\begin{tabular}{|c|c|c|c|c|}
\hline \multirow{2}{*}{$\begin{array}{l}\text { Measurement } \\
\text { Position (a) }\end{array}$} & \multirow{2}{*}{\multicolumn{4}{|c|}{$\begin{array}{c}\text { Dimensions, in. } \\
\end{array}$}} \\
\hline & Initial & After Welding & & Difference (c) \\
\hline IA & 2.2533 & 2.2537 & 2.4054 & 0.1517 \\
\hline $2 \mathrm{~A}$ & 2.2537 & 2.2537 & 2.2859 & 0.0322 \\
\hline $3 A$ & 2.2541 & 2.2543 & 2.2848 & 0.0305 \\
\hline $4 \mathrm{~A}$ & 2.2523 & 2.2532 & 2.2880 & 0.0359 \\
\hline $5 \mathrm{~A}$ & 2.2528 & 2.2540 & 2.2899 & 0.0359 \\
\hline $6 \mathrm{~A}$ & 2.2530 & 2.2530 & 2.3000 & 0.0470 \\
\hline 1B & 2.2538 & 2.2525 & 2.4021 & 0.1496 \\
\hline $2 B$ & 2.2548 & 2.2545 & 2.2880 & 0.0335 \\
\hline $3 B$ & 2.2538 & 2.2537 & 2.2897 & 0.0360 \\
\hline $4 B$ & 2.2535 & 2.2531 & 2.2862 & 0.0331 \\
\hline $5 B$ & 2.2534 & 2.2531 & 2.2884 & 0.0353 \\
\hline $6 B$ & 2.2530 & 2.2523 & 2.3000 & 0.0477 \\
\hline $1 C$ & 19.7172 & 19.7090 & 19.7350 & 0.0260 \\
\hline $2 \mathrm{C}$ & 19.7171 & 19.7098 & 19.7455 & 0.0357 \\
\hline $3 \mathrm{C}$ & 19.7191 & 19.7083 & 19.7341 & 0.0258 \\
\hline $4 C$ & 19.7185 & 19.7090 & 19.7283 & 0.0193 \\
\hline $5 \mathrm{C}$ & 19.7188 & 19.7093 & 19.7357 & 0.0264 \\
\hline
\end{tabular}

(a) See Figure 2 for position locations; $A$ and B positions are diameters, $90^{\circ}$ apart; $C$ dimensions are lengths.

(b) $90-$ min $810^{\circ} \mathrm{C}$ heat treatment.

(c) Difference was taken between "after heat treatment" and "after welding" mea surements. 
TABLE 3. Outer Capsule Dimensions

Measurement
Position(a)

Dimensions, in.

\begin{tabular}{|c|c|c|c|c|c|}
\hline $1 \mathrm{~A}$ & 2.6399 & 2.6398 & \multicolumn{2}{|c|}{2.6415} & 0.0017 \\
\hline $2 A$ & 2.6409 & 2.6409 & \multicolumn{2}{|c|}{2.6422} & 0.0013 \\
\hline $3 A$ & 2.6431 & 2.6428 & \multicolumn{2}{|c|}{2.6436} & 0.0008 \\
\hline $4 A$ & 2.6409 & 2.6415 & \multicolumn{2}{|c|}{2.6418} & 0.0003 \\
\hline $5 A$ & 2,6400 & 2.6403 & \multicolumn{2}{|c|}{2.6405} & 0.0002 \\
\hline $6 \mathrm{~A}$ & 2.6400 & 2.6403 & \multicolumn{2}{|c|}{2.6409} & 0.0006 \\
\hline 1B & 2.6420 & 2.6422 & \multicolumn{2}{|c|}{2.6445} & 0.0023 \\
\hline 2B & 2.6416 & 2.6512 & \multicolumn{2}{|c|}{2.6420} & 0.0008 \\
\hline $3 B$ & 2.6413 & 2.6412 & \multicolumn{2}{|c|}{2.6420} & 0.0008 \\
\hline $4 B$ & 2.6416 & 2.6415 & \multicolumn{2}{|c|}{2.6418} & 0.0003 \\
\hline $5 B$ & 2.6415 & 2.6417 & \multicolumn{2}{|c|}{2.1418} & 0.0001 \\
\hline $6 \mathrm{~B}$ & 2.6410 & 2.6410 & \multicolumn{2}{|c|}{2.6412} & 0.0002 \\
\hline $1 \mathrm{C}$ & 20.7589 & 20.7592 & 20.7592 & 20.7600 & 0.0004 \\
\hline $2 C$ & 20.7591 & 20.7598 & 20.7537 & 20.7535 & -0.0062 \\
\hline $3 C$ & 20.7606 & 20.7609 & 20.7502 & 20.7480 & -0.0118 \\
\hline $4 C$ & 20.7552 & 20.7558 & 20.7540 & 20.7528 & -0.0024 \\
\hline $5 C$ & 20.7575 & 20.7568 & 20.7513 & 20.7510 & -0.0057 \\
\hline
\end{tabular}

(a) See Figure 2 for position locations; $A$ and $B$ positions are diameters, $90^{\circ}$ apart; C positions are lengths.

(b) Lengths were measured twice after the $90-$ min $810^{\circ} \mathrm{C}$ heat treatment as a measure of the reproducibility of the measurements.

(c) Difference was taken between "after heat treatment" and "after welding" measurements. 
Outer Capsule

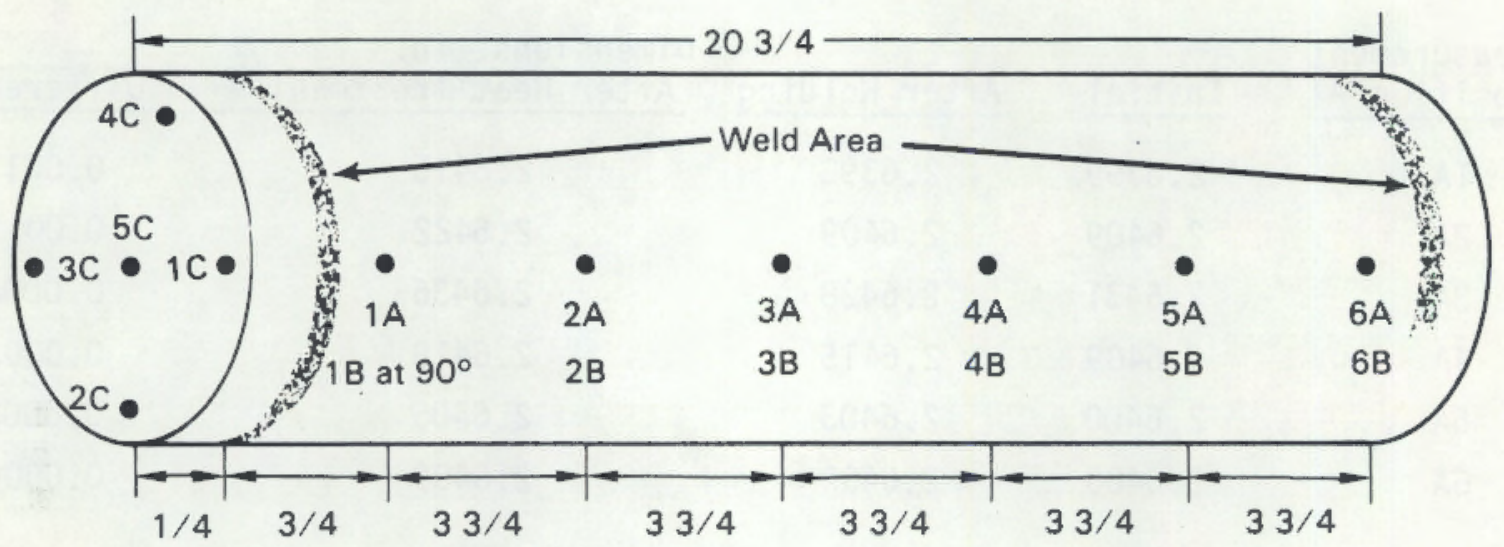

Inner Capsule

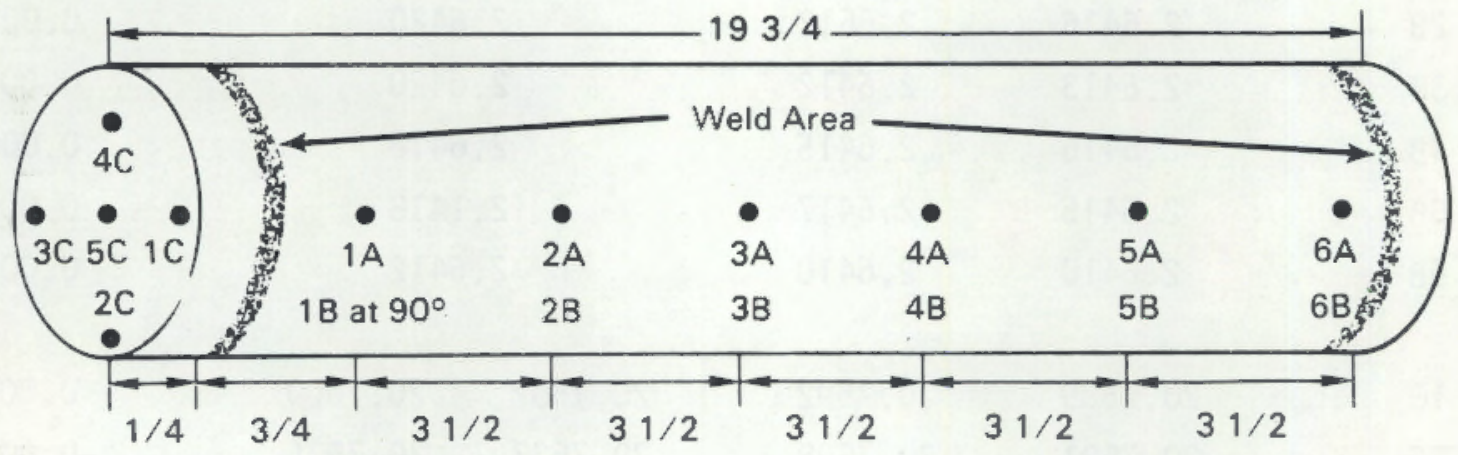

Inner Capsule

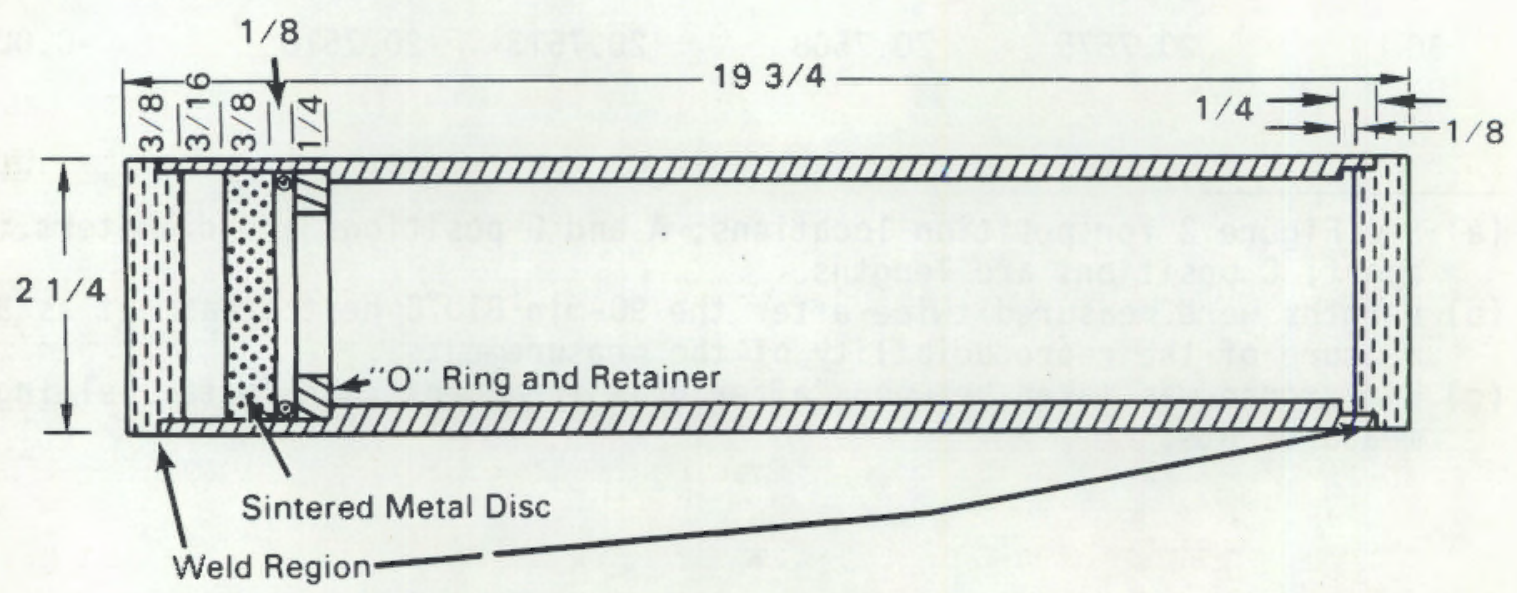

All measurements are in inches

FIGURE 2. WESF Capsules Showing Measurement Locations and Other Parameters ( $A$ and $B$ diameter measurement locations are $90^{\circ}$ apart) 


\section{TABLE 4. Additional Capsule Parameters}

Inside diameter, $\mathrm{cm}$

Internal volume, $\mathrm{cm}^{3(b)}$

External volume, $\mathrm{cm}^{3(d)}$
Inner Capsule

$5.00^{(a)}$

$918^{(c)}$

1290
Outer Capsule

6.10

1480

(a) Calculated based on measured internal volume.

(b) Determined by the weight of water required to fill the capsules.

(c) Includes only that volume up to the bottom of the sintered metal disk.

(d) Determined by measuring the amount of water displaced by the capsule.

The salt mixture was melted and poured into the inner capsule inside an argon glove box; the oxygen concentration was kept below $10 \mathrm{ppm}$. Even though the capsule was as full as possible, the total weight of salt was only $2854 \mathrm{~g}$ $\left(113 \mathrm{~g}\right.$ short of the desired amount), resulting in a loading factor of $3.11 \mathrm{~g} / \mathrm{cm}^{3}$. This lower-than-anticipated loading factor occurred because the salt mixture had a lower density $\left(3.29 \mathrm{~g} / \mathrm{cm}^{3}\right)$ than pure $\mathrm{CsCl}\left(4.04 \mathrm{~g} / \mathrm{cm}^{3}\right)$.

\section{Capsule Closure and Heat Treatment}

After the inner capsule was filled, a plastic bag was taped over the open end to prevent air from contacting the salt. The capsule was then transferred to a hel ium glove box where it was evacuated and backfilled with helium to allow for leak checking after welding the end caps in place. While in the helium glove box, the sintered metal frit was inserted and the end cap was placed on the capsule. Again, a plastic bag was taped over the end to minimize exchange of air for He during transport of the capsule to the welding facility. The end cap was welded in place by Rockwell Hanford Company personnel using the same technique established for radioactive WESF capsules (Tingey, Wheelwright, and Lytle 1984, pp. 45-46). No leaks were detected when the entire capsule was checked at a sensitivity of $2 \times 10^{-10} \mathrm{std} . \mathrm{cm}^{3}$ of helium/s.

The inner capsule was placed inside the outer capsule in a helium glove box, the end cap was set in place, and a plastic bag was taped over the end. The double capsule was then transported to the Rockwell welding facility where 
the end cap was welded on the outer capsule. The entire outer capsule was leak checked; again, no leaks were detected at a sensitivity of $2 \times 10^{-10} \mathrm{std} . \mathrm{cm}^{3}$ of helium/s.

The capsule was placed horizontally in a large furnace that had been preheated to $810^{\circ} \mathrm{C}$. The temperature and temperature uniformity were established by seven thermocouples attached to a 2-3/4-in. diameter $\times 24-i n$. 1ong pipe lying beside the capsule. The end-to-end temperature varied from 810 to $815^{\circ} \mathrm{C}$ at the beginning of the test and from 808 to $812^{\circ} \mathrm{C}$ at the end of the test. After $90 \mathrm{~min}$ in the $810^{\circ} \mathrm{C}$ furnace, the capsule was removed and allowed to cool in air while standing on end on a fire brick. Thermal calculations indicated that a capsule initially at $25^{\circ} \mathrm{C}$ would require about 30 min to reach $800^{\circ} \mathrm{C}$ when placed in a preheated furnace. Radioactive decay heat in a WESF capsule would make a negligible contribution to the heating rate but could increase the steady-state temperature of the inner capsule by as much as $80^{\circ} \mathrm{C}$. This increase was calculated to be only $10^{\circ} \mathrm{C}$ if the inner capsule swelled or if salt filled the annulus. Therefore, the 90-min heating period should exceed the time at temperature from a 30-min fire by more than a factor of two.

\section{Post-Heat-Treatment Analyses}

After heat treatment, the outer capsule was again leak checked at $2 \times 10^{-10}$ std. $\mathrm{cm}^{3}$ of helium/s and found to be leak free. Capsule dimensional measurements given in Table 3 show that, except for a very slight reduction in length, the outer capsule suffered essentially no dimensional changes as a result of the heat treatment.

Following visual observations and careful dimensional measurements, the ends of the outer capsule were cut off and the inner capsule was removed. Considerable force was required to push the inner capsule from the outer capsule because the thin-wall region of the inner capsule had bulged against the outer capsule wall. The end cap weld had developed a small crack, allowing $150 \mathrm{~g}$ of salt to flow into the annulus between the inner and outer capsules. Figure 3 shows the bulged end of the capsule encrusted with salt just as it was pushed from the outer capsule. Figure 4, which is the same area after the salt was cleaned off, shows the failed region of the weld covering an arc of nearly $90^{\circ}$. 


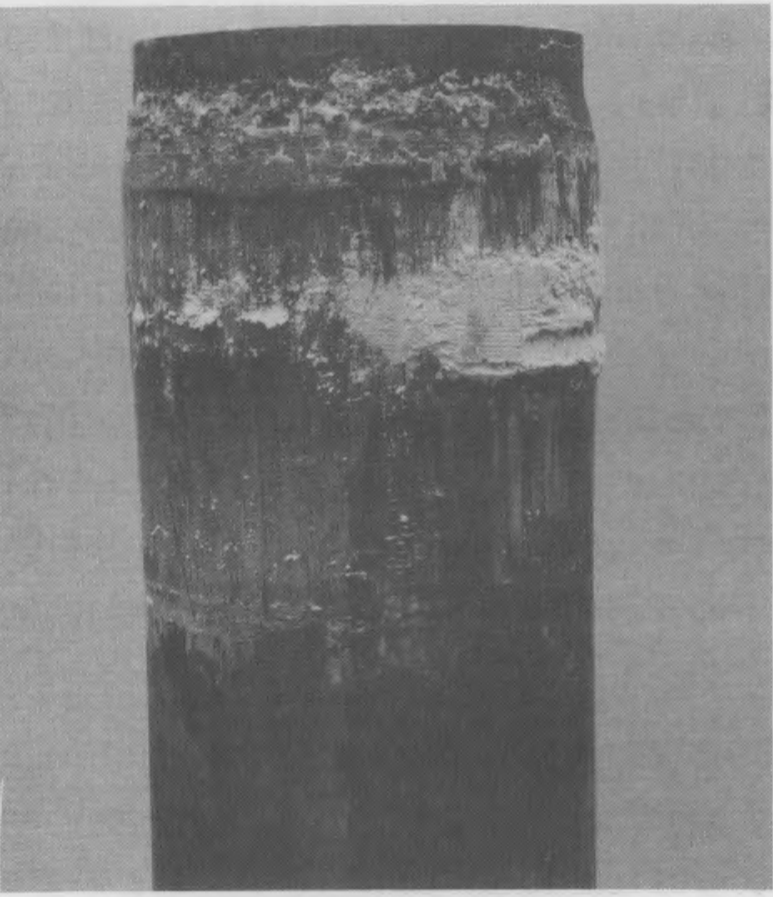

FIGURE 3. Inner Capsule Showing Bulged End, Failed Weld Area, and Salt Incrustation

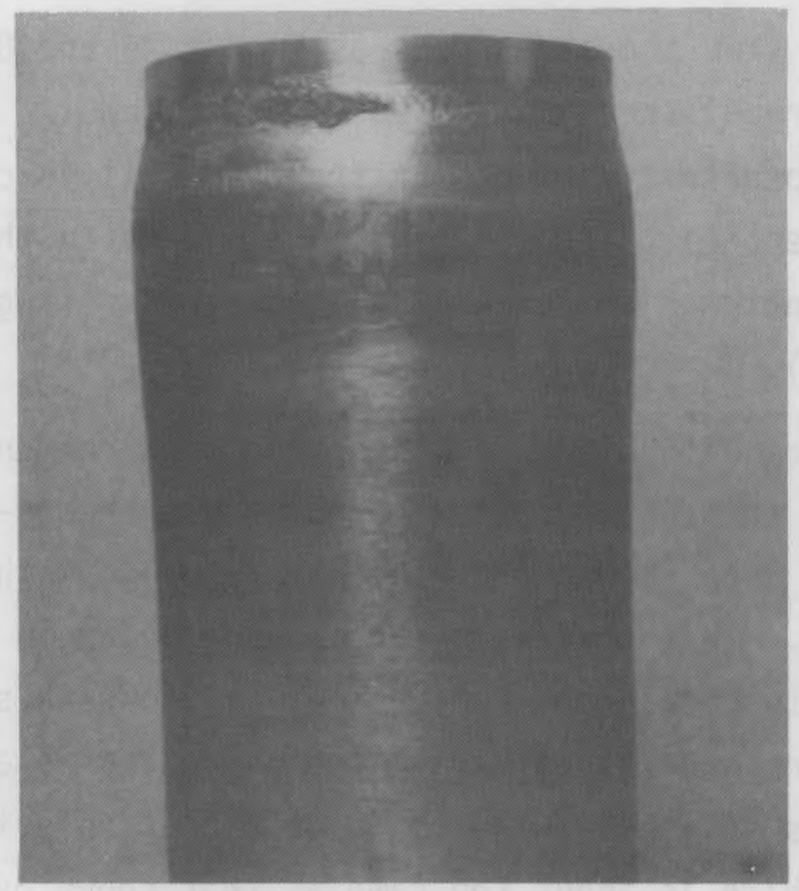

FIGURE 4. Inner Capsule After Salt Removal (note bulge and failed weld) 
The inner capsule swelled $0.150 \mathrm{in}$. in diameter in the region of the bulge where the wall had been machined to accommodate the end cap, the sintered metal disk, and the 0-ring retainer. Other than the bulge, the average swelling of the inner capsule was $0.037 \mathrm{in}$. in diameter and $0.027 \mathrm{in}$. in length (see Table 2), which compares with the diametral gap between the inner and outer capsules of $0.149 \mathrm{in}$. (see inner diameter listed in Table 4). Obviously, the bulged region of the inner capsule contacted the outer capsule, preventing additional bulging. If the weld had not cracked, allowing the salt to flow from the inner capsule, the diameter would have had to swell an average of $0.092 \mathrm{in}$. to accommodate the salt volume. This calculation is based on extrapolation of the swelled inner capsule volume and the weight of salt extruded from the inner capsule.

Figures 5 and 6 are micrographs of the failed region of the weld; Figures 7 and 8 are micrographs taken $180^{\circ}$ from the crack where the weld remained intact. Considerable corrosion is evident in all the micrographs, even in areas $1 \mathrm{in}$. from the weld. Figure 8 shows corrosive attack $0.010 \mathrm{in}$. deep near the intact weld region, apparently caused by the combination of corrosion and mechanical stress from bulging of the thin-wall region.

Figures 9 and 10 show the same areas as Figures 6 and 8, respectively, after the sample was repolished and etched (using a $1 \mathrm{HCl} / 2 \mathrm{HNO}_{3} / 3$ glycerin mixture) to show the penetration depth of the weld. It is clear that the weld fully penetrated the entire thickness of the wall despite the requirement that the weld need only penetrate $55 \%$ of the wall thickness (Tingey, Wheelwright, and Lytle 1984, p. 45).

Figure 11 is a scanning electron micrograph (SEM) of an area near the center of the capsule showing the SS/salt boundary. Energy-dispersive $x$-ray (EDX) analyses of the area showed that the dark regions within the salt were SS corrosion products. This corrosion was intergranular in nature, and EDX analysis showed that the grain boundaries were filled with salt. The prominant white spots are salt crystals that have pushed up out of the boundary regions after the specimen was polished. The depth of corrosion evident in Figure 11 is about 0.008 in., which is about the same as that shown by Figure 8 (exclusive of the cracks) near the weld area. Figure 12 is a $500 x$ magnification 


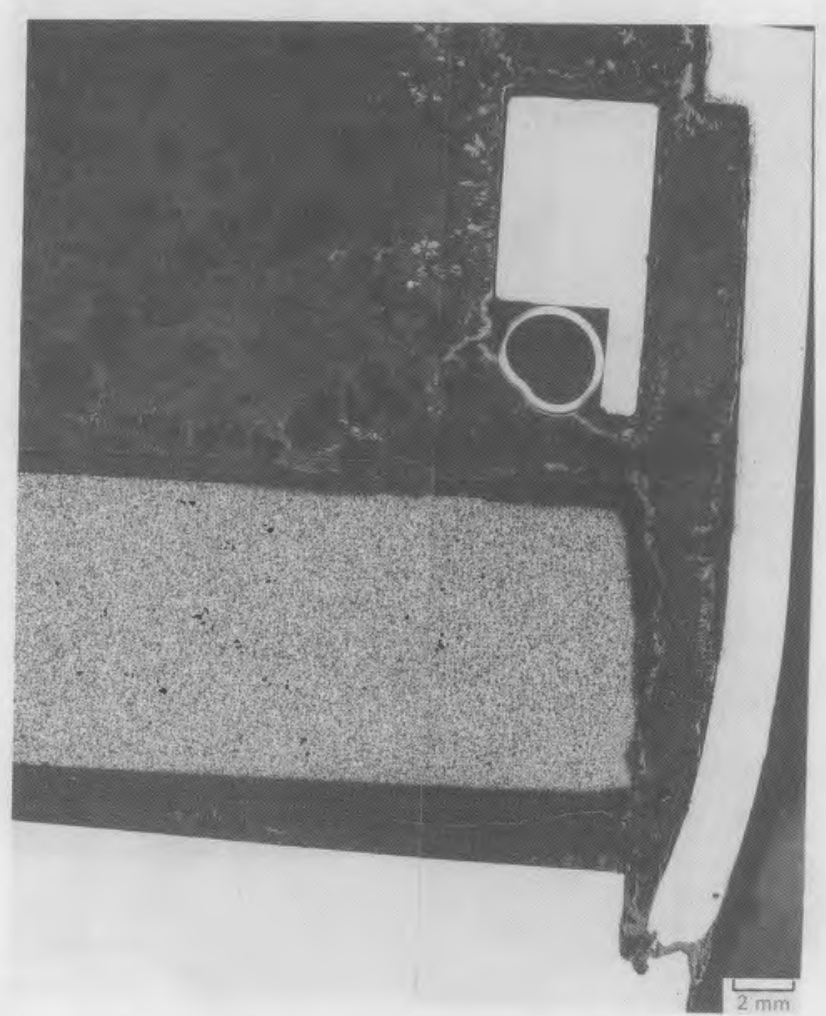

FIGURE 5. Macrographic Cross Section of Inner Capsule in Vicinity of Failed Weld

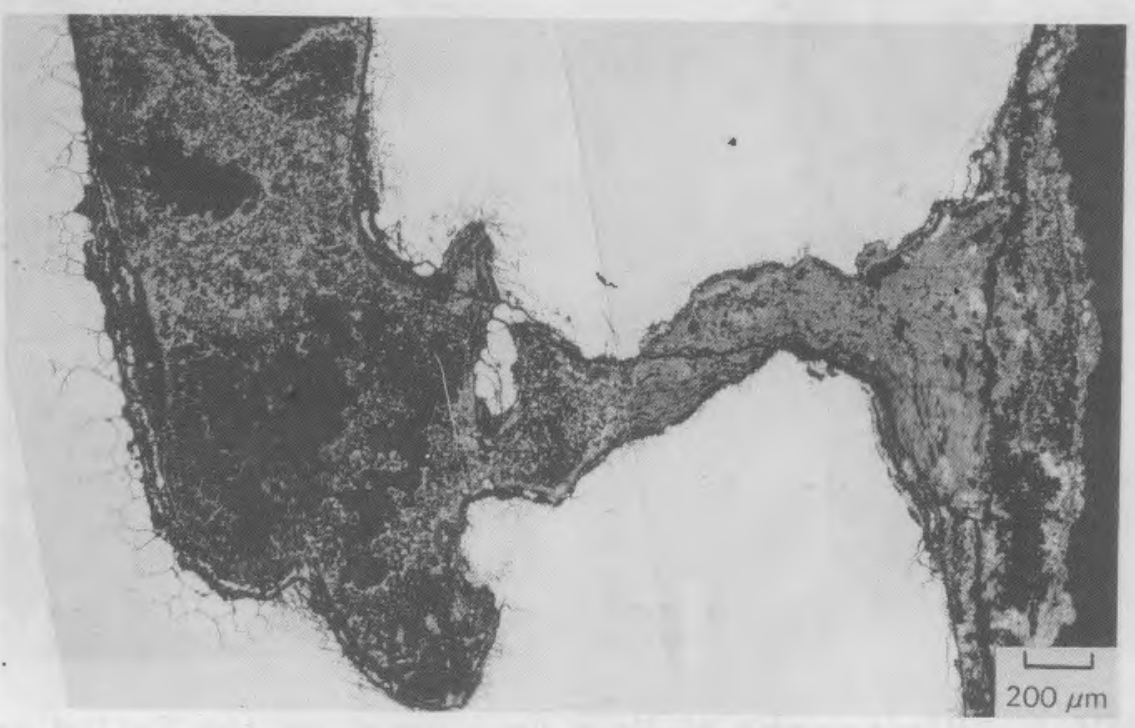

FIGURE 6. Micrograph of Failed Weld 


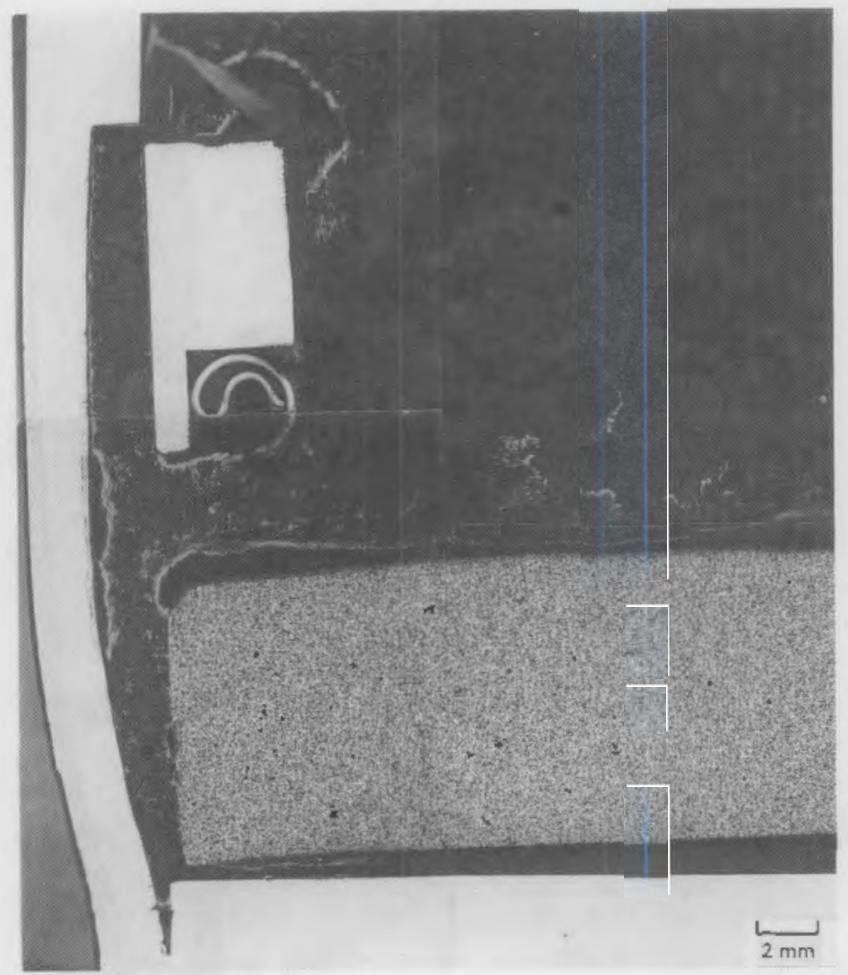

FIGURE 7. Macrographic Cross Section of Inner Capsule Opposite the Failed Weld Area
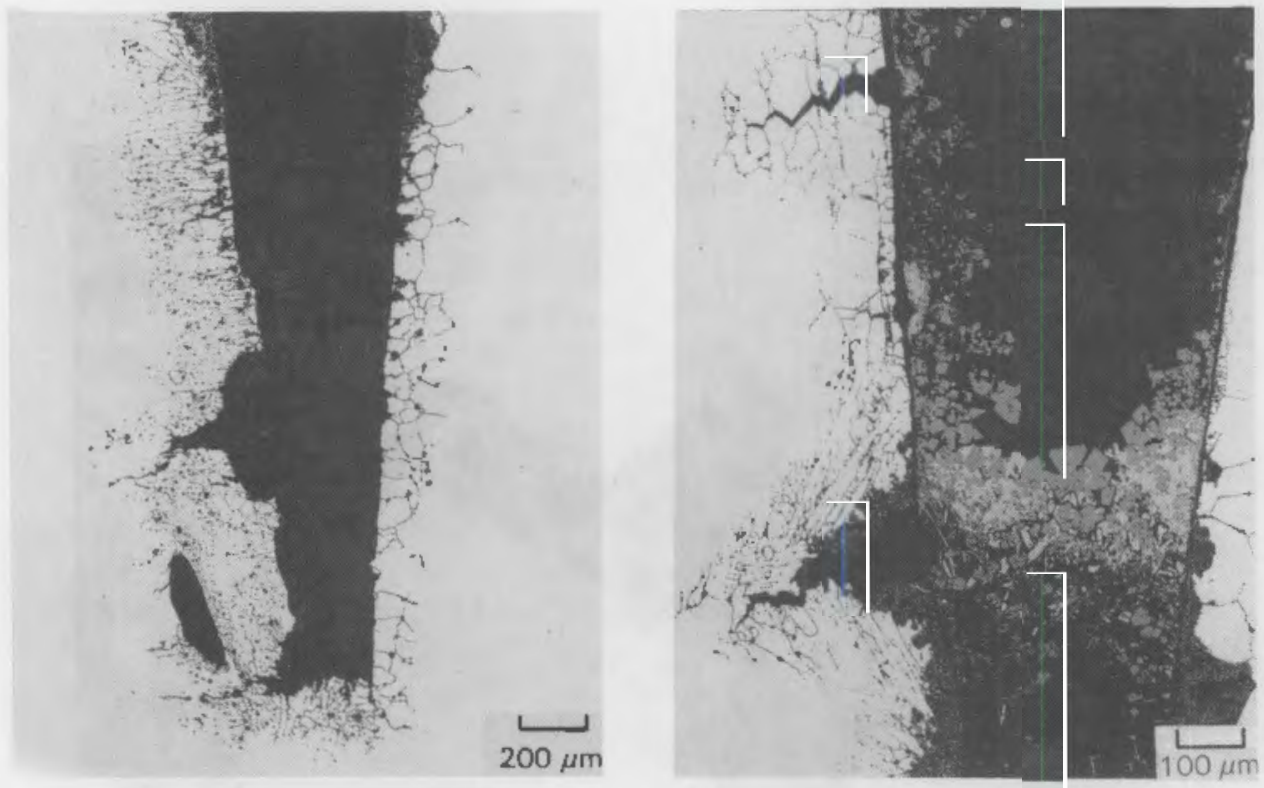

FIGURE 8. Micrographs of Weld Area Opposite the Failed Area 


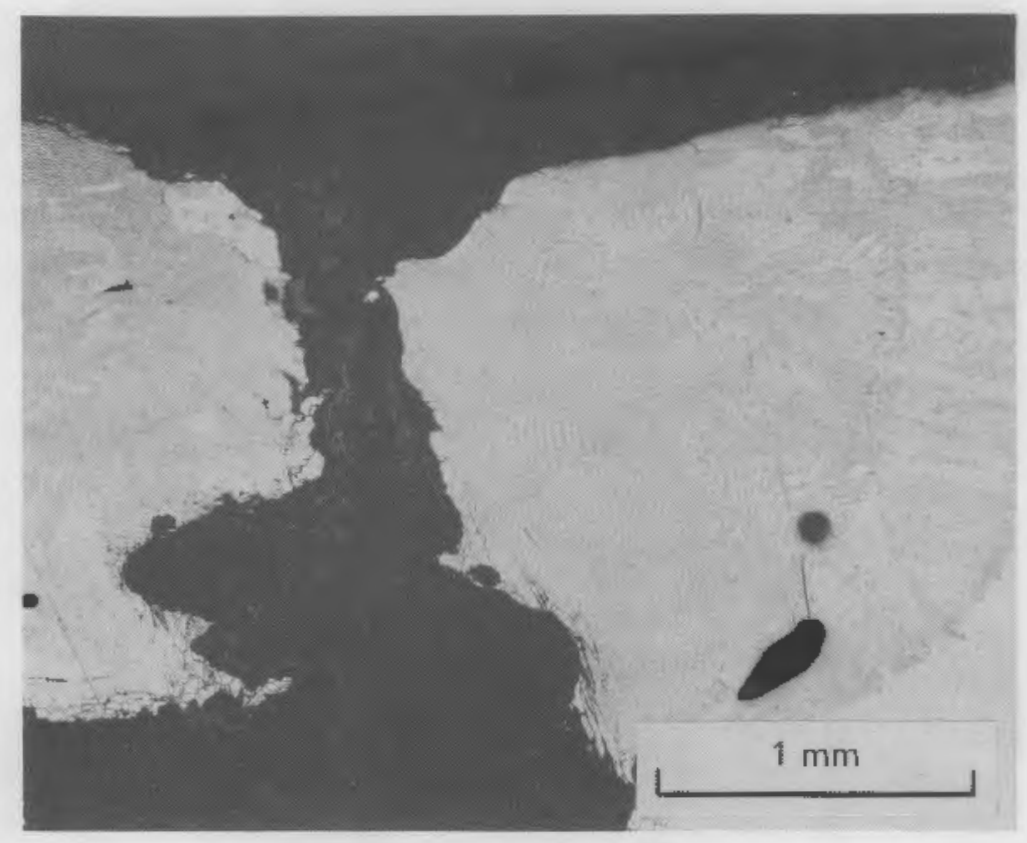

FIGURE 9. Failed Weld Area (Figure 6) After Repolishing and Etching

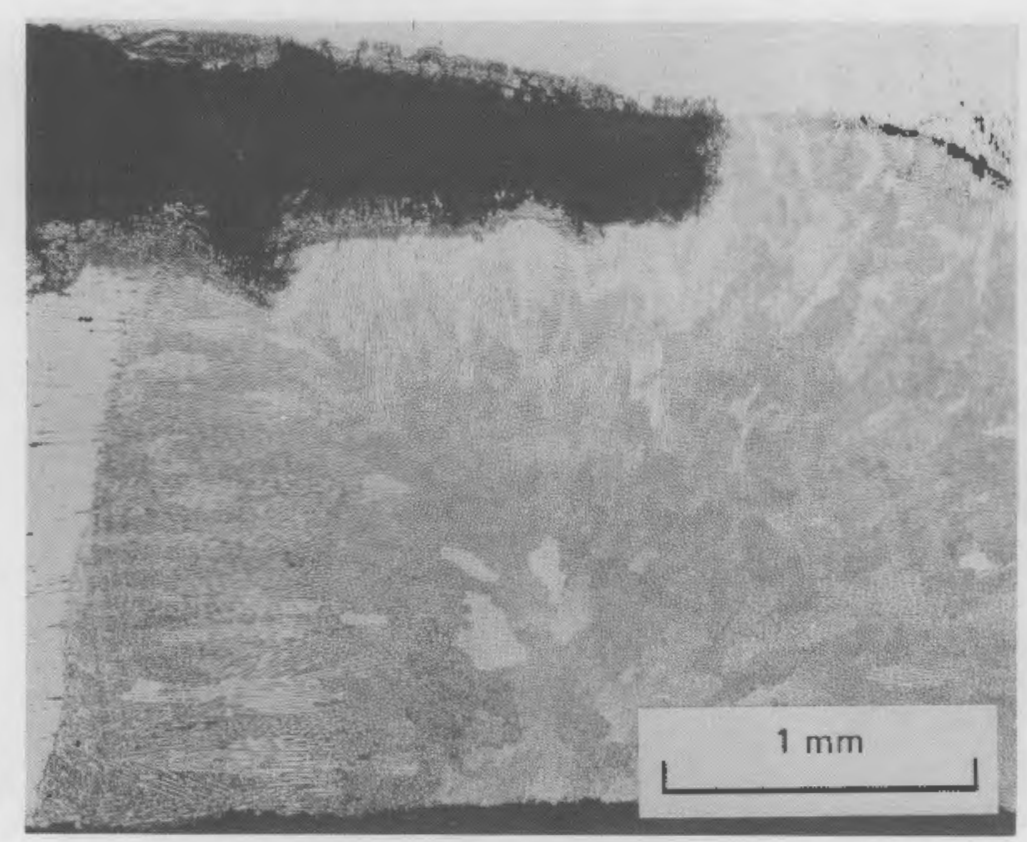

FIGURE 10. Weld Area Opposite the Failed Area (Figure 8) After Repolishing and Etching 


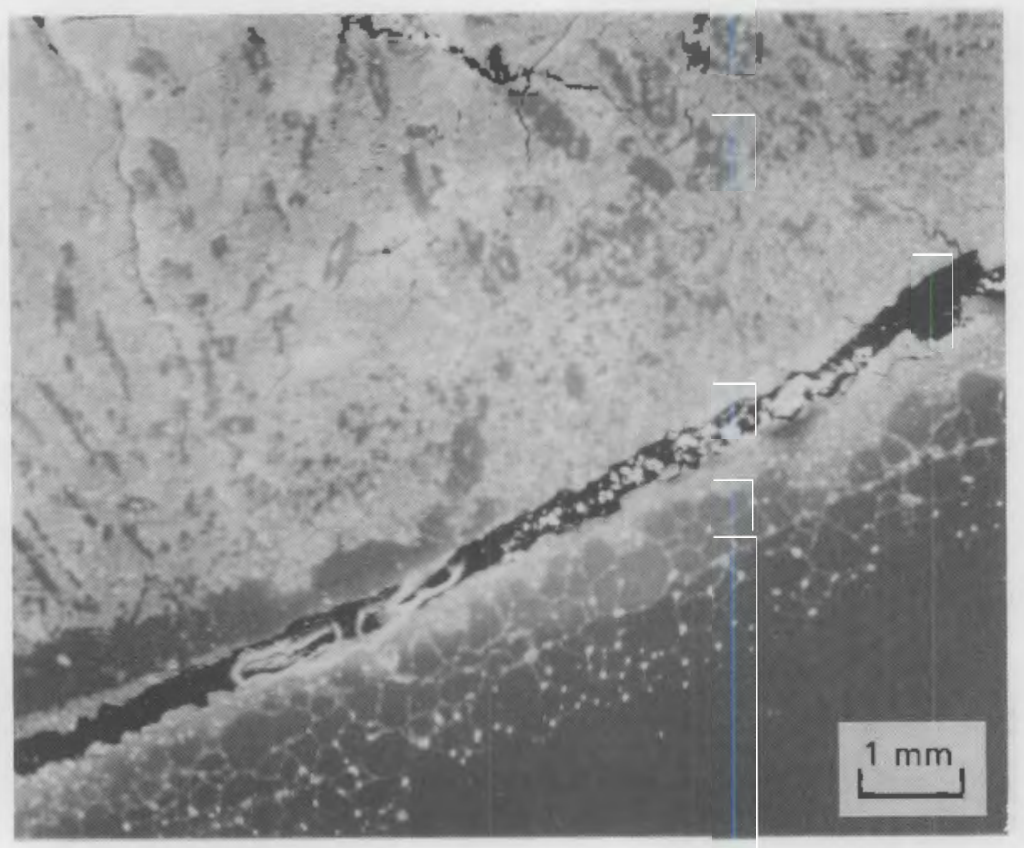

FIGURE 11. Micrograph of Center Region of Inner Capsule Showing the Salt/Stainless Steel Boundary

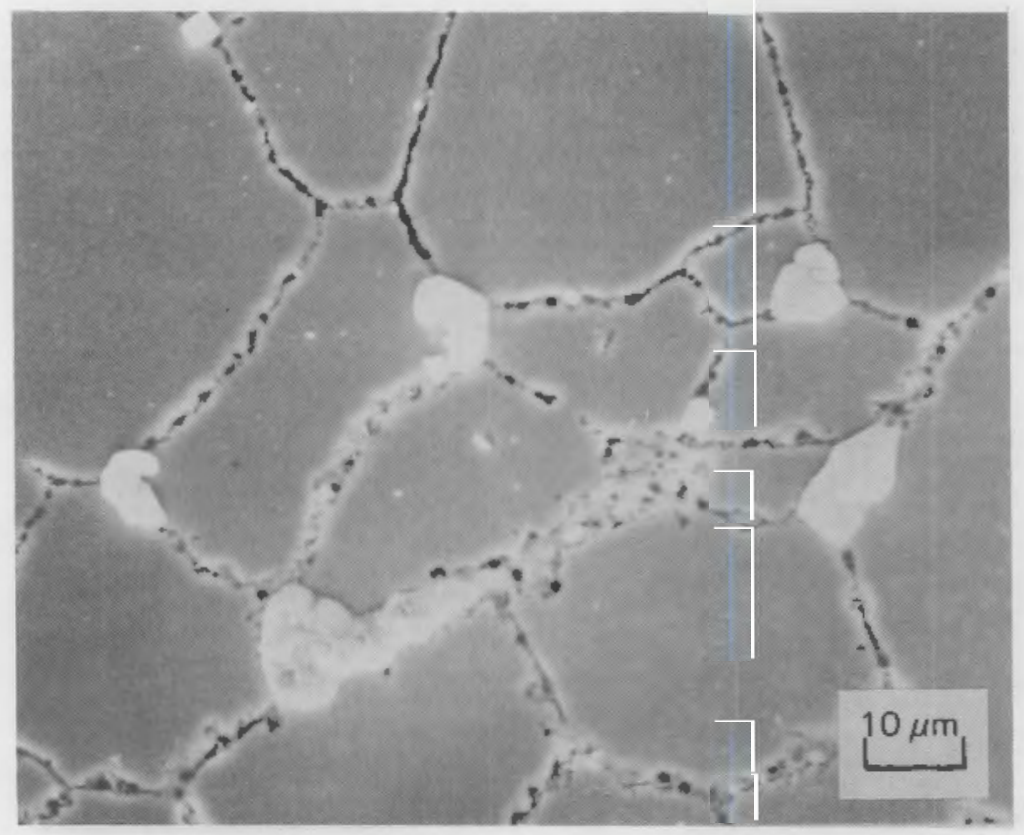

FIGURE 12. Magnification of the Stainless Steel Region in Figure 11 
of the stainless steel area in Figure 11. Figure 13 is an SEM of the sintered metal disk. EDX analyses showed that the open porosity within the disk was essentially completely filled with salt.

During examination of the salt after the heat treatment, it was evident that some separation had occurred. Two different regions were observed by an obvious color difference. The top 2 in. $^{(a)}$ of salt was a very light green color; the rest of the salt was gray. Samples were taken from both regions and analyzed; the results are shown in Table 5. The mass balance is not as good as the earlier analyses (Table 1) but shows that the composition difference between the two regions is small.

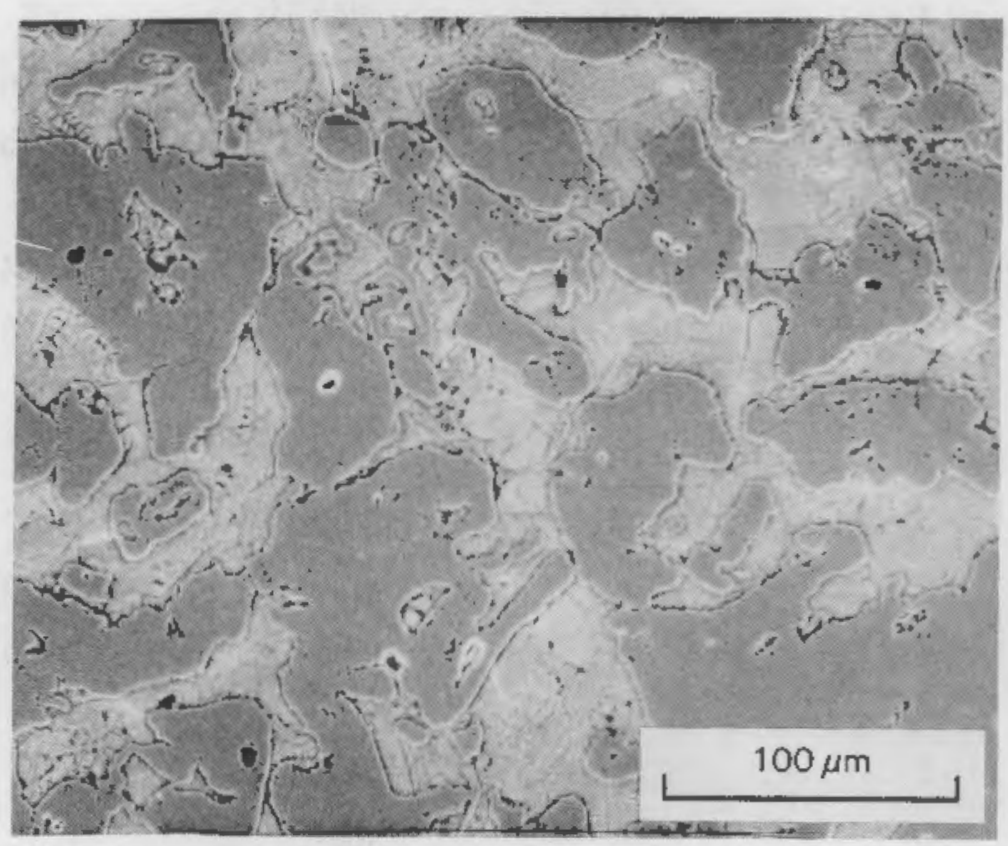

FIGURE 13. Micrograph of Sintered Disk

(a) The top of the capsule as it stood on end during cooling was the bottom of the capsule as filled and is the opposite end from the weld failure. 
TABLE 5. Composition of Salt in Capsule After Heat Treatment

\begin{tabular}{|c|c|c|c|}
\hline Element & Nominal & Green Salt & Gray Salt \\
\hline A1 & 0.37 & $N D^{(a)}$ & 0.34 \\
\hline B & 0.28 & 0.02 & 0.23 \\
\hline $\mathrm{Ba}$ & 10.24 & 7.81 & 9.49 \\
\hline $\mathrm{Ca}$ & 0.048 & 0.08 & 0.08 \\
\hline$C d$ & 0.030 & 0.04 & 0.03 \\
\hline Cs & 50.08 & 50.2 & 42.2 \\
\hline Co & 0.091 & 0.03 & 0.12 \\
\hline $\mathrm{Cr}$ & 1.29 & 0.04 & 1.76 \\
\hline $\mathrm{Cu}$ & 0.18 & 0.10 & 0.17 \\
\hline $\mathrm{Fe}$ & 1.87 & 1.23 & 2.91 \\
\hline K & 0.63 & $N A^{(b)}$ & NA \\
\hline Mn & 0.046 & 0.07 & 0.06 \\
\hline $\mathrm{Na}$ & 2.34 & 2.91 & 2.15 \\
\hline $\mathrm{Ni}$ & 0.092 & NA & NA \\
\hline$P$ & 0.10 & ND & 0.14 \\
\hline $\mathrm{Pb}$ & 0.13 & 0.18 & 0.16 \\
\hline $\mathrm{Pd}$ & 0.019 & NA & NA \\
\hline $\mathrm{Rb}$ & 0.019 & NA & NA \\
\hline $\mathrm{Sr}$ & 0.019 & 0.05 & 0.07 \\
\hline $\mathrm{Ti}$ & 0.067 & ND & 0.09 \\
\hline $\mathrm{Zn}$ & 0.044 & 0.06 & 0.06 \\
\hline $\mathrm{Cl}$ & 22.24 & 19.1 & 20.5 \\
\hline 0 & 5.65 & NA & NA \\
\hline$S$ & 1.47 & NO & 1.1 \\
\hline \multirow[t]{2}{*}{ Si } & 1.94 & 0.07 & 1.82 \\
\hline & 99.3 & 82.0 & 83.5 \\
\hline
\end{tabular}

(a) $N D=$ not detected.
(b) $N A=$ not analyzed. 


\section{DISCUSSION}

The primary purpose of this part of the study was to determine the behavior of a WESF cesium capsule with a high loading of salt. This objective was completed. In addition, more basic data such as salt density at $800^{\circ} \mathrm{C}$, loading factors of capsules that can be accommodated, and capsule corrosion rates can be inferred.

The results of this test indicated that initial capsule swelling will occur in the section of the capsule wall that was machined to $0.080 \mathrm{in}$. to allow for insertion of the end cap, sintered disk, and 0-ring retainer. Expansion of this area of the capsule continued until it reached the outer capsule wall and apparently placed considerable torque and/or other modes of stress on the top weld. Additional expansion of the salt would be accommodated by either expansion of the thicker area of the wall or fracture of the weld. The actual behavior will depend on the ductility of the capsule wall and the strength of the weld. In the test conducted for this study, only minimal swelling occurred ( 0.037 in. in diameter and 0.027 in. in length) before a small crack developed in the weld.

A measure of the inner capsule expansion and the amount of salt extruded in to the annulus can be used to estimate the salt density at $800^{\circ} \mathrm{C}$. The internal volume of the inner capsule (excluding the volume of the sintered disk) after heat treatment was determined to be about $960 \mathrm{~cm}^{3}$ at $25^{\circ} \mathrm{C}$, both from dimensional measurements and from water displacement of the inner container (expansion of the internal volume was assumed to be equal to the expansion of the external volume). Thus, at $800^{\circ} \mathrm{C}$, the capsule volume is calculated to be $1005 \mathrm{~cm}^{3}$ due to thermal expansion of the stainless steel. In addition, the open pore volume of the sintered disk $\left(\sim 6 \mathrm{~cm}^{3}\right)$ was also filled with salt, giving a total volume at $800^{\circ} \mathrm{C}$ of $1011 \mathrm{~cm}^{3}$. The initial salt content of the capsule was $2854 \mathrm{~g}$; but after the high-temperature treatment, only $2704 \mathrm{~g}$ remained in the inner capsule. Thus, the density of this salt mixture at $800^{\circ} \mathrm{C}$ is $2704 \mathrm{~g} / 1011 \mathrm{~cm}^{3}$ or $2.67 \mathrm{~g} / \mathrm{cm}^{3}$, which is in reasonable agreement with the measured value of $2.57 \mathrm{~g} / \mathrm{cm}^{3}$. Because these values are close to the density of pure $\operatorname{CsCl}\left(2.65 \mathrm{~g} / \mathrm{cm}^{3}\right)$, the uncertainty in density at $800^{\circ} \mathrm{C}$ due to 
uncertainty in salt composition is minimized. Nevertheless, the more conservative value $\left(2.57 \mathrm{~g} / \mathrm{cm}^{3}\right)$ is used in the following calculations.

Because the weld of the inner capsule failed in this test, it is worth considering capsule loading factors below which the welds would not fail. In this test, where $2704 \mathrm{~g}$ of salt remained in the capsule, it would appear that any loading factor below $2704 \mathrm{~g} / 918 \mathrm{~cm}^{3}=2.95 \mathrm{~g} / \mathrm{cm}^{3}$ would not have resul ted in weld failure. However, the capsule did swell somewhat prior to failure. A more conservative assessment indicates that weld failure might occur after only minimal swelling. The salt weight where swelling is expected to begin is $2.57 \mathrm{~g} / \mathrm{cm}^{3} \times 968 \mathrm{~cm}^{3}=2488 \mathrm{~g}$ (the volume of the unswelled capsule below the sintered disk at $800^{\circ} \mathrm{C}$ is $968 \mathrm{~cm}^{3}$ ). Thus, the maximum room temperature loading factor that would not produce capsule swelling is $2488 \mathrm{~g} / 918 \mathrm{~cm}^{3}=2.71 \mathrm{~g} / \mathrm{cm}^{3}$. of the 1500 cesium capsules stored in the WESF pool, about 600 (40\%) have loading factors above this value (Tingey, Wheelwright, and Lytle 1984, p. 35) and, thus, have potential for inner capsule weld failure if subjected to a fire that results in a salt temperature of $800^{\circ} \mathrm{C}$. The number of capsules with potential weld failure is reduced to about $300(20 \%)$ if a salt density at $800^{\circ} \mathrm{C}$ of $2.67 \mathrm{~g} / \mathrm{cm}^{3}$ is used. It would be further reduced if the salt penetrated the sintered disk and if capsule swelling occurred prior to weld failure.

Inner capsule weld failure would result in the flow of molten radioactive salt into the annulus of the outer capsule. The outer capsule has the same wall thickness and weld parameters as the inner capsule but has had only minimal machining of the wall to allow for insertion of the end caps. Furthermore, this capsule was not subjected to high-temperature salt during filling, storage, or use and has met quality control standards for the welds including ultrasonic weld inspection. Therefore, the radioactive salt would be contained in a high-quality outer capsule, al though it would no longer be doubly encapsulated. Thus, the capsules would not be expected to meet regulatory requirements for continued use in an irradiator after being subjected to an $800^{\circ} \mathrm{C}$ fire; it would be necessary to return them for reencapsulation and/or disposal.

It is also instructive to assess the potential for outer capsule swelling. If the annular volume were available to the salt, either from inner capsule swelling or from weld failure, the salt volume could reach $1120 \mathrm{~cm}^{3}$ at $800^{\circ} \mathrm{C}$ 
before mechanical stress on the outer capsule would occur. Therefore, $2.57 \mathrm{~g} / \mathrm{cm}^{3} \times 1120 \mathrm{~cm}^{3}=2878 \mathrm{~g}$ of salt could be accommodated. Thus, any loading factor below $2878 \mathrm{~g} / 918 \mathrm{~cm}^{3}=3.14 \mathrm{~g} / \mathrm{cm}^{3}$ would not produce outer capsule stress if the salt composition were the same as used in this study.

of the present capsules in the WESF p001, 21 have loading factors above $3.14 \mathrm{~g} / \mathrm{cm}^{3}$. However, all of these (about $1 \mathrm{MCi}$ of ${ }^{137} \mathrm{Cs}$ ) have been reserved for reencapsulation for other source needs (Tingey, Wheelwright, and Lytle 1984 , p. 37) and, thus, will not be available for irradiator use. The loading factor required to produce outer capsule stress increases to $3.28 \mathrm{~g} / \mathrm{cm}^{3}$ if $2.67 \mathrm{~g} / \mathrm{cm}^{3}$ is used as the salt density at $800^{\circ} \mathrm{C}$; only one WESF capsule has a higher loading factor.

As expected, the rate of corrosion that was observed on the inner surface of the inner capsule wall was much higher than the rate observed by Bryan (1983) at $450^{\circ} \mathrm{C}$. Thus, corrosion rates at high temperatures could be of concern for long periods of time; but for a short-duration fire (1 to $3 \mathrm{~h}$ ), they should be of little consequence.

The test performed used a nonradioactive salt mixture prepared to simulate the contents of a typical WESF capsule. The impurity content of the salt in WESF capsules is somewhat variable and is not well known. The composition selected for this test was based on the limited available data. Some differences in density are expected for different compositions. However, as mentioned earlier, the salt volume at $800^{\circ} \mathrm{C}$ is not expected to be vastly different because the measured density of the sal $t$ mixture used was close to that of pure $\mathrm{CsCl}$ at $800^{\circ} \mathrm{C}$ even though the room temperature densities were quite different. The apparent separation of the salt was observed by color change only and only minor compositional differences noted; this separation is not expected to be of consequence in the capsule behavior. The absence of radioactivity in the simulated salt is not expected to have a major effect on either swelling or corrosion results. In the $800^{\circ} \mathrm{C}$ fire, the heat flow will be mainly from the outside toward the inside; therefore, the relatively small heat generation rate from the salt should have little effect on the salt temperatures. This effect was accommodated by heating the capsule to $810^{\circ} \mathrm{C}$ rather than $800^{\circ} \mathrm{C}$ required for the standard tests. The effect of gamma irradiation on the corrosion was examined 
to a limited extent earlier at low temperatures (Fullam 1972) with little observable effect. At high temperatures, this effect is expected to be negligible because the radiolytic impact of the rate is not markedly affected by temperature. Thus, the thermal rate would be much greater than the radiolytic rate. 


\section{THERMAL STRESS DURING THERMAL CYCLING}

Initial studies on WESF capsules considered primarily underwater storage and ul timate disposal either near the surface of the earth or in a deep geologic repository. In both cases, the capsules reach a quasi-steady-state temperature that decreases slowly with time as the isotope decays. A similar environment is encountered in the Sandia Irradiator for Dried Sewage Solids (SIDSS) or any dry storage/dry operation system where the capsules are maintained in air during both irradiation and storage. In these instances, the capsules are not subjected to large temperature cycling.

However, most irradiators in use today store the capsules in a water basin when not in use and lift them from the water during the irradiation processing. This concept cycles the source capsules from the water basin to air one to several times each day. This periodic removal and reinsertion process cycles the temperature and, thus, might induce thermal stresses in the upper and lower end cap welds. The long-term effect of this cyclic thermal loading is possible crack initiation and subsequent fatigue crack growth, which may eventually result in loss of outer capsule integrity. The inner capsule is subjected to much smaller temperature variations; thus, thermal stresses are also smaller. Therefore, a study was undertaken to examine the effects of the thermal stresses generated during this thermal cycling of WESF cesium capsules. The results of a finite-element analysis of these thermal stresses and an experimental program in which a WESF capsule was cycled for 6 months ( 3845 cycles) to verify the calculations are discussed in the following sections.

\section{METHOD OF ANALYSIS}

An analytical estimate of possible fatigue crack growth in partial penetration end welds was performed using Revision 4.0 of the finite-element code ANSYS. (a) ANSYS is capable of solving for the thermal transients that correspond to the in-air heatup and in-water quench associated with capsule removal and return to storage. The thermal pass solution is used to define

(a) ANSYS is a proprietary engineering analysis program owned, distributed, and maintained by Swanson Analysis Systems, Inc., Houston, Pennsylvania. 
the time-temperature history for the stress solution. The crack opening and crack tip forces from the stress pass solution can be used to estimate the peak-to-peak stress intensity factor $(K)$ corresponding to the peak-to-peak thermal effects. This change in $\mathrm{K} c$ an be related to the amount of crack growth per cycle and the growth expected during the design life of the capsule. The results include a discussion of the one-dimensional (1-D) verification study, the 2-D temperature profiles, and the fatigue crack propagation rate predictions.

Assumptions

A few simplifying assumptions are necessary to make any analysis practical within time and budget limits. Such general assumptions are mentioned here. Several more assumptions appear in the remainder of this section.

The capsule was assumed to be axisymmetric and horizontally oriented. The nonaxisymmetric features were addressed in the T-D scoping analyses, ignored, or their effects were averaged into the local element properties. The ambient fluid was assumed to extend axisymmetrically for a large radius around the capsule. This assumption omitted the effects of neighboring capsules and nonaxisymetric fluid temperatures and thermal properties. Natural convection and radiation were the exchange mechanisms at the capsule surface to the isothermal sink.

The CSCl salt was in intimate contact with the inner wall of the inner capsule and was assumed to have a uniform thermal power density. Intimate contact was also assumed to exist between the end caps of the inner and outer capsule at the bottom (away-from-fill) end of the assembly. This resulted in the coupling of the temperature degrees-of-freedom at the inner and outer capsule end cap interface and the inner capsule and salt interface, respectively. No attempt was made to model voids or nonuniformities at any interface.

When capsules are returned to storage pools, thermal cycling and the difference in thermal mass from the end cap to the sidewall induce a thermal stress in the vicinity of the weld. The transition from the in-air to in-water environment was assumed to occur instantaneously, without boiling. 
Geometry

The 1-D model is shown in Figure 14. The fuel and capsule walls were modeled using four-node quadrilateral continuum elements (STIF 55). The ANSYS element type 55 is capable of 2-D steady-state or transient thermal analysis. The element has four nodal points with a single degree-of-freedom (temperature) at each node. The first 10 elements modeled the fuel; the next three, the inner capsule wall. A series of radiation links (STIF 31 ) and conduction links (STIF 32) were used to thermally connect the inner and outer walls through the annulus. Element type 31 is capable of modeling 2- or 3-D steady-state or transient radiation. The element is uniaxial with two nodes and a single degree-of-freedom (temperature) at each node. Element type 32 is capable of 2-D steady-state or transient conduction. It also has two nodes and temperature associated with its degree-of-freedom. The next three elements represented the outer capsule wall. The outer three links were used to allow radiation from the capsule wall to the environment. A total of 38 nodes and 25 elements were used in the 1-D scoping study.

The geometry for the 2-D finite-element mesh was taken directly from Figure 1. Amplified views of the mesh in the weld areas are shown in Figures 15 and 16 for the upper and lower welds, respectively. The element types were the same as those used in the 1-D model except that the annulus conduction links were replaced with the STIF 55 quadrilateral. A total of 2140 nodes and 2424 elements were used for the capsule assembly.

Boundary Conditions

Convection and radiation surfaces were established between the outer capsule and the air. Convection coefficients of 10 and $13 \mathrm{w} / \mathrm{m}^{2}-{ }^{\circ} \mathrm{C}$ were used for the horizontal sidewall and vertical end caps, respectively. A constant temperature of $27^{\circ} \mathrm{C}\left(80^{\circ} \mathrm{F}\right)$ was assumed for air. Convection was the principal cooling mode for the water quench portion of the thermal cycle. Convection coefficients of 568 and $738 \mathrm{~W} / \mathrm{m}^{2}-{ }^{\circ} \mathrm{C}$ were used for the quench portion of the thermal cycle. The water was assumed to remain at a constant $21^{\circ} \mathrm{C}\left(70^{\circ} \mathrm{F}\right)$. The annulus between the inner and outer capsules was too small for convection 


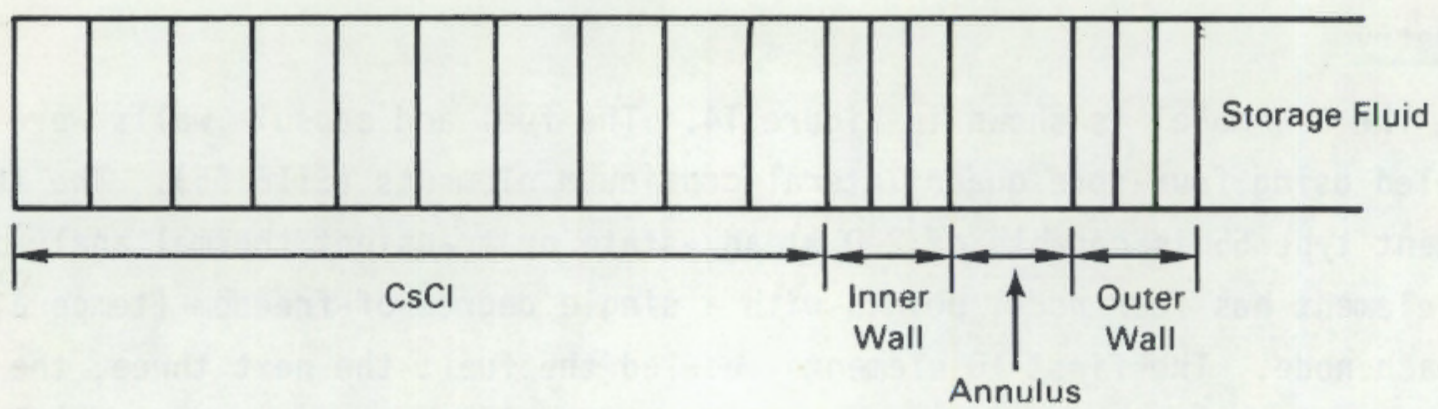

FIGURE 14. Finite-Element Mesh of the One-Dimensional Thermal Model

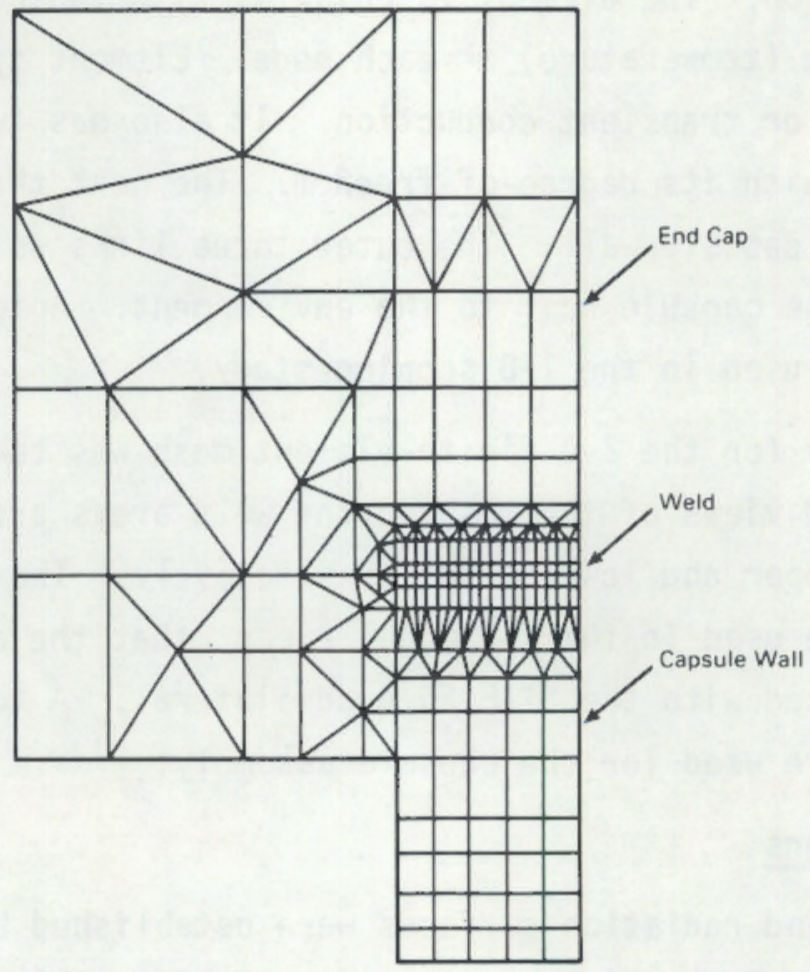

FIGURE 15. Finite-Element Mesh of the Upper Weld Region Two-Dimensional Model

to occur. This was noted from previous studies (Campbell 1981) and was also confirmed by the approach presented by Holman (1976). The calculation for the nominal annulus geometry is presented in Appendix A. All other unspecified free surfaces were assumed to be adiabatic. 


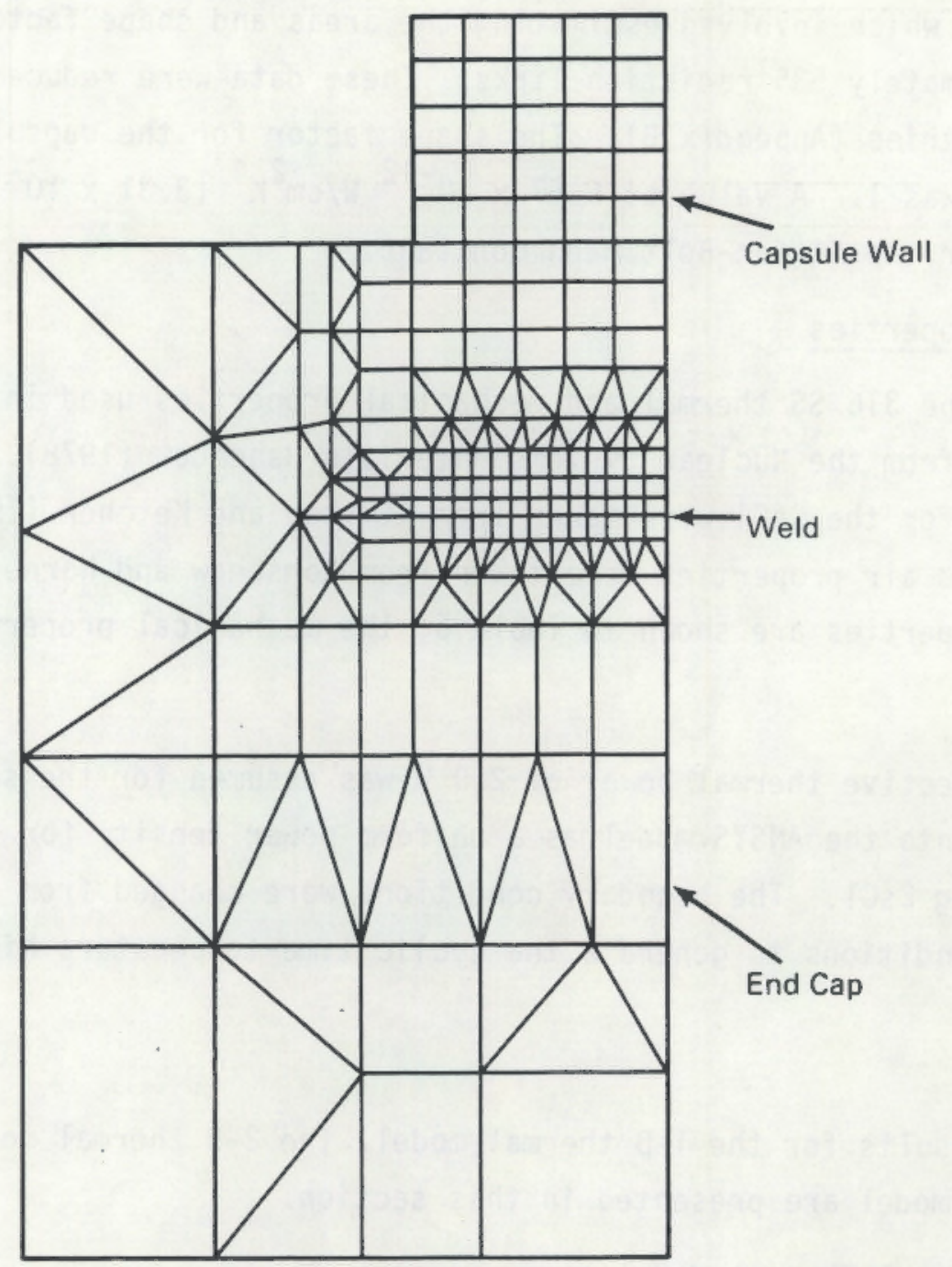

FIGURE 16. Finite-Element Mesh of the Lower Weld Region Two-Dimensional Model

\section{Real Constants}

The radiation links require area, shape factor, and emissivities in the form of real constant input to ANSYS. Three emissivities were needed for this analysis: the fuel to the inner capsule; the outer wall of the inner capsule to the inner wall of the outer capsule; and the outer wall of the outer capsule to air. These values were assumed to be $0.9,0.5$, and 0.65 , respectively, based on observations of a capsule destructive examination. The nodal areas and element shape factors were dependent on the local finite-element mesh 
resolution, which involved estimating the areas and shape factors for all of the approximately 535 radiation links. These data were reduced to 119 real constant entries (Appendix B). The shape factor for the capsule-to-air radiation links was 1. A value of $5.67 \times 10^{-12} \mathrm{~W} / \mathrm{cm}^{2} \mathrm{~K}^{4}\left(3.31 \times 10^{-15} \mathrm{Btu} / \mathrm{s}-\mathrm{in} .^{2}-\mathrm{R}^{4}\right)$ was used for the Stefan-Boltzmann constant.

Material Properties

The Type 316 SS thermal and mechanical properties used in this analysis were taken from the Nuclear Systems Materials Handbook (1978). The thermal properties for the $\mathrm{CsCl}$ were taken from Rimshaw and Ketchen (1967). The nitrogen and air properties were taken from Rohsenow and Harnett (1973). The thermal properties are shown in Table 6; the mechanical properties, in Table 7. $\underline{\text { Loads }}$

An effective thermal power of $200 \mathrm{~W}$ was assumed for the salt. This value was input into the ANSYS model as a uniform power density for the elements representing $\mathrm{CsCl}$. The boundary conditions were changed from in-air to in-water conditions to generate the cyclic time-temperature history.

\section{RESULTS}

The results for the 1-D thermal model, the 2-D thermal model, and the 2-D mechanical model are presented in this section.

\section{One-Dimensional Thermal Model}

The mechanisms for heat transfer in the 1-D model were uniform heat generation and conduction in the salt, conduction through the inner capsule wall, radiation and conduction across the annulus, conduction through the outer wall, and radiation and convection from the outer surface to the storage fluid. These steady-state calculations were performed using Revision 4.0 of the finite-element code ANSYS. To check the 1-D ANSYS solution, the temperature distributions were also generated using a closed-form approach. The 1-D solution provided verification for the 2-D solution scheme. 
TABLE 6. CSC1 Capsule ANSYS Thermal Properties

\begin{tabular}{|c|c|c|c|c|c|}
\hline Materia & $\begin{array}{l}\text { Temp } \\
\mathrm{C}\end{array}$ & $\frac{\text { ature }}{{ }^{F}}$ & $\begin{array}{l}\text { Conductivity, } \\
\mathrm{W} / \mathrm{cm}-{ }^{\circ} \mathrm{C}\end{array}$ & $\begin{array}{l}\text { Density, } \\
\mathrm{g}-\mathrm{s}^{2} / \mathrm{cm}^{4}\end{array}$ & $\begin{array}{l}\text { Specific Heat, } \\
\mathrm{W}-\mathrm{cm} / \mathrm{s}-\mathrm{g}-{ }^{\circ} \mathrm{C}\end{array}$ \\
\hline $\mathrm{CsCl}$ & $\begin{array}{r}20 \\
150 \\
260 \\
370 \\
480 \\
600\end{array}$ & $\begin{array}{r}70 \\
300 \\
500 \\
700 \\
900 \\
1100\end{array}$ & $\begin{array}{l}8.301 \times 10^{-3} \\
5.741 \times 10^{-3} \\
4.502 \times 10^{-3} \\
3.703 \times 10^{-3} \\
3.145 \times 10^{-3} \\
3.733 \times 10^{-3}\end{array}$ & $\begin{array}{l}4.082 \times 10^{-3} \\
4.004 \times 10^{-3} \\
3.933 \times 10^{-3} \\
3.853 \times 10^{-3} \\
3.212 \times 10^{-3} \\
3.160 \times 10^{-3}\end{array}$ & $\begin{array}{l}299 \\
305 \\
308 \\
309 \\
309 \\
390\end{array}$ \\
\hline 316 SS & $\begin{array}{r}20 \\
150 \\
260 \\
370 \\
480 \\
600\end{array}$ & $\begin{array}{r}70 \\
300 \\
500 \\
700 \\
900 \\
1100\end{array}$ & $\begin{array}{l}1.336 \times 10^{-1} \\
1.551 \times 10^{-1} \\
1.731 \times 10^{-1} \\
1.905 \times 10^{-1} \\
2.070 \times 10^{-1} \\
2.230 \times 10^{-1}\end{array}$ & $\begin{array}{l}8.103 \times 10^{-3} \\
8.718 \times 10^{-3} \\
8.002 \times 10^{-3} \\
7.956 \times 10^{-3} \\
7.910 \times 10^{-3} \\
7.862 \times 10^{-3}\end{array}$ & $\begin{array}{l}444 \\
497 \\
527 \\
546 \\
559 \\
569\end{array}$ \\
\hline Air & $\begin{array}{r}20 \\
150 \\
260 \\
370 \\
480 \\
600\end{array}$ & $\begin{array}{r}70 \\
300 \\
500 \\
700 \\
900 \\
1100\end{array}$ & $\begin{array}{l}1.823 \times 10^{-4} \\
2.618 \times 10^{-4} \\
3.332 \times 10^{-4} \\
3.982 \times 10^{-4} \\
5.120 \times 10^{-4} \\
6.066 \times 10^{-4}\end{array}$ & $\begin{array}{l}1.746 \times 10^{-6} \\
1.165 \times 10^{-6} \\
8.710 \times 10^{-7} \\
6.962 \times 10^{-7} \\
5.034 \times 10^{-7} \\
3.873 \times 10^{-7}\end{array}$ & \\
\hline Air & $\begin{array}{r}-70 \\
30 \\
130 \\
230 \\
430 \\
630\end{array}$ & $\begin{array}{r}-100 \\
80 \\
260 \\
400 \\
800 \\
1160\end{array}$ & & & $\begin{array}{l}1023 \\
1021 \\
1027 \\
1036 \\
1077 \\
1125\end{array}$ \\
\hline
\end{tabular}

TABLE 7. CsC1 Capsule ANSYS Mechanical Properties

\begin{tabular}{|c|c|c|c|c|}
\hline Material & Temperature, & $\begin{array}{c}\text { Elastic Modulus, } \\
\text { psi }\end{array}$ & $\begin{array}{c}\text { Poisson's } \\
\text { Ratio } \\
\end{array}$ & $\begin{array}{c}\text { of Thermal Expansion, } \\
\text { in./in. } /{ }^{\circ} \mathrm{C}\end{array}$ \\
\hline 316 SS & $\begin{array}{r}20 \\
150 \\
260 \\
370 \\
480 \\
600\end{array}$ & $\begin{array}{l}28.11 \times 10^{6} \\
27.16 \times 10^{6} \\
26.07 \times 10^{6} \\
24.77 \times 10^{6} \\
23.31 \times 10^{6} \\
21.72 \times 10^{6}\end{array}$ & $\begin{array}{l}0.265 \\
0.275 \\
0.284 \\
0.292 \\
0.301 \\
0.309\end{array}$ & $\begin{array}{l}1.511 \times 10^{-5} \\
1.617 \times 10^{-5} \\
1.695 \times 10^{-5} \\
1.760 \times 10^{-5} \\
1.814 \times 10^{-5} \\
1.859 \times 10^{-5}\end{array}$ \\
\hline
\end{tabular}




\section{Radial Temperatures}

ANSYS thermal results were generated for steady-state in-air and in-water conditions. The maximum radial temperature distribution corresponded to the steady-state in-air solution (Figure 17). The closed-form steady-state in-air solution is also shown in this figure. Closed-form sample calculations are presented in Appendix C. The maximum temperature of about $293^{\circ} \mathrm{C}$ was found at the centerline of the assembly. This temperature varied, as a function of power, through the salt to about $218^{\circ} \mathrm{C}$ at the salt/inner capsule interface. The canister wall acted as a thermal short and there was no noticeable temperature drop across it. There was, however, a substantial drop (about $98^{\circ} \mathrm{C}$ ) across the inner annulus to the $149^{\circ} \mathrm{C}$ outer wall temperature.

The minimum radial temperature distribution corresponded to in-water steady-state storage. The ANSYS and closed-form predictions appear in Figure 18. A maximum temperature of about $193^{\circ} \mathrm{C}$ occurred at the capsule center.

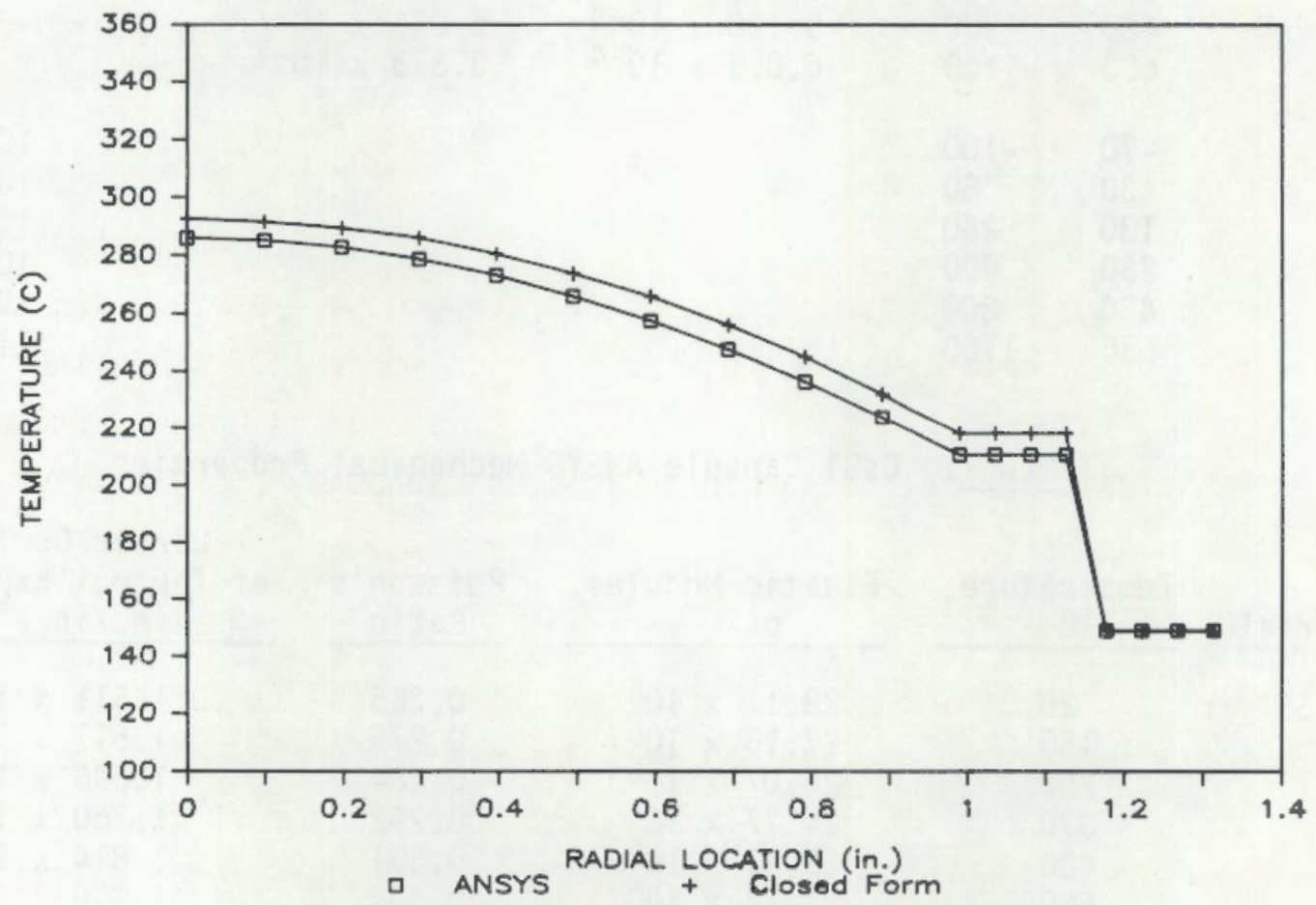

FIGURE 17. One-Dimensional Radial Temperature Profiles at Steady-State In-Air Condition 


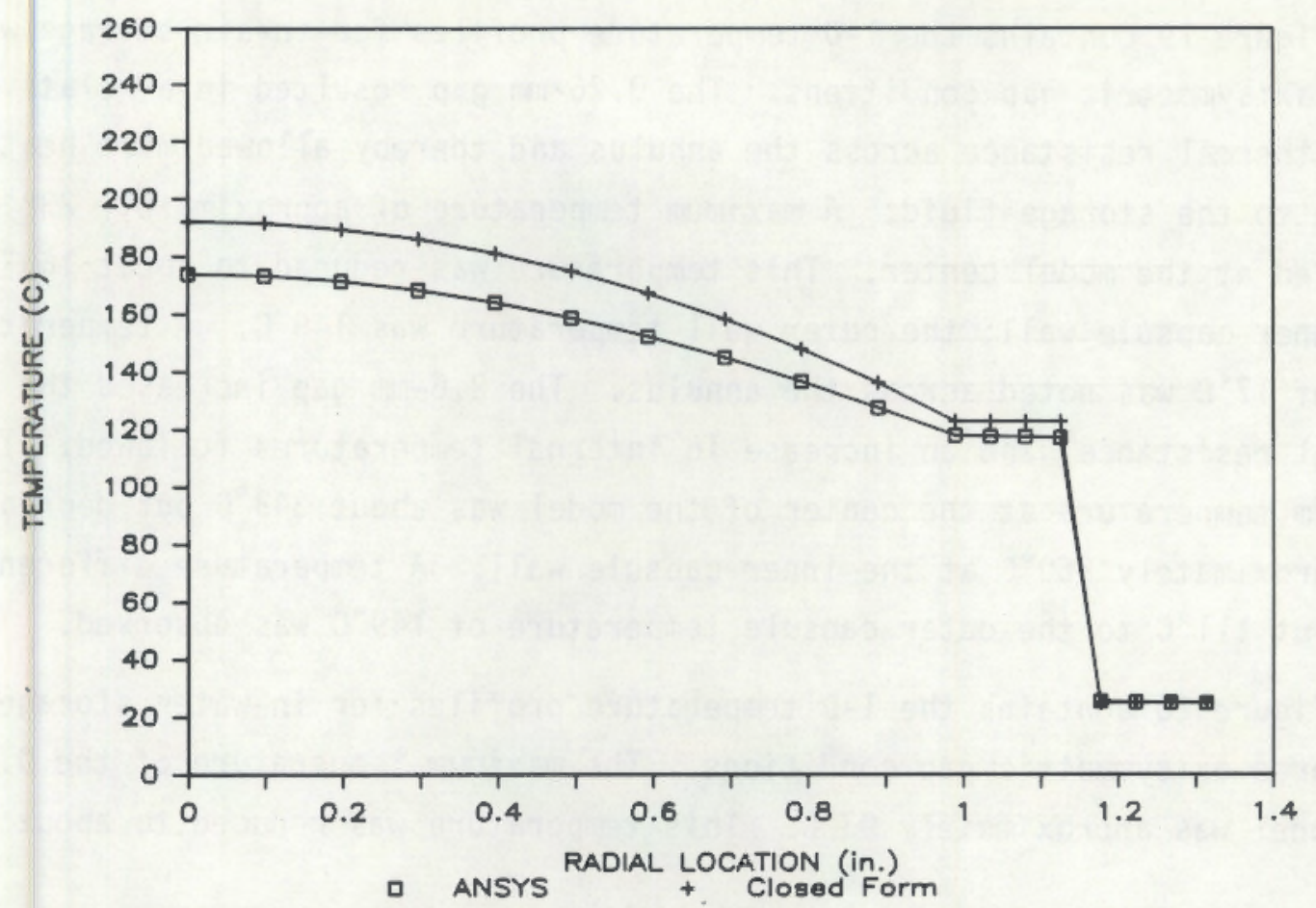

FIGURE 18. One-Dimensional Radial Temperature Profiles at Steady-State In-Water Condition

This temperature varied through the salt to about $121^{\circ} \mathrm{C}$ at the sal $t /$ inner capsule interface. The inner capsule wall temperature was essentially a constant $121^{\circ} \mathrm{C}$ through its thickness; the outer wall temperature was about $25^{\circ} \mathrm{C}$. The temperature drop across the annulus was identical to that for air storage, approximately $98^{\circ} \mathrm{C}$. The same profile was observed for the steady-state inwater condition, with the temperatures shifted downward from those for air storage.

\section{Annulus Variation}

The effect that nonconcentricity could have on the temperature profiles was estimated by analyzing several annulus widths. These widths included the full gap $=2.6 \mathrm{~mm}$, nominal gap $=1.31 \mathrm{~mm}$, and one-tenth full gap $=0.26 \mathrm{~mm}$. The 1-D model real constants were adjusted to accommodate these values as an axisymmetric annulus between the inner and outer capsules. A true nonconcentricity study would have involved a series of 3-D analyses that were considered beyond the scope of this project. 
Figure 19 contains the 1-D temperature profiles for in-air storage with three axisymmetric gap conditions. The $0.26-\mathrm{mm}$ gap resulted in a relatively lower thermal resistance across the annulus and thereby allowed more heat to escape to the storage fluid. A maximum temperature of approximately $232^{\circ} \mathrm{C}$ occurred at the model center. This temperature was reduced to about $166^{\circ} \mathrm{C}$ at the inner capsule wall; the outer wall temperature was $149^{\circ} \mathrm{C}$. A temperature drop of $17^{\circ} \mathrm{C}$ was noted across the annulus. The $2.6-\mathrm{mm}$ gap increased the thermal resistance, and an increase in internal temperatures followed. The maximum temperature at the center of the model was about $343^{\circ} \mathrm{C}$ but decreased to approximately $260^{\circ} \mathrm{C}$ at the inner capsule wall. A temperature differential of about $111^{\circ} \mathrm{C}$ to the outer capsule temperature of $149^{\circ} \mathrm{C}$ was observed.

Figure 20 contains the 1-D temperature profiles for in-water storage with the three axisymmetric gap conditions. The maximum temperature of the $0.26-\mathrm{mm}$ gap model was approximately $93^{\circ} \mathrm{C}$. This temperature was reduced to about $46^{\circ} \mathrm{C}$

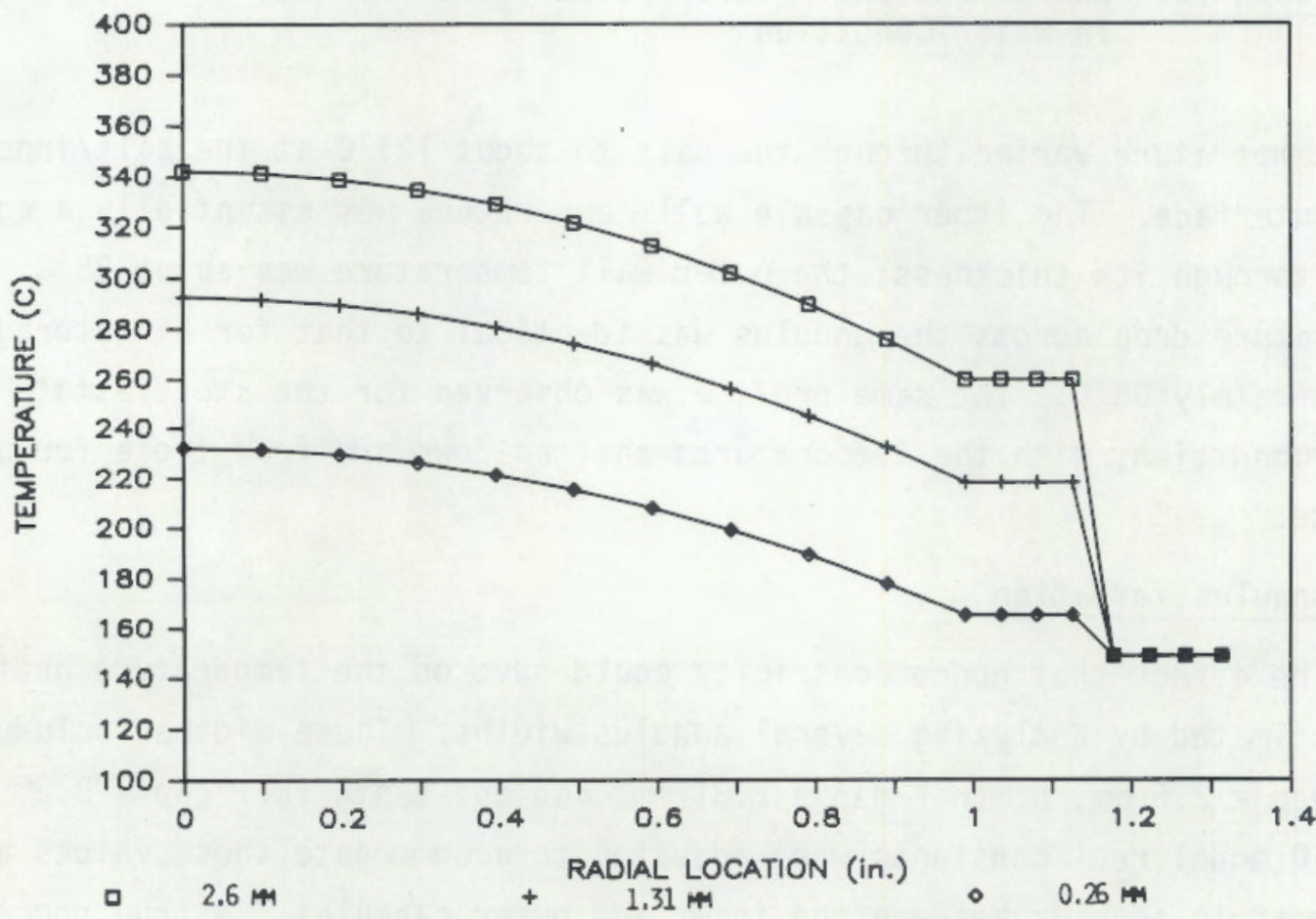

FIGURE 19. One-Dimensional Radial Temperature Profiles at Steady-State In-Air Condition with Varying Annulus Gap 


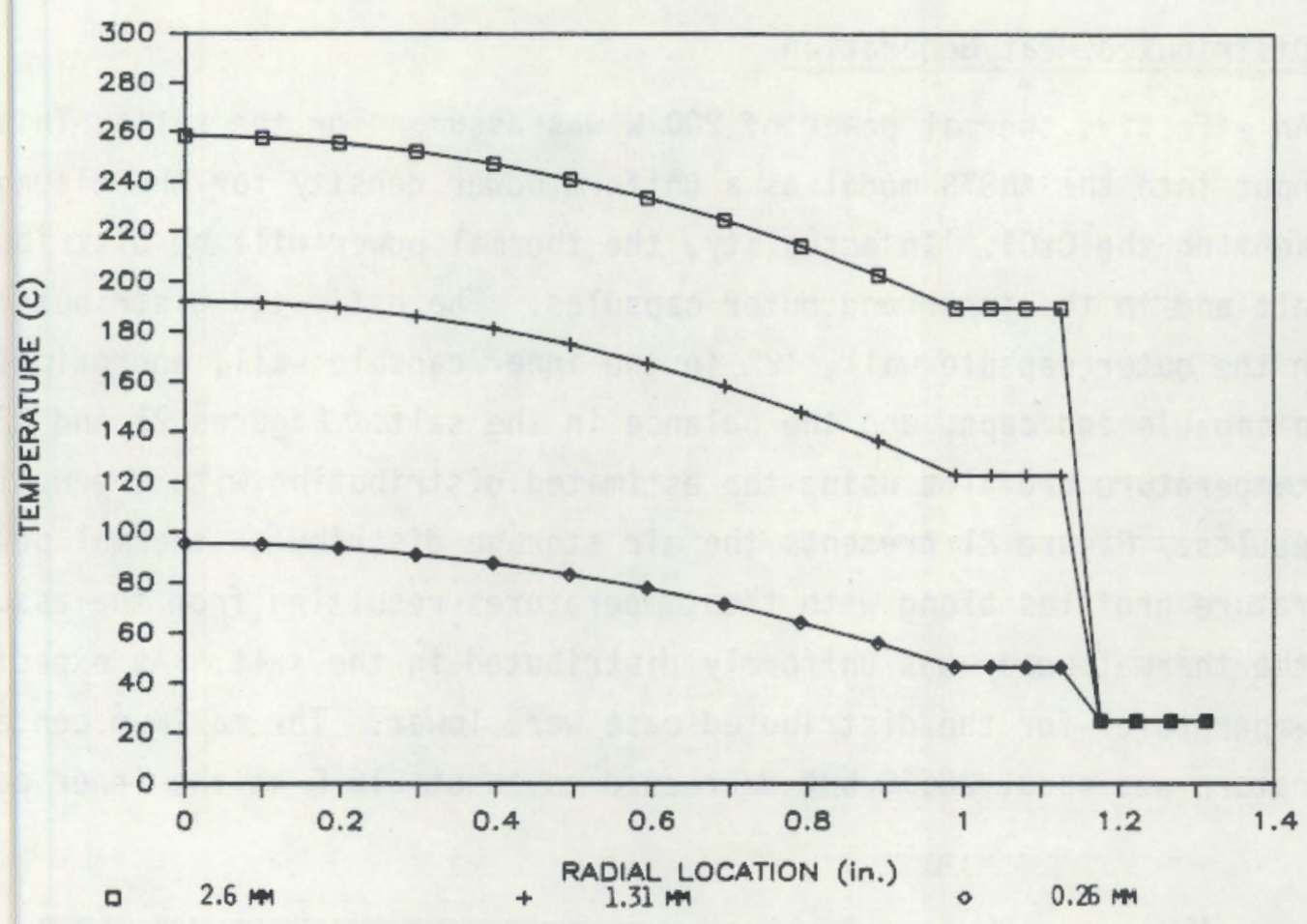

FIGURE 20. One-Dimensional Radial Temperature Profiles at Steady-State In-Water Condition with Varying Annulus Gap

at the inner capsule wall; the outer wall temperature was at $25^{\circ} \mathrm{C}$. A temperature drop of $22^{\circ} \mathrm{C}$ was noted across the annulus. The maximum temperature at the center of the 2.6 -mm annulus model was about $260^{\circ} \mathrm{C}$ but decreased to approximately $188^{\circ} \mathrm{C}$ at the inner capsule wall. A temperature differential of about $163^{\circ} \mathrm{C}$ to the outer capsule temperature of $25^{\circ} \mathrm{C}$ was observed. Since the total heat through the outer wall did not change, the outer skin temperatures remained constant for each gap condition.

In the actual configuration, the heat transfer rate around the skin of the capsule would be much greater than the transfer through the wall, which would tend to reduce or redistribute the nonconcentricity influence on the temperature profiles. Analysis of the nominal gap arrangement was considered adequate for this study. 


\section{Distributed Heat Generation}

An effective thermal power of $200 \mathrm{~W}$ was assumed for the salt. This value was input into the ANSYS model as a uniform power density for the elements representing the $\mathrm{CsCl}$. In actuality, the thermal power will be distributed in the salt and in the inner and outer capsules. The estimated distribution is $15 \%$ in the outer capsule wal1, $12 \%$ in the inner capsule wall, approximately $3 \%$ in the capsule end caps, and the balance in the salt. Figures 21 and 22 compare temperature profiles using the estimated distribution with the nominal 1-D results. Figure 21 presents the air storage distributed thermal power temperature profiles along with the temperatures resulting from the assumption that the thermal power was uniformly distributed in the salt. As expected, the temperatures for the distributed case were lower. The maximum center temperature was about $266^{\circ} \mathrm{C}$ but decreased to about $216^{\circ} \mathrm{C}$ at the inner capsule

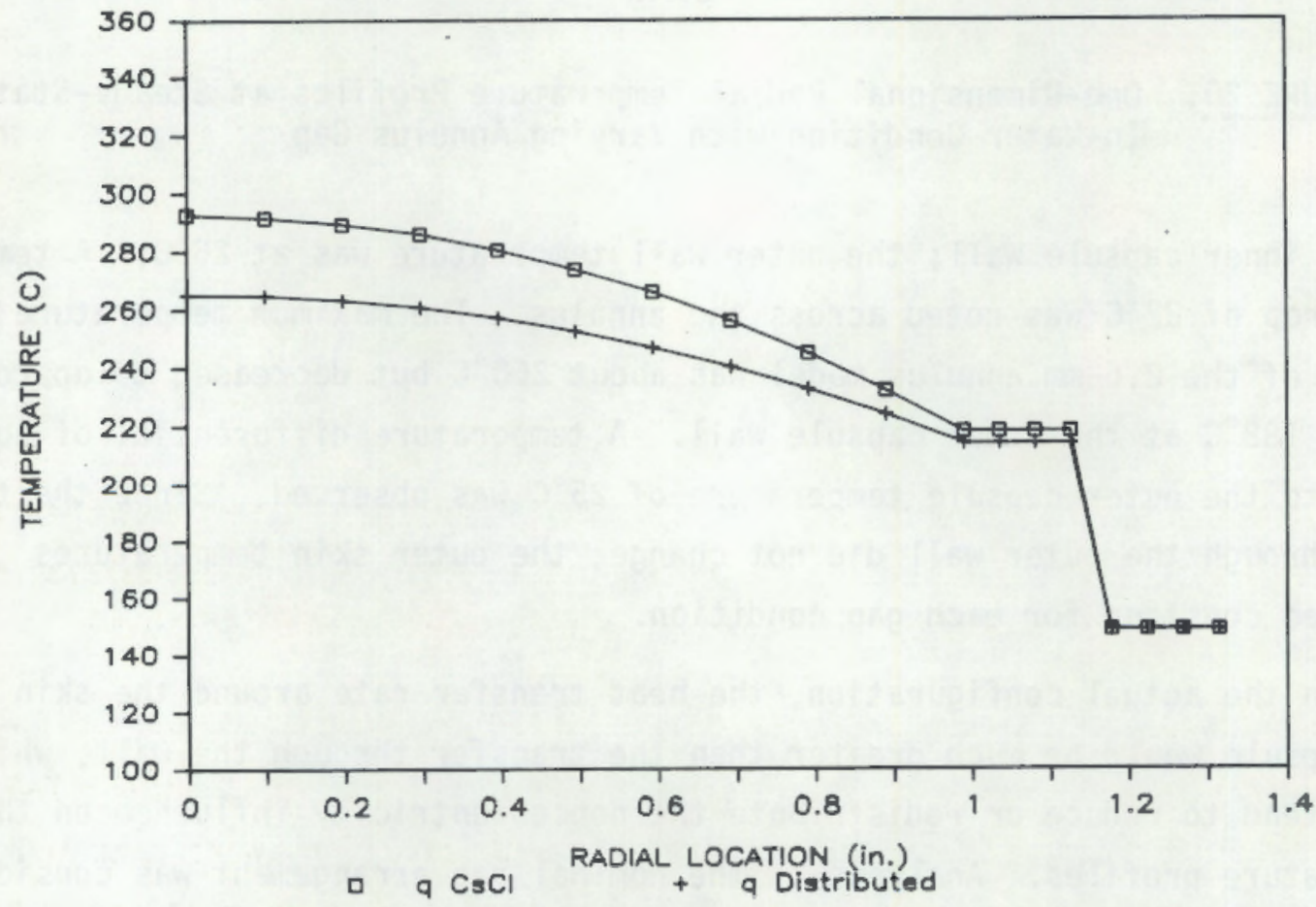

FIGURE 21. One-Dimensiona1 Radial Temperature Profiles at Steady-State In-Air Condition with Distributed Thermal Power 


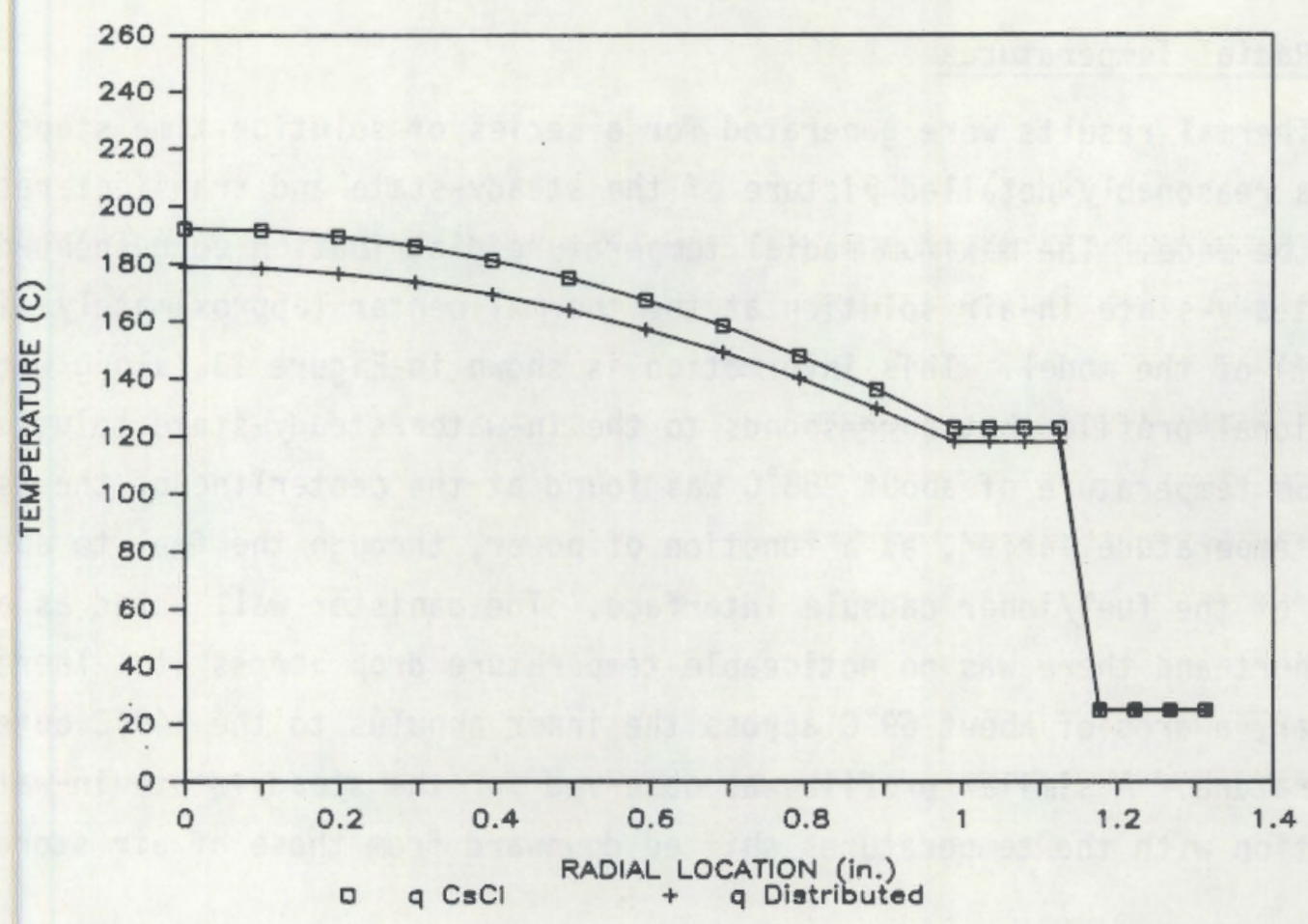

FIGURE 22. One-Dimensional Radial Temperature Profiles at Steady-State In-Water Condition with Distributed Thermal Power

wal1. The outer capsule wall temperature was $149^{\circ} \mathrm{C}$. The in-water steady-state results are shown in Figure 22. Similar trends were noted; temperatures of $177^{\circ} \mathrm{C}, 118^{\circ} \mathrm{C}$, and $25^{\circ} \mathrm{C}$ occurred at the center, inner capsule wal1, and outer capsule wall, respectively.

Since the two cases produced very little difference in temperatures for the inner capsule and no difference in the outer capsule, the assumption of uniform power in the salt was considered acceptable for this analysis.

Two-Dimensional Thermal Model

The 2-0 model allowed heat transfer to occur in both the radial (1-D case) and axial directions. Steady-state and transient solutions were examined using Revision 4.0 of ANSYS. The 2-D temperature profiles were used as input to the 2-D mechanical solution. 


\section{Radial Temperatures}

Thermal results were generated for a series of solution time steps so that a reasonably detailed picture of the steady-state and transient response could be made. The maximum radial temperature distribution corresponded to the steady-state in-air solution at the thermal center (approximately midheight) of the model. This information is shown in Figure 23, along with an additional profile that corresponds to the in-water steady-state solution. A maximum temperature of about $288^{\circ} \mathrm{C}$ was found at the centerline of the assembly. This temperature varied, as a function of power, through the fuel to about $218^{\circ} \mathrm{C}$ at the fuel/inner capsule interface. The canister wall acted as a thermal short and there was no noticeable temperature drop across it. There was, however, a drop of about $69^{\circ} \mathrm{C}$ across the inner annulus to the $149^{\circ} \mathrm{C}$ outer wall temperature. A similar profile was observed for the steady-state in-water condition with the temperatures shifted downward from those of air storage.

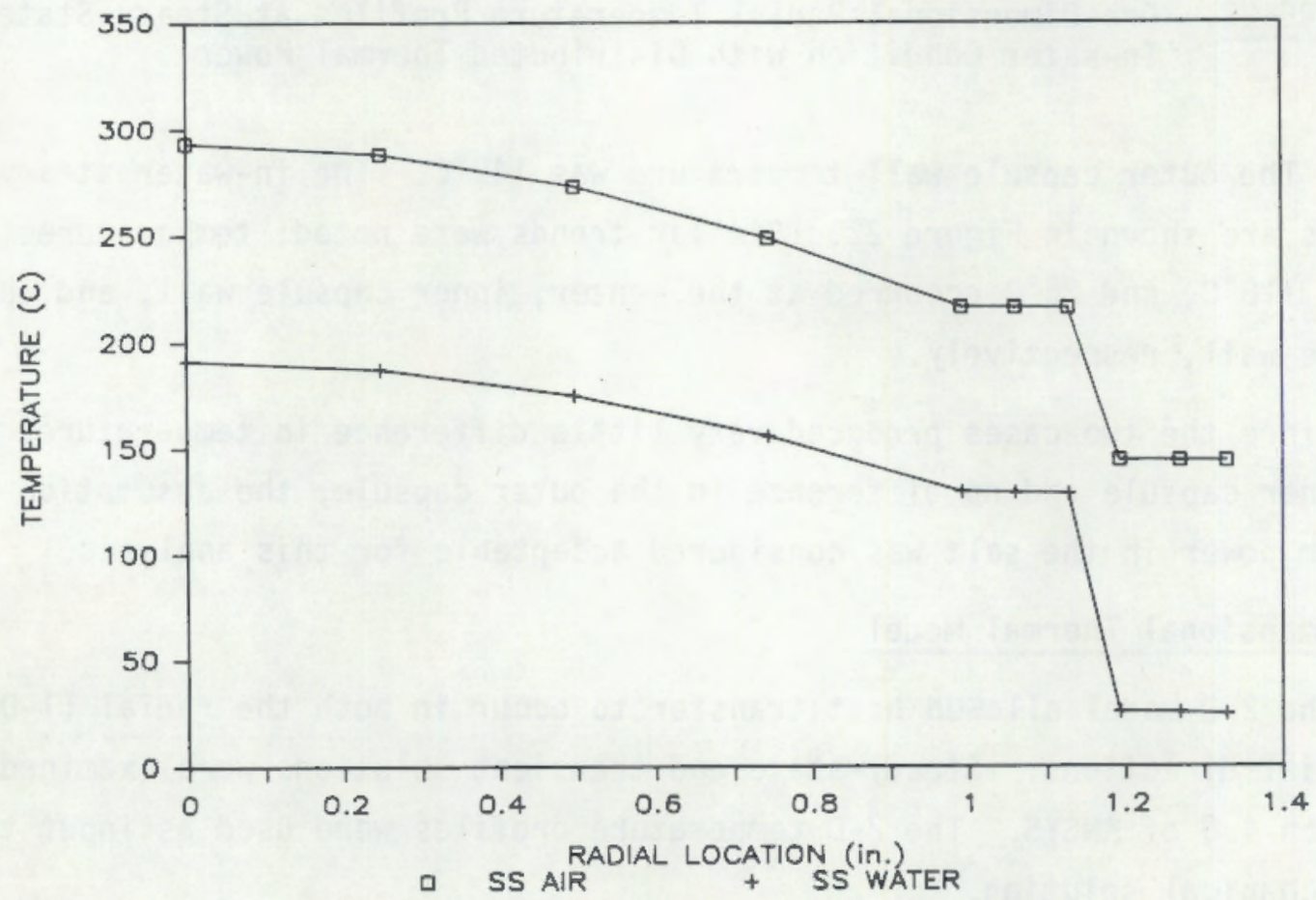

FIGURE 23. Two-Dimensional Maximum Radial Temperature Profiles at SteadyState In-Air and In-Water Conditions 


\section{Sal $t /$ Wall Interface Temperatures}

Figure 24 presents the temperature profiles for the inner capsule salt/ wall interface for both steady-state in-air and in-water conditions. The highest temperatures were associated with in-air storage. At the assembly end, where both of the end caps were in contact, the salt/wall interface temperature was approximately $138^{\circ} \mathrm{C}$. The temperature increased to a maximum of about $216^{\circ} \mathrm{C}$ at a distance of 7 to 8 in. from this end and remained constant for the next 5 to $6 \mathrm{in}$. At the fill end of the capsule, the temperature was about $154^{\circ} \mathrm{C}$. The in-water temperatures were substantially lower. The temperature at the end of the assembly was approximately $38^{\circ} \mathrm{C}$. The temperature increased to about $127^{\circ} \mathrm{C}$ at a distance of $7 \mathrm{in}$. from the end. The interface temperature remained $127^{\circ} \mathrm{C}$ from about 7 to $14 \mathrm{in}$. The temperature at the fill end of the capsule was approximately $88^{\circ} \mathrm{C}$.

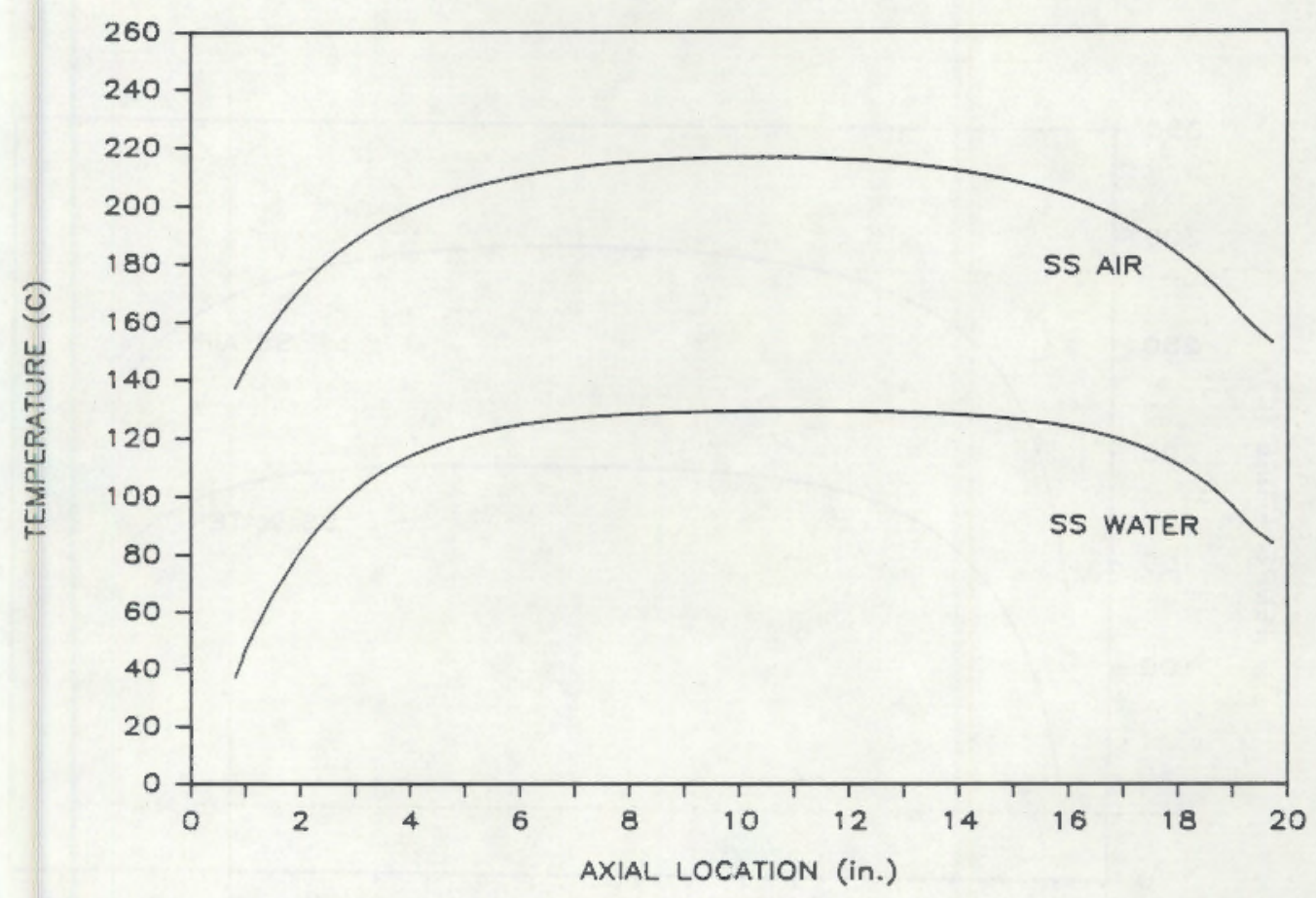

FIGURE 24. Two-Dimensional Salt/Wall Interface Axial Temperature Profiles at Steady-State In-Air and In-Water Conditions 


\section{Salt Temperatures}

The maximum assembly temperatures occurred at the centerline of the model in the $\mathrm{CSCl}$ (Figure 25). The steady-state in-air solution predicted an end temperature of approximately $135^{\circ} \mathrm{C}$, increasing to a maximum of about $288^{\circ} \mathrm{C}$. This temperature was essentially constant for the region 7 to $14 \mathrm{in}$. from the bottom. At the fill end, the salt temperature was about $218^{\circ} \mathrm{C}$. The in-water temperatures, lower profile, were $32^{\circ} \mathrm{C}$ at the bottom. A maximum of $193^{\circ} \mathrm{C}$ was observed 7 to $14 \mathrm{in}$. from the end. The fill end temperature was slightly below $149^{\circ} \mathrm{C}$.

\section{Temperature Differential}

The potential for crack propagation is driven by the temperature differential between the end cap and near-weld region of the capsule. The temperatures associated with the end cap and near-weld area maximum differences (between the in-water and in-air transients) were used in the stress portion of this

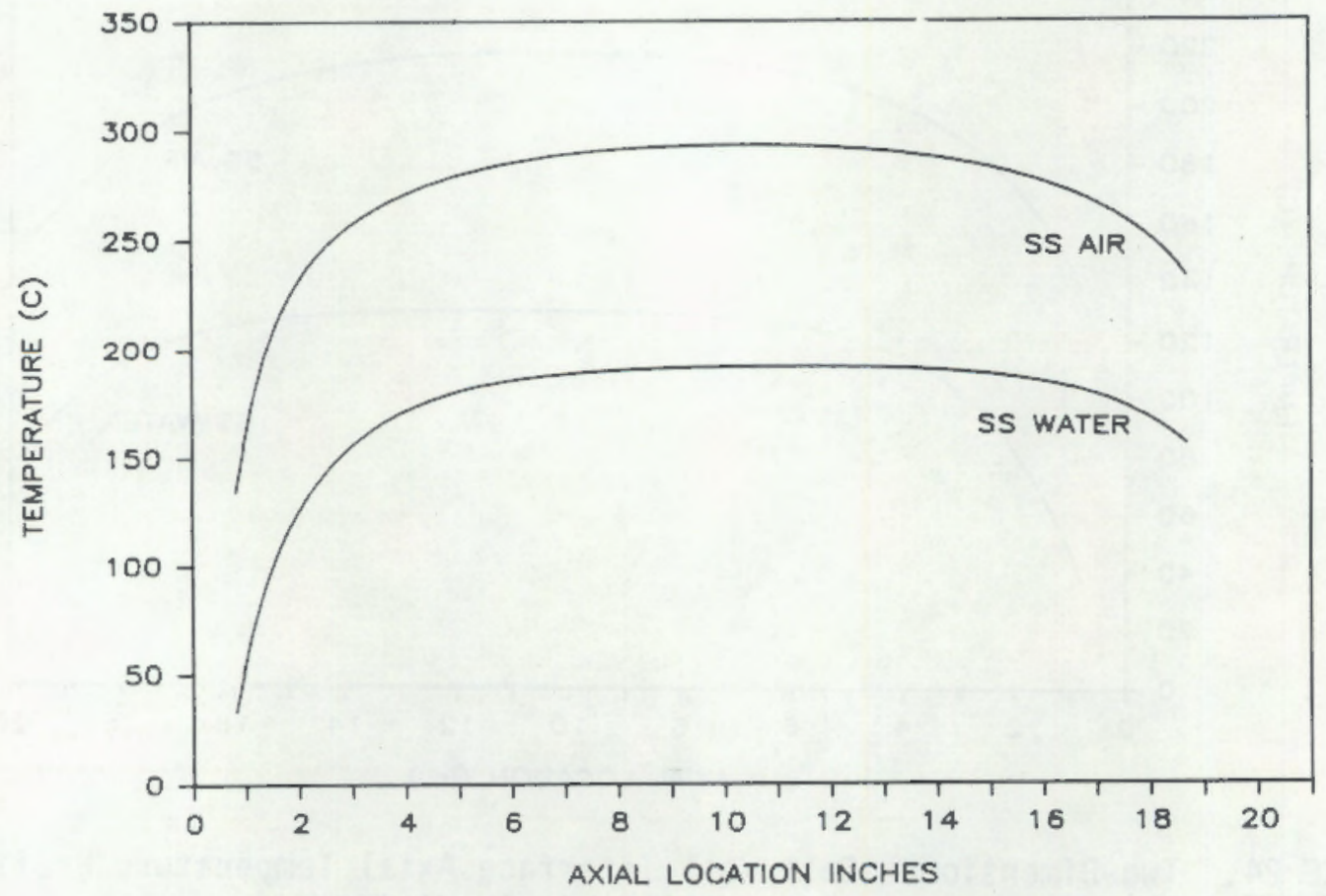

FIGURE 25. Two-Dimensional Maximum CsCl Axial Temperature Profiles at SteadyState In-Air and In-Water Conditions 
study. The cooling curves for the upper and lower welds, from a steady-state in-air condition to the water quench, are shown in Figures 26 and 27 , respectively. The temperatures for the center cap (CNTR Cap), corner cap (CNR cap), weld side (W side), and midheight (Mid HT) locations are shown in Figure 26. The midheight steady-state in-air temperature was approximately $143^{\circ} \mathrm{C}$. The quench exponentially reduced the temperature until $29^{\circ} \mathrm{C}$ was reached after about 90 to $100 \mathrm{~s}$. The trends were similar for the other portions of the capsule. The center end cap temperature dropped from about 88 to $29^{\circ} \mathrm{C}$. The corner end cap and the weld side temperatures fell from about $88^{\circ} \mathrm{C}$ and $93^{\circ} \mathrm{C}$ to $24^{\circ} \mathrm{C}$ after the 90 - to 100-s quench time. The differences in starting temperatures, c001ing rates, and final temperatures were determined by the local heat transfer coefficients, heat load, and thermal mass.

The upper weld, end cap, and weld sidewall maximum temperature differences are shown in Figure 28 . The steady-state in-air difference was $-6^{\circ} \mathrm{C}$. The negative difference means that the weld area sidewall was at a higher temperature

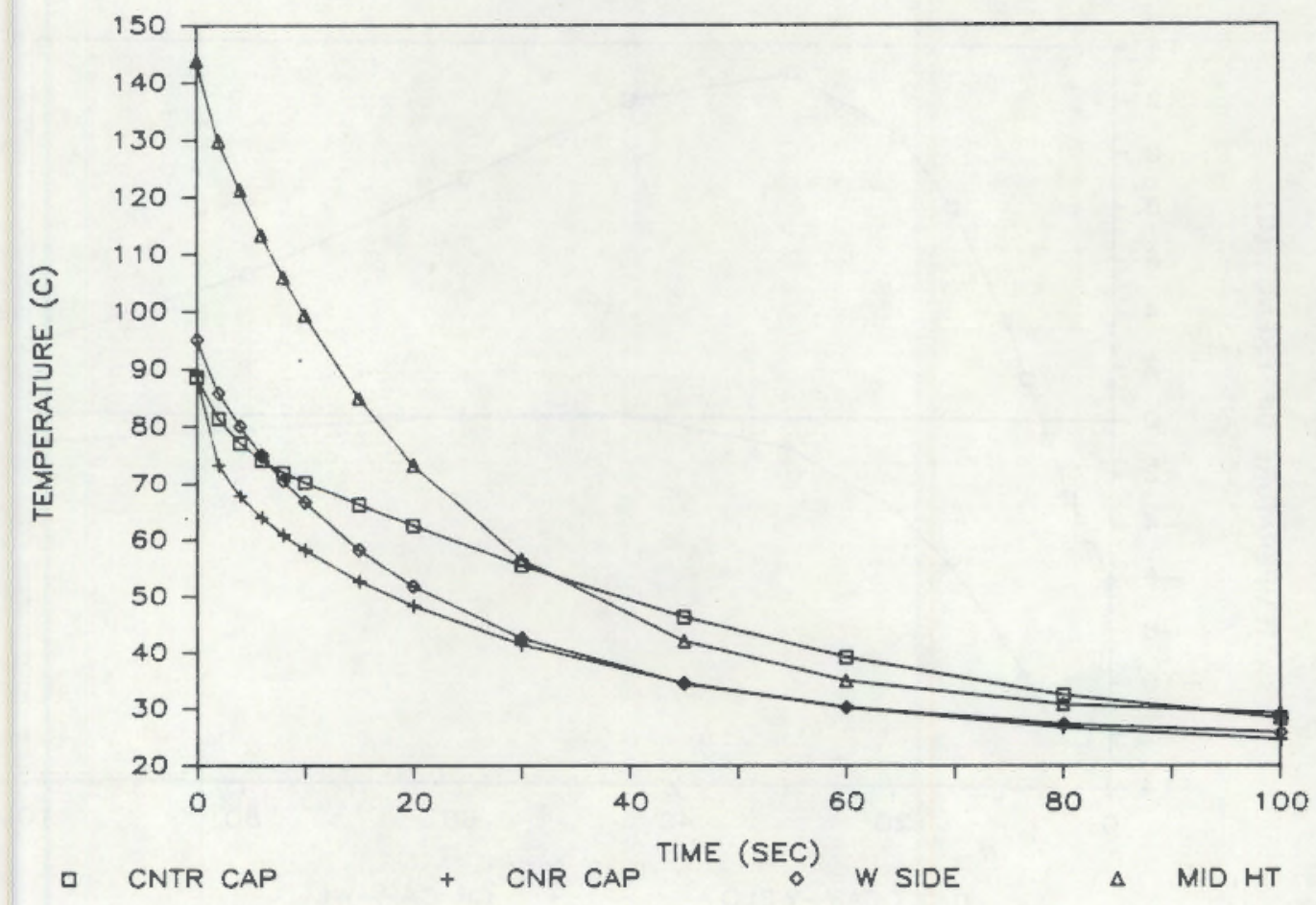

FIGURE 26. Two-Dimensional Temperature Profiles of Upper Weld Area Response to Water Quench 


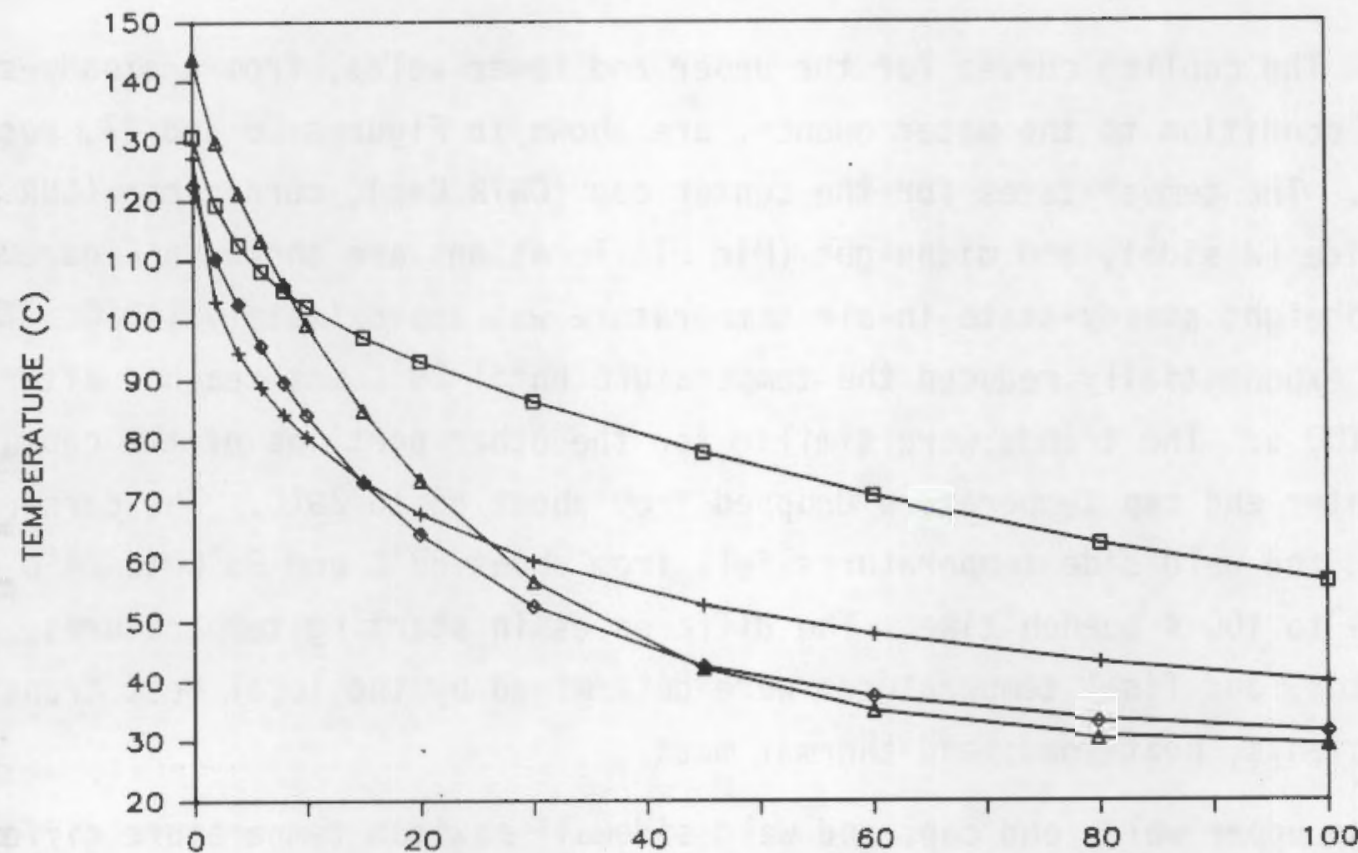

- CNTR CAP + CNR CAP TIME (SEC) $\underset{0}{\text { S SIDE }} \Delta$ MID HT

FIGURE 27. Two-Dimensional Temperature Profiles of Lower Weld Area Response to Water Quench

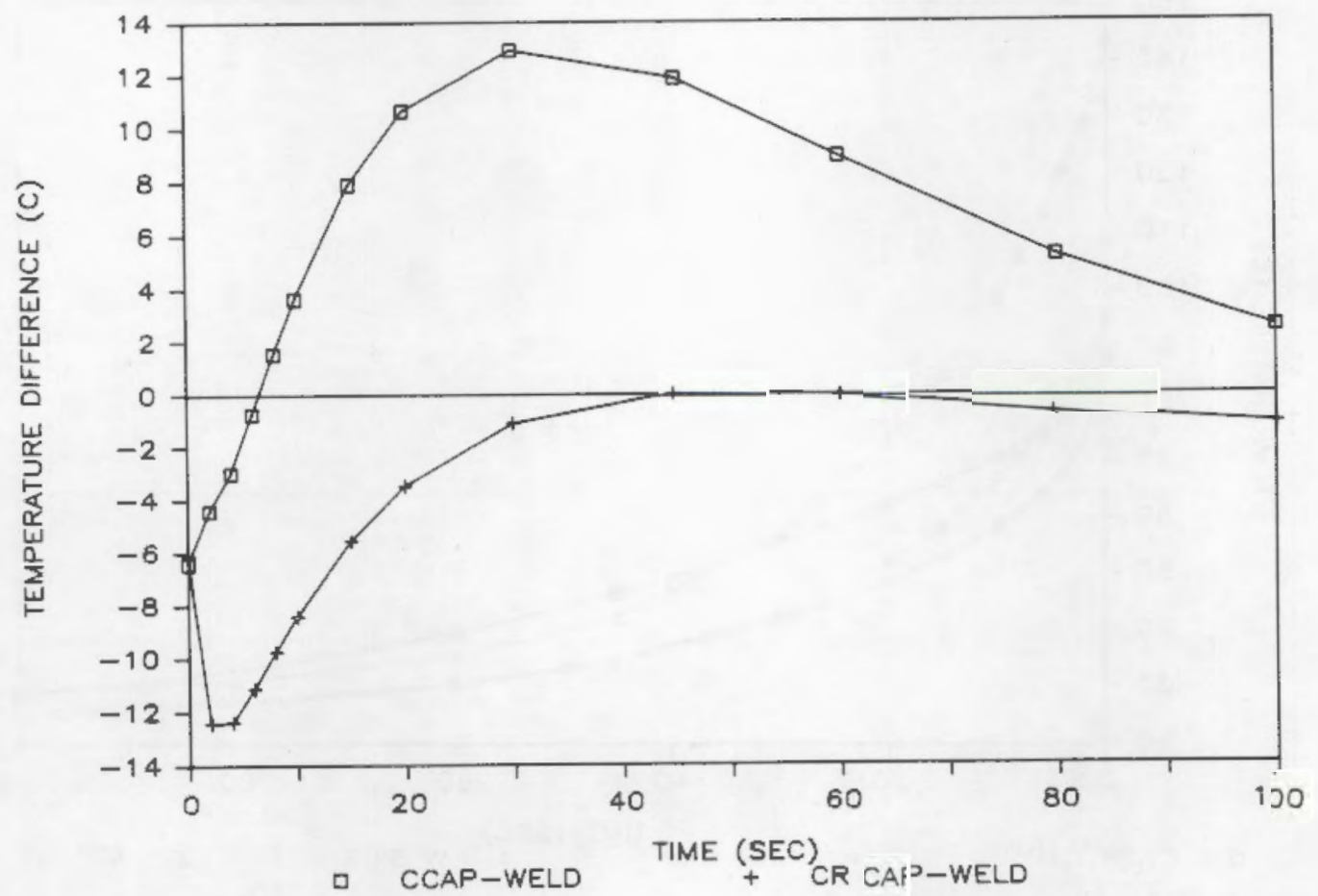

FIGURE 28. Two-Dimensional Temperature Differences in Upper Weld Area as Result of Water Quench 
than either of the end cap locations. The corner of the end cap lost heat at a greater rate than the center of the cap, which accounted for the increase in negative difference to about $-13^{\circ} \mathrm{C}$ for the corner cap-to-weld difference and a decrease in the center cap-to-weld difference. The extreme differences noted for the center cap-to-weld were approximately $-6^{\circ} \mathrm{C}$ and $13^{\circ} \mathrm{C}$. The corner capto-weld differences were about $-13^{\circ} \mathrm{C}$ and $0^{\circ} \mathrm{C}$.

Figure 27 shows the cooling response of the lower weid area. The center cap location had a steady-state in-air temperature of $129^{\circ} \mathrm{C}$ that decreased to about $63^{\circ} \mathrm{C}$ after $100 \mathrm{~s}$ in the water bath. The corner cap and weld location steady-state temperature of $127^{\circ} \mathrm{C}$ cooled to $46^{\circ} \mathrm{C}$ and $35^{\circ} \mathrm{C}$ after $100 \mathrm{~s}$. Temperature difference curves (similar to those generated for the upper weld area) are shown in Figure 29. The extreme differences for the corner cap-to-weld and center cap-to-weld location are about $-8^{\circ} \mathrm{C}$ and $8^{\circ} \mathrm{C}$ to $36^{\circ} \mathrm{C}$, respectively.

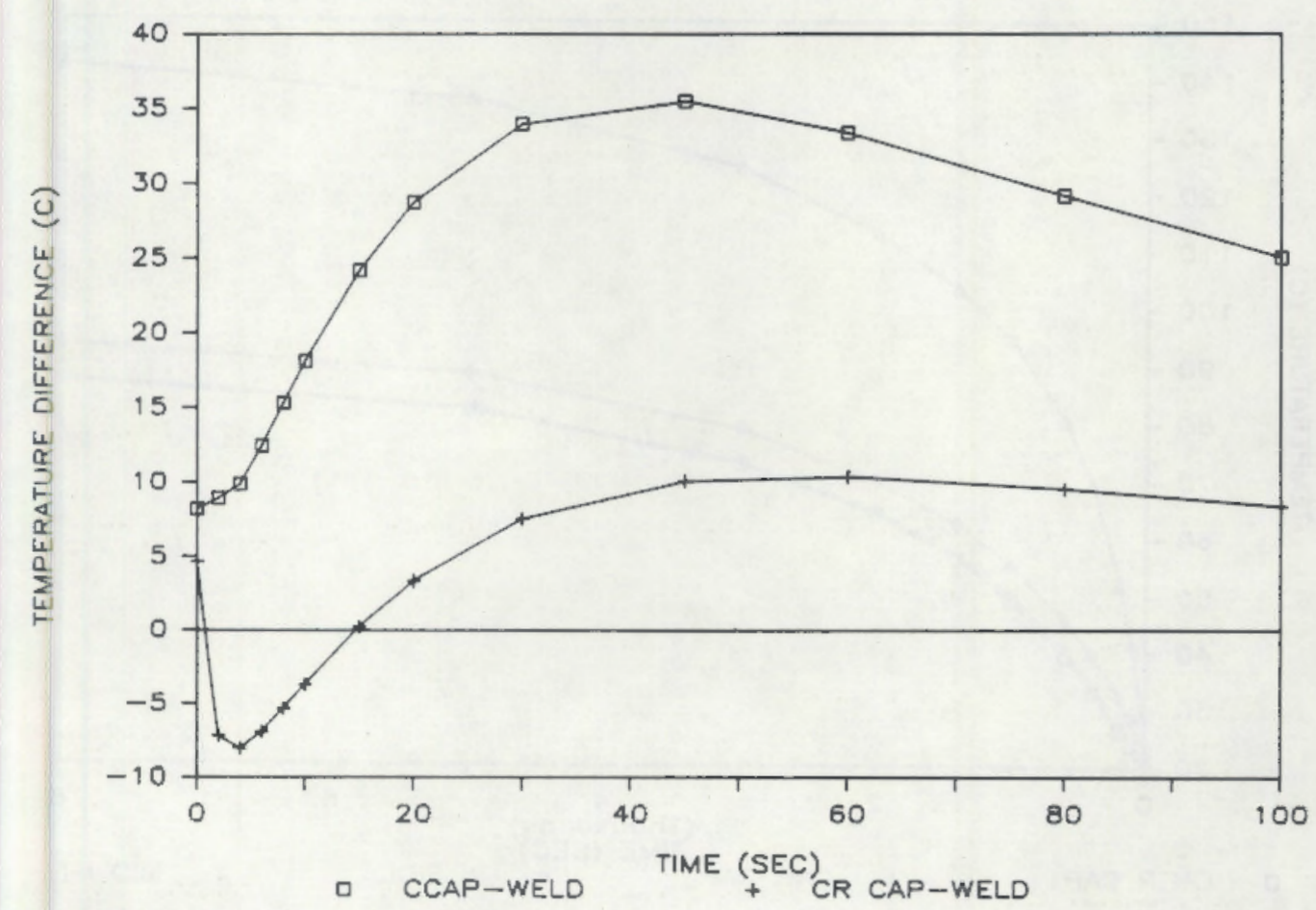

FIGURE 29. Two-Dimensional Temperature Differences in Lower Weld Area as Result of Water Quench 
The above information covered the steady-state in-air to in-water transient portion of the thermal results. The second portion of the thermal cycle was concerned with the steady-state in-water to in-air transient results.

These temperature contours are shown in Figures 30 and 31 for the upper and lower weld regions, respectively. From the upper weld area in Figure 30 , the four locations on the capsule heat up in an exponential fashion. The midheight started at about $29^{\circ} \mathrm{C}$ and increased to approximately $141^{\circ} \mathrm{C}$ after $8000 \mathrm{~s}$ $(2.2 \mathrm{~h})$. The weld location temperature varied from $24^{\circ} \mathrm{C}$ to $93^{\circ} \mathrm{C}$, while both the center and corner end cap temperatures increased from $24^{\circ} \mathrm{C}$ to approximately $88^{\circ} \mathrm{C}$. The temperature differences for the upper weld area steady-state water to in-air transients are presented in Figure 32. The extremes were -0.9 to $-6^{\circ} \mathrm{C}$ and -0.8 to $-7^{\circ} \mathrm{C}$ for the corner cap-to-weld and center cap-to-weld locations, respectively.

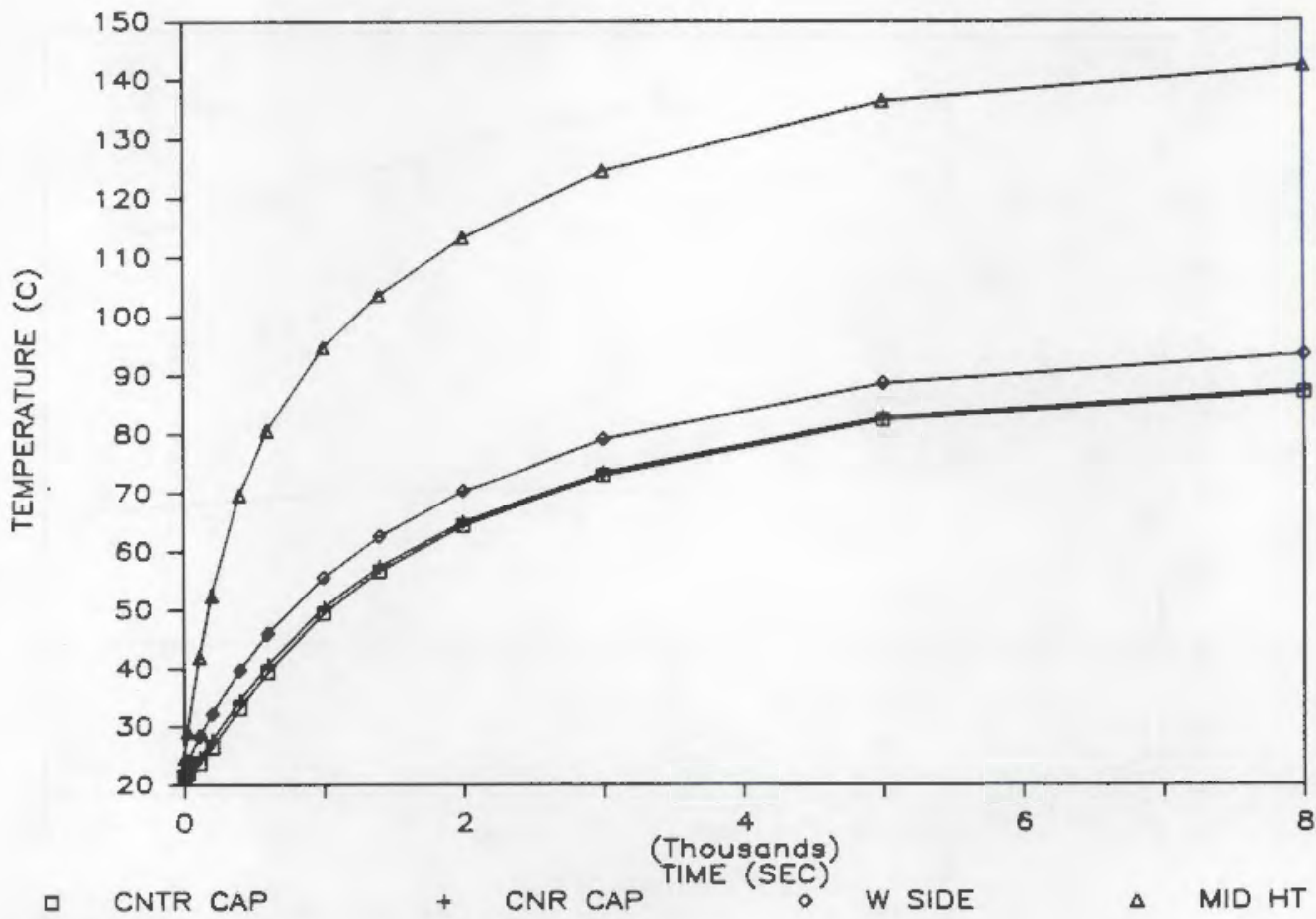

FIGURE 30. Two-Dimensional Temperature Profiles of Upper Weld Area Response to Air Hea tup 
$\therefore 0$
$\therefore$
$\therefore$
$\therefore$
$\because \because$

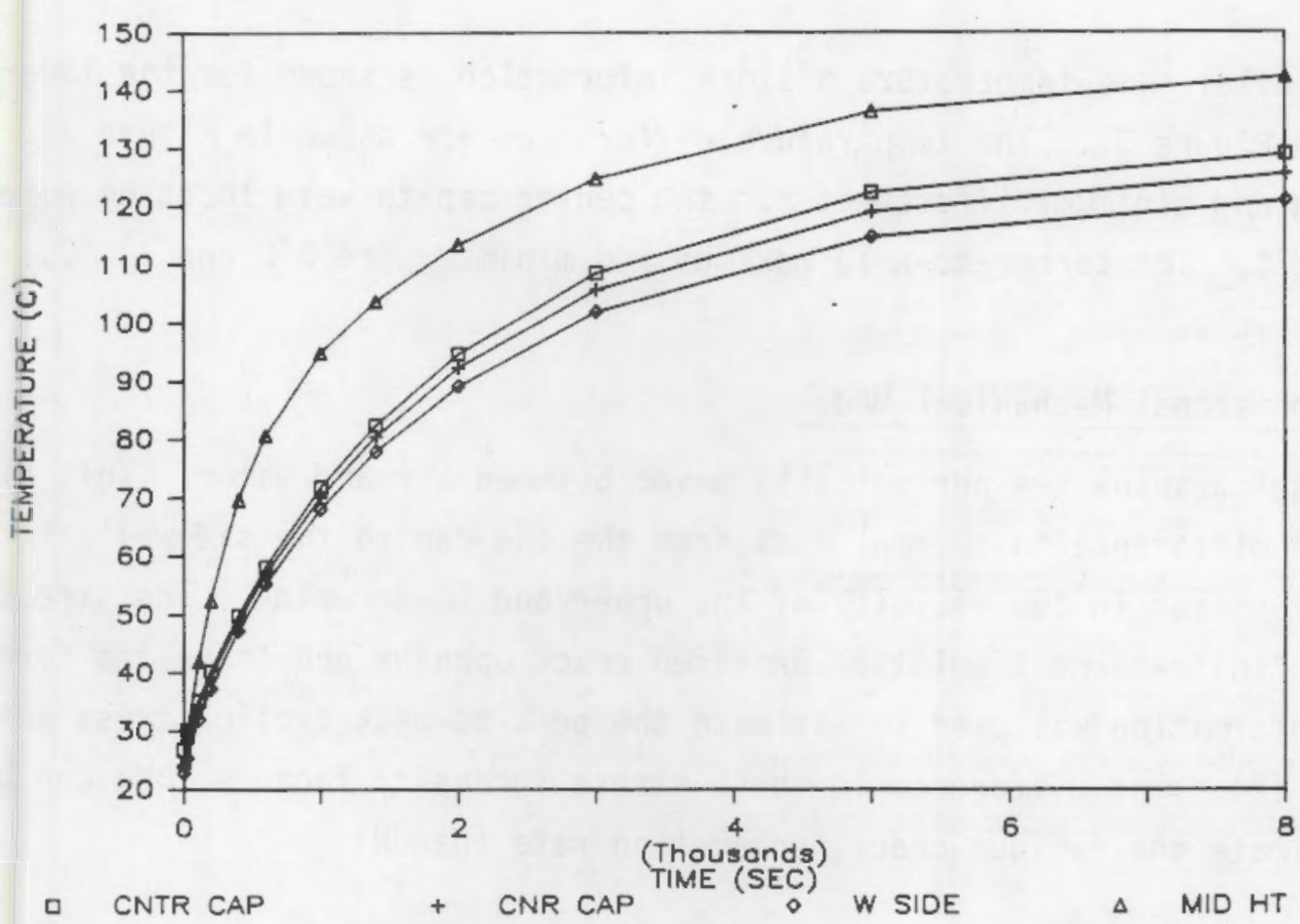

FIGURE 31. Two-Dimensional Temperature Profiles of Lower Weld Area Response to Air Heatup

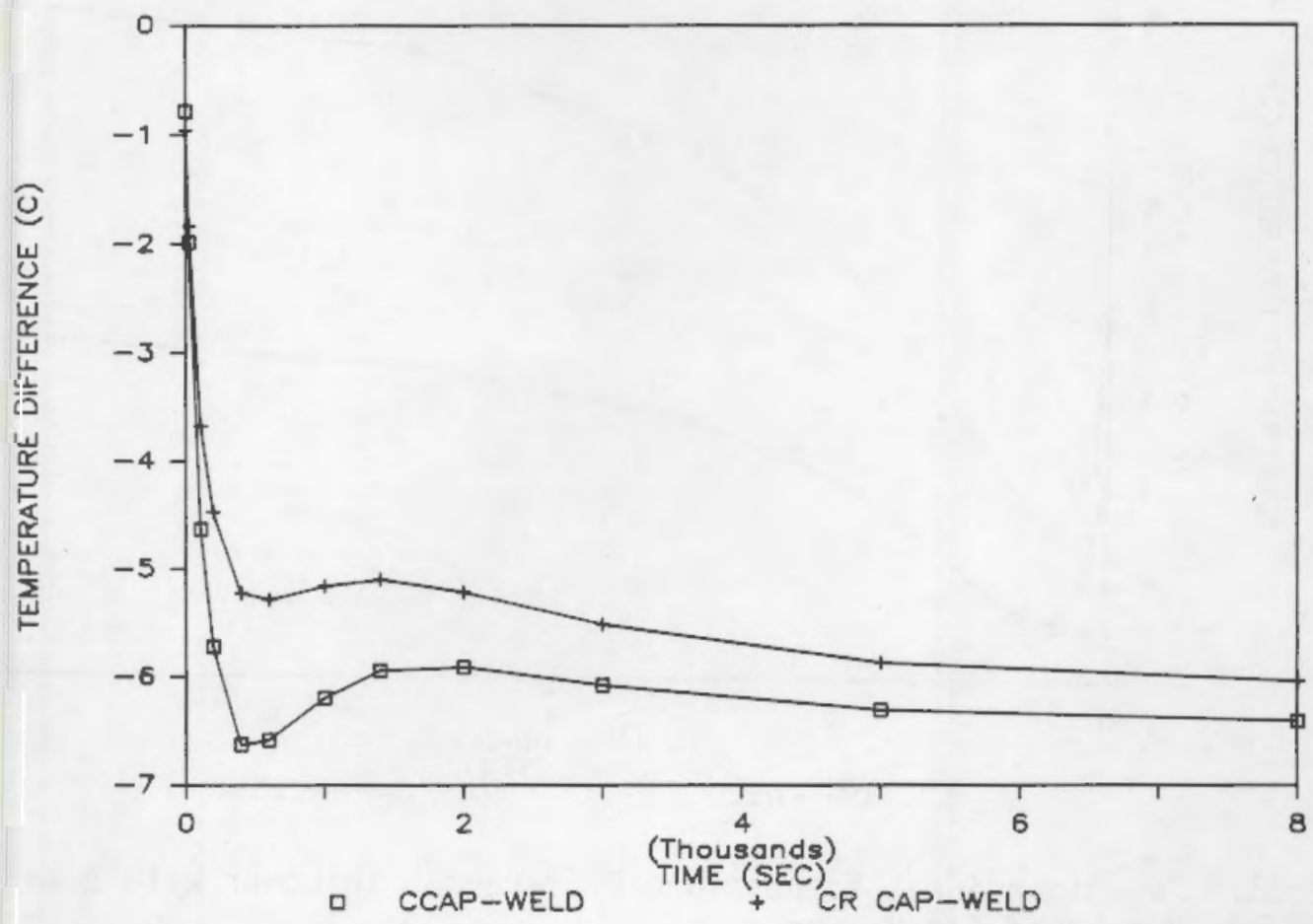

FIGURE 32. Two-Dimensional Temperature Differences in Upper Weld Area as Result of Air Heatup 
Similar time-temperature history information is shown for the lower weld area in Figure 31. The temperature differences are shown in Figure 33. The maximum and minimum differences for the center cap-to-weld location were $8^{\circ} \mathrm{C}$ and $2.5^{\circ} \mathrm{C}$. The corner-to-weld maximum and minimum were $5^{\circ} \mathrm{C}$ and $1.4^{\circ} \mathrm{C}$, respectively.

Two-Dimensional Mechanical Model

The capsules are periodically moved between air and water. This cycling, and the difference in thermal mass from the end cap to the sidewall, induces a thermal stress in the vicinity of the upper and lower welds. The stress pass of the finite-element solution provided crack opening and crack tip force data. This information was used to estimate the peak-to-peak cyclic stress intensity factor $(K)$. The difference in these stress intensity factors $(\Delta K)$ can be used to estimate the fatigue crack propagation rate (da/dN).

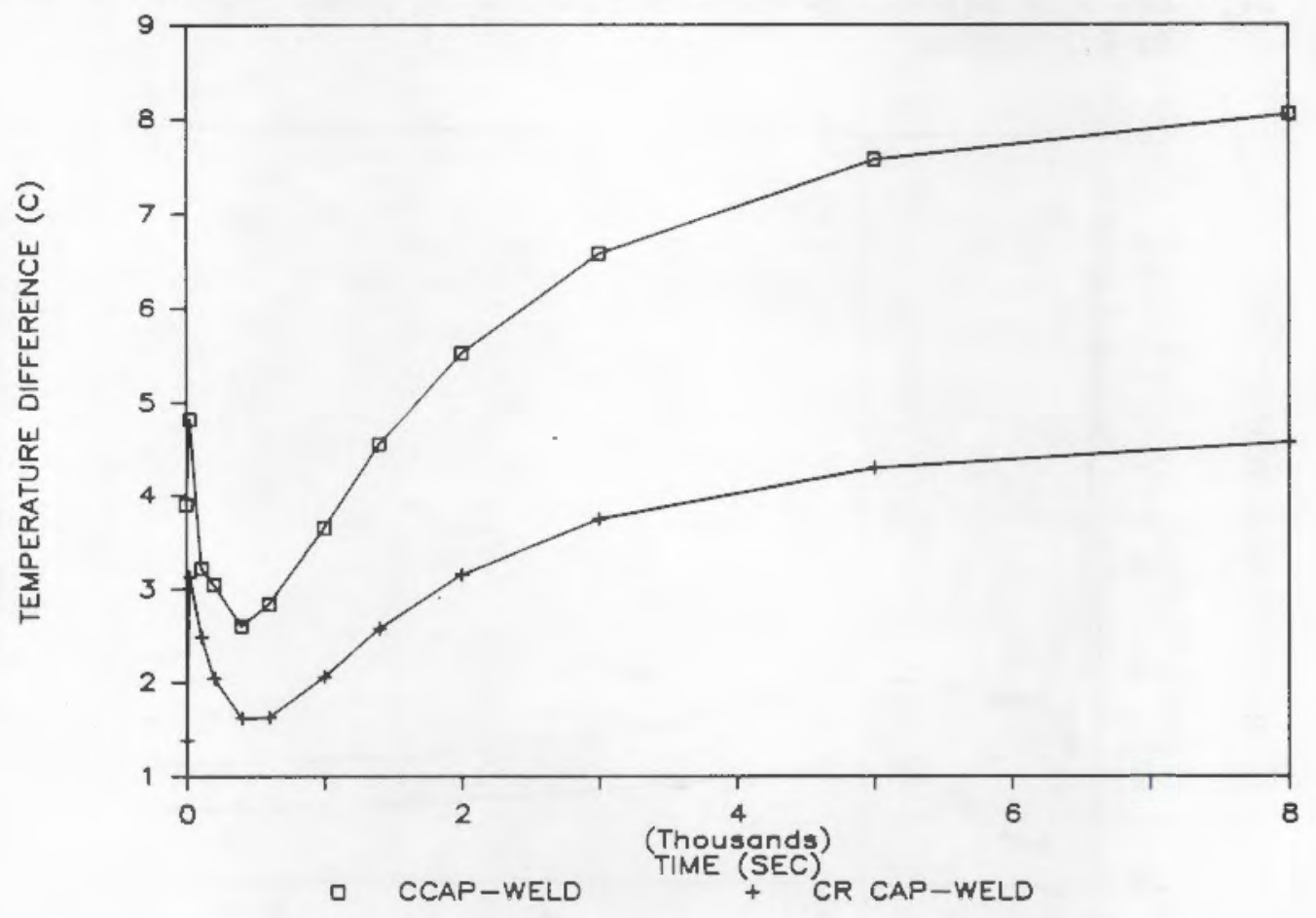

FIGURE 33. Two-Dimensional Temperature Differences in Lower Weld Area as Result of Air Heatup 


\section{Stress Intensity Factor}

One technique for estimating $K$, the displacement method, involves examining the nodal displacements that correspond to the maximum temperature differences. The displacement solution approach used in this portion of the study was based on the work by Tada (1973). The plane strain crack opening (v) is given by the following equation:

$$
v=\frac{K_{I}}{G}\left[\frac{r}{2 \pi}\right]^{\frac{1}{2}} \sin \frac{\theta}{2}\left[2-2 v-\cos ^{2} \frac{\theta}{2}\right]
$$

$$
\text { where } \begin{aligned}
K_{I} & =\text { stress intensity } \\
G & =E / 2(1+v) \\
r & =\text { distance from crack tip to displacements } \\
\theta & =180^{\circ} \\
\nu & =\text { Poisson's ratio } \\
E & =\text { elastic modulus. }
\end{aligned}
$$

This equation was applied to the near-crack tip displacement field for the upper and lower welds (Appendix D). The extreme stress intensity factors for the upper weld were approximately $0.43 \mathrm{ksi} \sqrt{\mathrm{in}}$. and $-2.1 \mathrm{ksi} \sqrt{\mathrm{in}}$., for a change in $k$ of about $2.5 \mathrm{ksi} \sqrt{\mathrm{in}}$. The lower weld stress intensity factor varied between $-0.31 \mathrm{ksi} \sqrt{\mathrm{in}}$. to $-5.5 \mathrm{ksi} \sqrt{\mathrm{in}}$. The thermal loads in the lower weld area tend to close the crack. However, a conservative technique for accommodating some crack opening due to possible residual welding stress was to consider the difference as a change in reversing $K$. A value of $5.2 \mathrm{ksi} \sqrt{\mathrm{in}}$. Was used for the lower weld.

The second estimate of the stress intensity factor was based on an energy method using the ANSYS-generated nodal forces and displacements. The crack closure work was calculated from:

$$
W=1 / 2\left(f_{x} d u_{x}+f_{y} d u_{y}\right)
$$

where $f_{x}$ and $f_{y}$ were components of the nodal reaction forces across the crack plane in the uncracked state. The components $d_{x}$ and $d u_{y}$ were calculated from 
the relative nodal displacements. For this study, the mode I stress intensity factor was calculated from the crack closure work (Tada 1973) by

$$
K_{I}=\left[\frac{E\left(f_{y} u_{y}\right)}{2 R\left(a_{2}-a_{1}\right)\left(1-v^{2}\right)}\right]^{1 / 2}
$$

where $R=$ radius to crack tip

$a_{2}=$ crack length after node release

$a_{1}=$ original crack length.

The crack closure equations were applied to the upper and lower welds. These calculations are shown in Appendix E. The extreme stress intensity factors for the upper weld were approximately $0.43 \mathrm{ksi} \sqrt{\mathrm{in}}$. and $-2.05 \mathrm{ksi} \sqrt{\mathrm{in}}$., for a change in $K$ of about $2.5 \mathrm{ksi} \sqrt{\mathrm{in}}$. The lower weld stress intensity factor was $-0.32 \mathrm{ksi} \sqrt{\mathrm{in}}$. and $-5.26 \mathrm{ksi} \sqrt{\mathrm{in}}$. A change in $\mathrm{K}$ of approximately $5.26 \mathrm{ksi}$ in. was used for the lower weld.

The two solution approaches were in good agreement between the stress intensity factor predictions for the upper and lower welds.

\section{Crack Acceleration}

The preceding section deals with estimating the stress intensity factor for the nominal weld geometry. During service, the periodic opening and closing of the welds will cause crack growth and possible increase in $K$. This effect was modeled by moving the crack tip along the crack plane and allowing the crack to grow from node to node in a controlled manner. At each new crack location the displacement and crack closure methods were used to estimate the new factors. The difference between these peak-to-peak stress intensity factors $(\Delta K)$ is shown in Figures 34 and 35 . The upper weld response to changing crack length is shown in Figure 34 . The $\Delta K$ for the nominal weld penetration was about $2.5 \mathrm{ksi} \sqrt{\mathrm{in}}$. Any growth in crack length reduced this. A $\Delta \mathrm{K}$ between 1.9 and $2.1 \mathrm{ksi} \sqrt{\mathrm{in}}$. Was observed for an increase in crack length of about $0.028 \mathrm{in}$. A value of $2.5 \mathrm{ksi} \sqrt{\mathrm{in}}$. was assumed as a conservative level of $\Delta \mathrm{K}$ for the upper weld. Figure 35 presents the relative change in stress intensity as a function of crack length for the lower weld. Both methods predicted a 


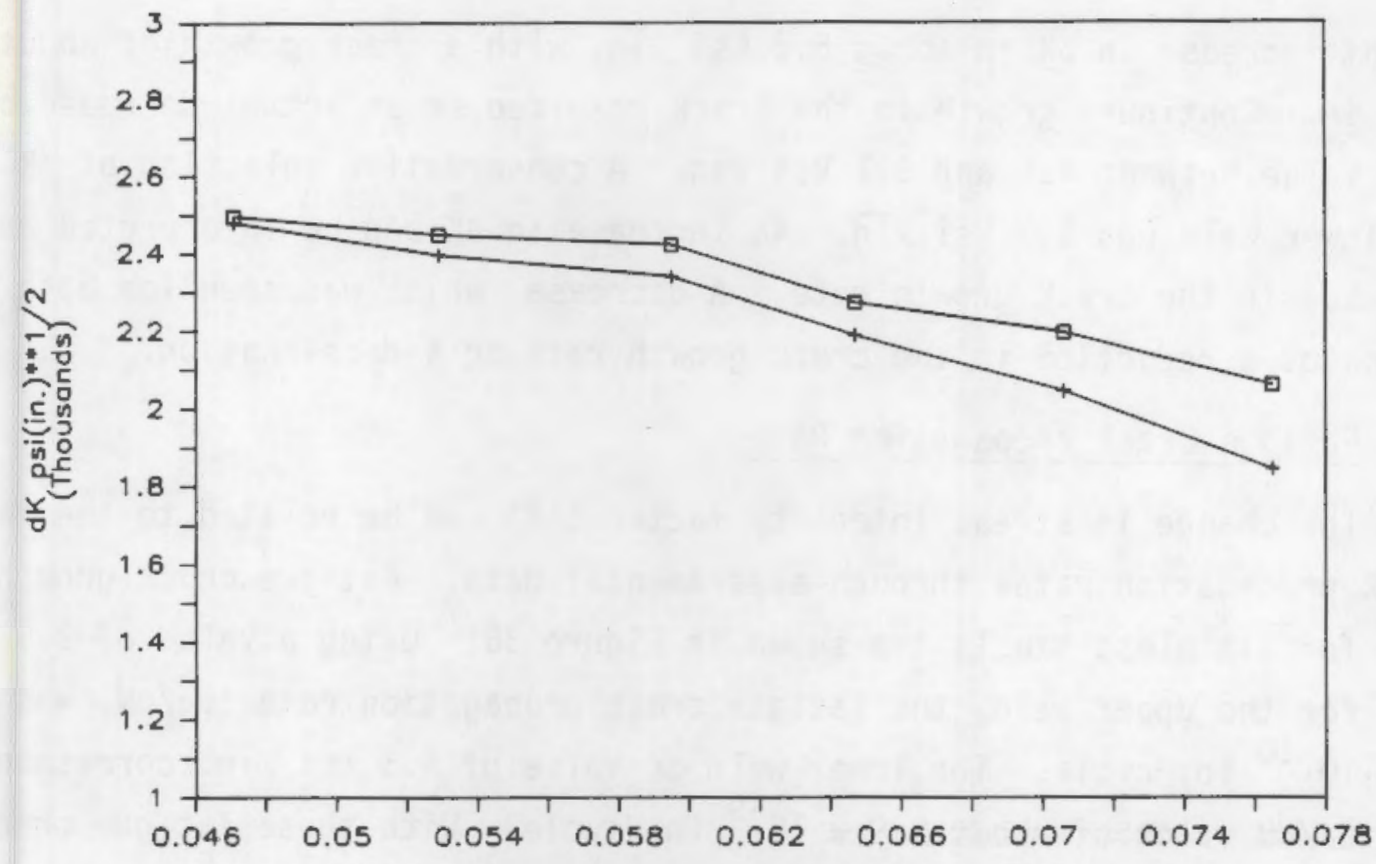

- DISPLACEMENT METHOD Crock Length (in.) $\stackrel{+}{+}$ ENERGY METHOD

FIGURE 34. Effect of Crack Growth on the Relative Change in Stress Intensity Factor for the Upper Weld

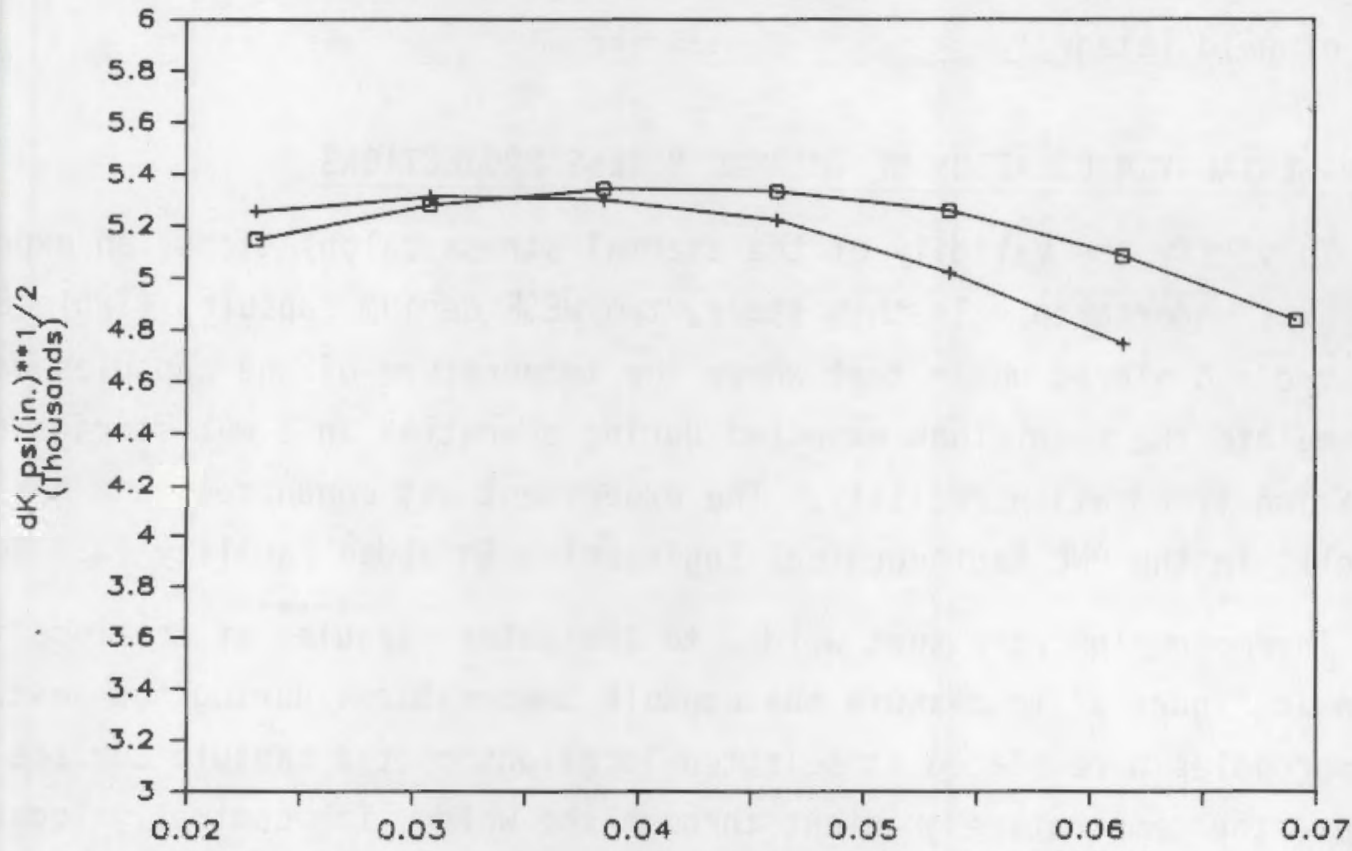

- DISPLACEMENT METHOD Crock Length (in.) ENERGY METHOD

FIGURE 35. Effect of Crack Growth on the Relative Change in Stress Intensity Factor for the Lower Weld 
slight increase in $\Delta K$ to about $5.3 \mathrm{ksi} \sqrt{\text { in. }}$ with a crack growth of about $0.02 \mathrm{in.}$ Continued growth in the crack resulted in an actual decrease of $\Delta K$ to a value between 4.8 and $5.1 \mathrm{ksi} \sqrt{\mathrm{in}}$. A conservative selection of $\Delta K$ for the lower weld was $5.3 \mathrm{ksi} \sqrt{\mathrm{in}}$. An increase in $\Delta \mathrm{K}$ can be interpreted as an increase in the crack growth rate. A decrease, which was seen for both welds, indicates a reduction in the crack growth rate or a deceleration.

\section{Fatigue Crack Propagation Rate}

The change in stress intensity factor $(\Delta K)$ can be related to the fatigue crack propagation rates through experimental data. Fatigue crack growth rate data for stainless steels are shown in Figure 36 . Using a value of $2.5 \mathrm{ksi}$ $\sqrt{i n}$. for the upper weld, the fatigue crack propagation rate ( $d a / d N)$ was less than $10^{-10} \mathrm{in./cycle.} \mathrm{The} \mathrm{lower} \mathrm{weld} \Delta \mathrm{K}$ value of $5.3 \mathrm{ksi} \sqrt{\mathrm{in}}$. corresponded to a da/dN value of about $2.9 \times 10^{-9} \mathrm{in./cycle.} \mathrm{With} \mathrm{these} \mathrm{fatigue} \mathrm{crack} \mathrm{propa-}$ gation rates, it will take approximately $1 \times 10^{7}$ and $3.5 \times 10^{5}$ cycles to observe crack growths of $1 \mathrm{mil}$ in the upper and lower welds, respectively. If the service life of the capsule is 30 years with one cycle per day, this is equivalent to about $1.1 \times 10^{4}$ cycles. Thus, there should be little chance of loss of weld integrity.

\section{EXPERIMENTAL VERIFICATION OF THERMAL STRESS PROJECTIONS}

To verify the validity of the thermal stress calculations, an experimental study was undertaken. In this study, two WESF cesium capsules (Table 8) were selected and placed under test where the temperature of the capsules was cycled to simulate the conditions expected during operation in a wet storage/dry operation irradiation facility. The experiment was conducted in a hot cell (C-Cel1) in the PNL Radiochemical Engineering Shielded Facility (324 Building).

Thermocouples were spot welded to the outer capsules at the locations shown in Figure 37 to measure the capsule temperatures during the test. Ten thermocouples were placed at selected locations on the capsule surface to measure the temperature gradient through the weld. The centrally located thermocouples were monitored as a measure of the maximum capsule temperature under various conditions. Twelve thermocouples were attached to Capsule C-105 


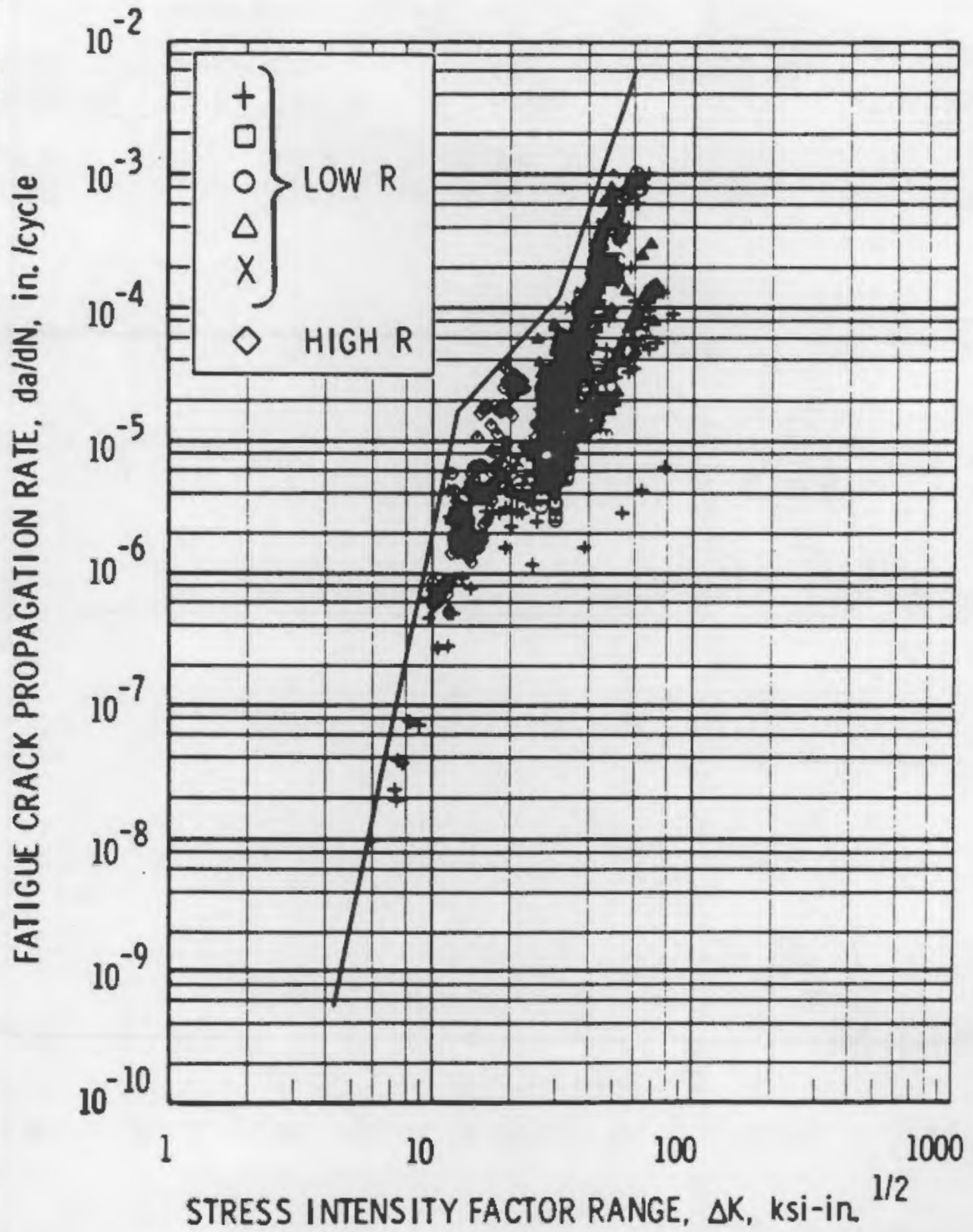

FIGURE 36. Fatigue Crack Growth Rate Data for Stainless Steels - Conditions of Low and High Stress Ratio (R), Laboratory Air, and Simulated PWR Environment (taken from Simonen et al. 1983) 
TABLE 8. Description of WESF Cesium Capsules

\begin{tabular}{|c|c|c|c|c|}
\hline $\begin{array}{c}\text { Capsule } \\
\text { Identification }\end{array}$ & $\begin{array}{c}\text { Cs Content, } \\
\mathrm{KCi} \\
\end{array}$ & $\begin{array}{l}\text { Heat } \\
\text { Output, w }\end{array}$ & $\begin{array}{c}\text { Salt } \\
\text { Weight, } \mathrm{kg}\end{array}$ & $\begin{array}{c}\text { Inner Capsule Wall } \\
\text { Thickness, in. }\end{array}$ \\
\hline $\begin{array}{l}C-105 \\
C-903\end{array}$ & $\begin{array}{l}55.3 \\
54.7\end{array}$ & $\begin{array}{l}265.6 \\
262.7\end{array}$ & $\begin{array}{l}2.904 \\
2.737\end{array}$ & $\begin{array}{l}0.095 \\
0.136\end{array}$ \\
\hline
\end{tabular}
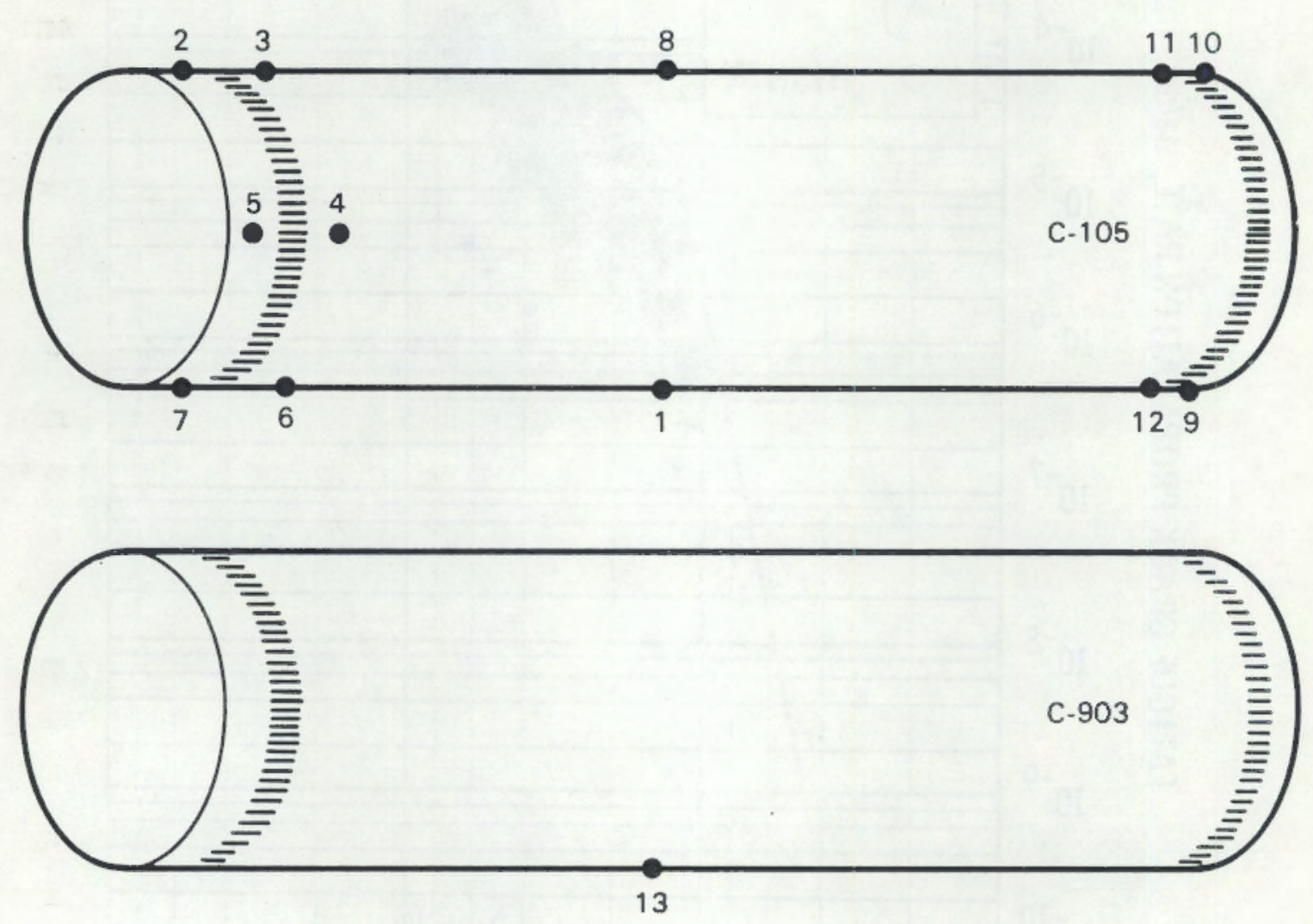

FIGURE 37. Location of Thermocouples on the Thermocycled Cesium Capsules

to characterize the temperature gradients. The remaining thermocouple was spot welded to the bottom of Capsule C-903 at its axial center.

The thermocouples were Type K with Type 304 SS grounded sheaths. They were $12 \mathrm{in.}$ long and $0.062 \mathrm{in}$. in diameter with 0.100-in. caps for wel ded installation and had standard miniplugs that were fastened to the capsulehol ding rack to minimize stress on the spot weld during in-cell movement of the capsule rack. Each couple was $x$-ray inspected by the vendor, calibrated against standard thermocouples, and insulated with a thin coating of 
self-curing silicone rubber to prevent erroneous readings due to cooling of the sheath during the quench cycle.

The two capsules were positioned about 1.5 in. apart in a wire-framed rack. The rack was placed into an open-top tank plumbed to cycle cooled water over the capsules hourly to provide the thermal cycling. The tank was placed above a refrigerated reservoir to facilitate rapid gravity release of the water from the tank. An automatic timing circuit was set to activate a pump that circulated cooled $\left(20^{\circ} \mathrm{C}\right)$ water over the capsules at a rate of $28 \mathrm{gal} / \mathrm{min}$ and to close a normally open solenoid drain valve. At this flow rate, the capsules were totally immersed in $5 \mathrm{~s}$, but the pump continued to circulate the water for the entire 90-s quench period. The timer then deactivated the circulating pump and solenoid valve, and the water drained by gravity into the reservoir through a 1-1/2-in. overflow line and 1-1/2-in. drain line.

During the cycling operation, the temperature was monitored using either a twelve-point recorder, a rapid response two-pen recorder, or a digital volt meter.

\section{Temperature Measurements}

Prior to initiation of the thermal cycling, the capsule temperatures were monitored to obtain equilibrium temperatures under a variety of conditions. Table 9 lists the temperatures observed for each thermocouple and capsule condition examined.

When the capsule was suspended horizontally in the cell, the capsule centerline on the bottom side (the hottest point) was $167^{\circ} \mathrm{C}$. The top center was slightly cooler $\left(158^{\circ} \mathrm{C}\right)$ because of the larger gap at the top. The capsule ends were considerably cooler, as expected, because of lower heat generation rates. The end of the capsule with Thermocouples 2 through 7 was apparently the fill end of the capsule with the substantial void volume and the smaller heat generation rate yielding the lower temperatures observed.

Positioning the capsules vertically produced some minor changes in the equilibrium temperature because of the change in the annulus between the freefloating inner capsule and the outer capsule. 


\section{TABLE 9. Capsule Temperatures}

Capsule Location

Horizontal in $28^{\circ} \mathrm{C}$ air

Vertical in $28^{\circ} \mathrm{C}$ air

Equilibrium in air in tank

Maximum during cycling (air)

Minimum during cycling

(water quench)

\begin{tabular}{|c|c|c|c|c|c|c|c|c|c|c|c|c|}
\hline 1 & 2 & 3 & 4 & 5 & 6 & 7 & 8 & 9 & 10 & 11 & 12 & 13 \\
\hline 167 & 88 & 91 & 96 & 91 & 101 & 93 & 158 & 132 & 118 & 124 & 136 & \\
\hline 156 & 86 & 85 & 89 & 86 & 84 & 85 & 151 & 126 & 124 & 131 & 128 & 149 \\
\hline 200 & 101 & 105 & 112 & 108 & 120 & 111 & 182 & 159 & 147 & 152 & 162 & 190 \\
\hline 192 & 102 & 102 & 105 & 102 & 108 & 104 & 170 & 125 & 124 & 127 & 132 & 174 \\
\hline 28 & 23 & 26 & 24 & 26 & 25 & 26 & 24 & 26 & 26 & 28 & 25 & 25 \\
\hline
\end{tabular}

(a) See Figure 37 for location of thermocouples.

When the capsules were permitted to equilibrate for $16 \mathrm{~h}$ in the air of the tank, they achieved a significantly higher temperature than when suspended in the cell. This is a result of the restricted free air flow around the capsules. This effect led to a somewhat higher temperature during the thermocycling than would be expected in circulating or free flowing air in an irradiator, slightly exaggerating the thermal stress during the test. The minimum temperatures achieved were also slightly lower than expected in an operating irradiator because cooled $\left(20^{\circ} \mathrm{C}\right)$ water was used for the quench cycle.

Thermal cycle Test

During thermal cycling, the quench cycle was set for $90 \mathrm{~s}$, followed by a self-heating cycle of 60 min in air. The temperature change with time for a point on each side of the weld during cycling is shown in Figure 38 .

The system was automatically cycled on this schedule during a period of six months, giving a total of 3219 cycles over the temperature range shown in Figure 38. After nearly 2000 cycles, the refrigeration unit located in the high radiation field failed, and the lower quench temperature increased with time. With the refrigeration unit operating, the temperatures in the vicinity of the weld (Thermocouples 11 and 12) cycled from about 24 to $136^{\circ} \mathrm{C}(\Delta T=$ $112^{\circ} \mathrm{C}$ ); without a functioning refrigeration unit, the temperatures cycled from 43 to $138^{\circ} \mathrm{C}\left(\Delta \mathrm{T}=95^{\circ} \mathrm{C}\right)$. Therefore, an additional $626 \mathrm{cycles}$ were achieved with a slightly smaller temperature difference between the maximum and minimum cycle temperature. At this point, the test was interrupted, and a new 


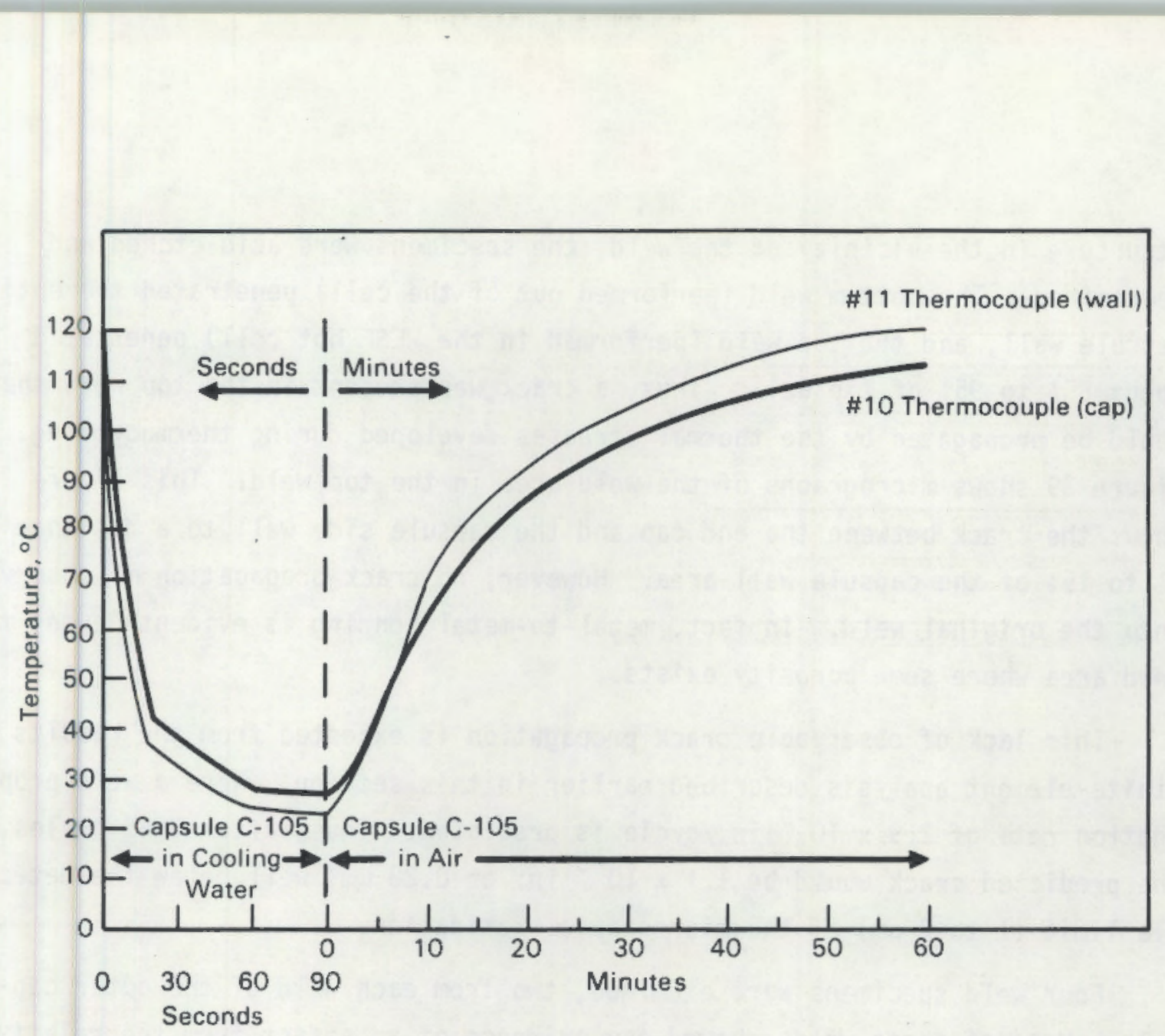

FIGURE 38. Temperature Cycles of Thermocycled Capsules at Two Points, One on Each Side of Weld

refrigeration unit was installed with the compressor located outside of the cell. The total number of cycles achieved was 3845 .

\section{Weld Examination}

Following the test, Capsule C-903 was removed from the rack to obtain samples from the outer capsule welds for metallographic examination. An air-powered grinder with a $1 / 16-i n$. thick abrasive wheel was used to cut the end caps from the capsule. A guide cap.attachment aided in removing the end welds and caps without damaging the inner capsule. The caps were washed with water and removed from the hot cell. Two metallographic specimens were taken from each weld $\left(180^{\circ}\right.$ apart) to permit a thorough examination of the weld. Each of these samples was potted and polished in preparation for the microscopic examination. The micrographs from the as-polished samples showed no structural features even at high magnification. To more clearly observe the 
structure in the vicinity of the weld, the specimens were acid etched and reexamined. The bottom weld (performed out of the cell) penetrated the entire capsule wal1, and the top weld (performed in the WESF hot cell) penetrated about $85 \%$ to $95 \%$ of the wal1. Thus, a crack was present in the top weld that could be propagated by the thermal stresses developed during thermocycling. Figure 39 shows micrographs of the weld area in the top weld. This figure shows the crack between the end cap and the capsule side wall to a distance of $5 \%$ to $15 \%$ of the capsule wall area. However, no crack propagation is observed into the original weld. In fact, metal-to-metal bonding is evident beyond the weld area where some porosity exists.

This lack of observable crack propagation is expected from the results of finite-element analysis described earlier in this section, where a weld propagation rate of $2.9 \times 10^{-9} \mathrm{in.} /$ cycle is predicted. Thus, after 3845 cycles, the predicted crack would be $1.1 \times 10^{-5} \mathrm{in}$. or $0.28 \mu \mathrm{m}$, well bel ow the detectable limit ( 1 to $2 \mu \mathrm{m})$ of the microscopic examination.

Four weld specimens were examined, two from each weld of the outer capsule. None of these welds showed any evidence of an effect from the relatively minor thermal stress generated by cycling capsules from an air environment to water. This test is expected to develop somewhat more stress than would be present in an actual irradiator because the water used was maintained at $20^{\circ} \mathrm{C}$, significantly cooler than expected in an irradiator. Furthermore, the air flow around the capsule was restricted by the water bath and the capsules appear to equilibrate at about $20^{\circ} \mathrm{C}$ higher than in free flowing air.

\section{DISCUSSION}

The results of this study indicate that the outer capsule welds, which receive the maximum thermal stress for the thermal cycle described, will maintain integrity over the 30-year service life. This period is equivalent to approximately $1.1 \times 10^{4}$ cycles if cycled at the rate of one cycle/day.

The highest thermal loading occurs in the bottom weld of the outer capsule where an approximate fatigue crack propagation rate of $2.9 \times 10^{-9} \mathrm{in./cycle}$ is predicted. This means that $3.5 \times 10^{5}$ cycles are required for the crack to 

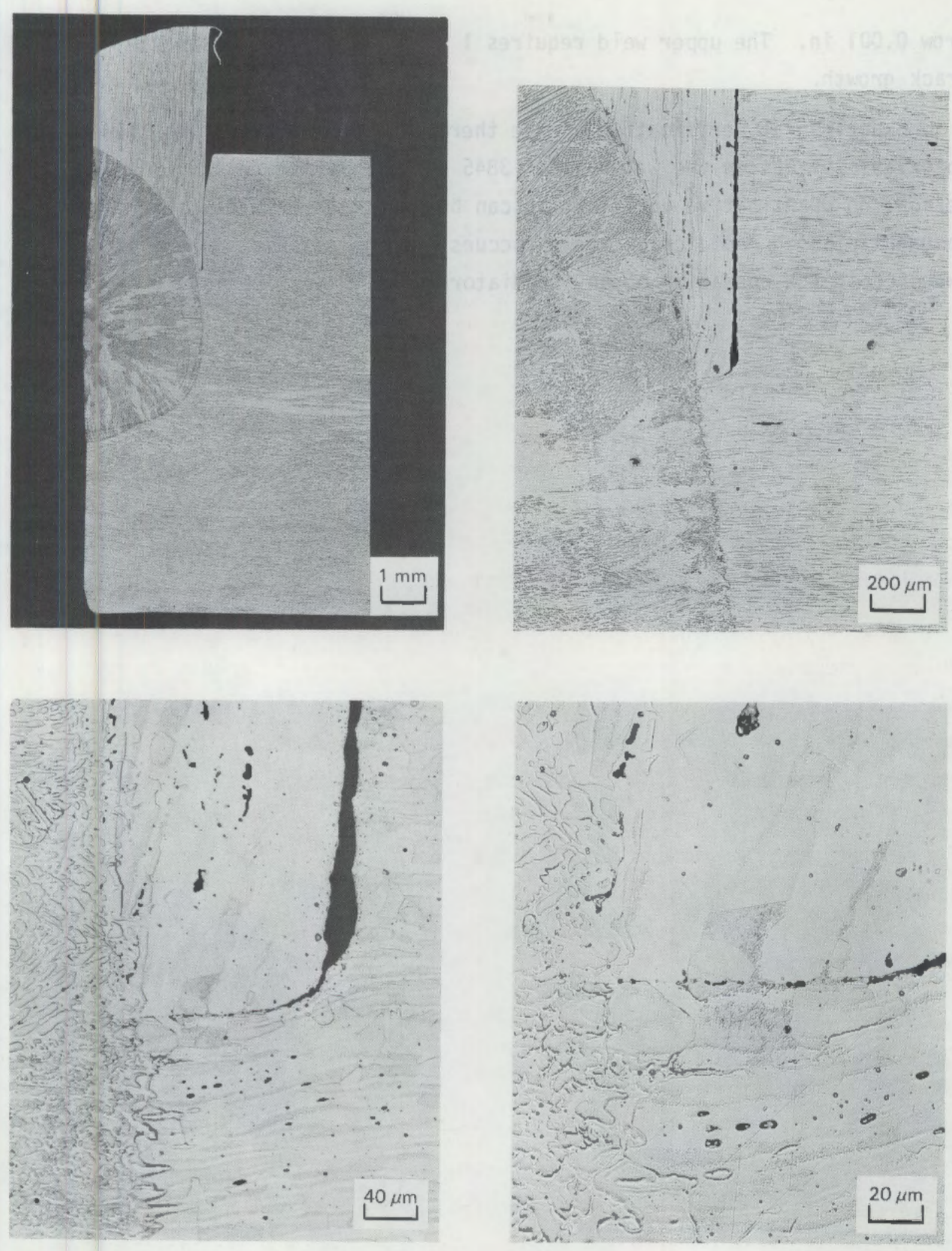

FIGURE 39. Micrographs of the Etched Weld Section of a WESF Cesium Capsule After Thermal Cycling for 3845 Cycles 
grow $0.001 \mathrm{in}$. The upper weld requires $1 \times 10^{7}$ cycles to obtain the same crack growth.

Experimental verification of the thermal stress calculations showed no observable effect on the welds after 3845 cycles. Although, for this limited period, no quantitative verification can be made, the results do verify that no unanticipated rapid crack growth occurs. This test exceeds the stress expected in the operation of an irradiator for a 10-year period. 


\section{REFERENCES}

Bryan, G. H. 1983. Cesium Chloride Compatibility Testing Program Annual Report - Fiscal Year 1983. PNL-4847, Pacific Northwest Laboratory, Richland, Washington.

Campbel1, G. D. 1981. Strontium and Cesium Capsule Heat Transfer Analysis. RHO-LD-167, Rev. 1, RockweTT Hanford Operations, Richtand, Washington.

Fullam, H. T. 1972. Compatibility of Cesium Chloride and Strontium Fluoride with Containment Materials. BNWL-1673, Pacific Northwest Laboratory, Richland, Washington.

Holman, J. P. 1976. Heat Transfer. McGraw Hill Book Company, New York.

Kenna, B. T., and F. J. Schultz. 1983. Characterization of an Aged WESF

Capsule. SAND 83-0928, Sandia National Laboratories, Albuquerque, New Mexico, and Livermore, California.

Nuclear Systems Materials Handbook. 1978. Part I - Structural Materials, Group 1-High Alloy Steels, Section 4 - 316SS.

Rimshaw, S. J., and E. E. Ketchen. 1967. "Cesium-137 Data Sheets."

ORNL-4186, Oak Ridge National Laboratory, Oak Ridge, Tennessee.

Rohsenow, W. M., and J. P. Harnett. 1973. Handbook of Heat Transfer. McGraw Hill Book Company, New York.

Simonen, F. A., M. E. Mayfield, T. P. Fort, and D. Jones. 1983. Crack Growth Evaluation for Small Cracks in Reactor Coolant Piping. NUREG/CR-3176, PNL-4642, Pacific Northwest Laboratory, Richland, Washington.

Tada, H. 1973. "The Stress Analysis of Crack Handbook." Oel Research Corp., St. Louis, Missouri.

Tingey, G. L., E. J. Wheelwright, and J. M. Lyt1e. 1984. "A Review of Safety Issues That Pertain to the Use of WESF Cesium Chloride Capsules in an Irradiator." PNL-5170, Pacific Northwest Laboratory, Richland, Washington. 
1

$\therefore$ 


\section{APPENDIX A}

CALCULATIONS SUPPORTING ASSUMPTION REGARDING HEAT TRANSFER ACROSS THE ANNULUS BETWEEN THE INNER AND OUTER CAPSULE WALLS 


\section{FREE CONVECTION IN ENCLOSED SPACES}

From "Heat Transfer" by J. P. Holman, 4th ed., McGraw-Hi11, 1976, pp. 255-256.

$$
\begin{aligned}
& \prod_{\rightarrow \infty}^{T_{1}} \prod^{T_{2}} \\
& G r_{\delta}=\frac{g B\left(T_{1}-T_{2}\right) \delta^{3}}{r^{2}} \\
& \text { Low Grashof numbers = no convection } \\
& \mathrm{Gr} s \leq 7000 \\
& \beta=\frac{1}{\left(\frac{1+T_{2}}{2}\right)} \\
& Y_{\text {air }}=26.26 \times 10^{-5} \mathrm{~m}^{2} / \mathrm{sec} \quad \text { kinematic viscosity } \\
& g=\text { gravity acceleration } \\
& \gamma_{\mathrm{N}_{2}} 200^{\circ} \mathrm{K}\left(-100^{\circ} \mathrm{F}\right)=7.568 \times 10^{-6} \mathrm{~m}^{2} / \mathrm{sec} \\
& 1200^{\circ} \mathrm{K}\left(1700^{\circ} \mathrm{F}\right)=156 . \mathrm{I} \times 10^{-6} \mathrm{~m}^{2} / \mathrm{sec} \\
& \gamma=51.19 \times 10^{-6} \frac{\mathrm{m}^{2}}{\mathrm{~s}} \cdot 1.55 \times 10^{3} \frac{\mathrm{in} .^{2} / \mathrm{s}}{\mathrm{m}^{2} / \mathrm{s}}=0.07934 \frac{\mathrm{in.} .^{2}}{\mathrm{~s}} \\
& G r_{\delta}=\frac{386 \frac{\text { in. }}{\sec ^{2}} \frac{2}{\left(T_{1}+T_{2}\right)}\left(T_{1}-T_{2}\right)(0.0515)^{3}}{(0.07934)^{2}}=16.75\left(\frac{T_{1}-T_{2}}{T_{1}+T_{2}}\right) \\
& 16.75\left(\frac{T_{1}-T_{2}}{T_{1}+T_{2}}\right)=1000 \text { Minimum Grashof for free convection to occur } \\
& \frac{T_{1}-T_{2}}{T_{1}+T_{2}}=60 \\
& T_{1}-T_{2}=60 T_{1}+60 T_{2} \\
& (1-60) \mathrm{T}_{1}=61 \mathrm{~T}_{2} \\
& -59 T_{1}=61 T_{2} \\
& \frac{T_{1}}{T_{2}}=-\frac{61}{59}=-1.0334, G r_{6}=1000
\end{aligned}
$$


$T_{1} \simeq-T_{2}$ to satisfy Grashof requirement

Therefore, no convection heat transfer in annulus.

A. 2 


\section{APPENDIX B}

REAL CONSTANT INPUT FOR ANSYS RADIATION LINKS 
TABLE OF ELEMENT REAL CONSTANTS

\begin{tabular}{|c|c|c|c|c|}
\hline No. & Area & Shape Factor & Emissivity & Boltzman Constant \\
\hline 1 & $0.99000-001$ & $0.34500+000$ & $0.50000+000$ & $0.33060-014$ \\
\hline 2 & $0.99000-001$ & $0.31600+000$ & $0.50000+000$ & $0.33060-014$ \\
\hline 3 & $0.99000-001$ & $0.12200+000$ & $0.50000+000$ & $0.33060-014$ \\
\hline 4 & $0.16800+000$ & $0.10000+001$ & $0.50000+000$ & $0.33060-014$ \\
\hline 5 & $0.99000-001$ & $0.10800+000$ & $0.50000+000$ & $0.33060-014$ \\
\hline 6 & $0.99000-001$ & $0.88000-001$ & $0.50000+000$ & $0.33060-014$ \\
\hline 7 & $0.72000-001$ & $0.13700+000$ & $0.50000+000$ & $0.33060-014$ \\
\hline 8 & $0.72000-001$ & $0.15600+000$ & $0.50000+000$ & $0.33060-014$ \\
\hline 9 & $0.72000-001$ & $0.17700+000$ & $0.50000+000$ & $0.33060-074$ \\
\hline 10 & $0.72000-001$ & $0.49000+000$ & $0.50000+000$ & $0.33060-014$ \\
\hline 11 & $0.11800+000$ & $0.10000+001$ & $0.50000+000$ & $0.33060-014$ \\
\hline 12 & $0.14100+000$ & $0.10000+001$ & $0.50000+000$ & $0.33060-014$ \\
\hline 13 & $0.19700+000$ & $0.64700+000$ & $0.50000+000$ & $0.33060-014$ \\
\hline 14 & $0.19700+000$ & $0.34500+000$ & $0.50000+000$ & $0.33060-014$ \\
\hline 15 & $0.22500+000$ & $0.26800+000$ & $0.50000+000$ & $0.33060-014$ \\
\hline 16 & $0.22500+000$ & $0.49000+000$ & $0.50000+000$ & $0.33060-014$ \\
\hline 17 & $0.15300+000$ & $0.34500+000$ & $0.50000+000$ & $0.33060-014$ \\
\hline 18 & $0.15300+000$ & $0.64700+000$ & $0.50000+000$ & $0.33060-014$ \\
\hline 19 & $0.15300+000$ & $0.10800+000$ & $0.50000+000$ & $0.33060-014$ \\
\hline 20 & $0.15300+000$ & $0.12200+000$ & $0.50000+000$ & $0.33060-014$ \\
\hline 21 & $0.15300+000$ & $0.88000-001$ & $0.50000+000$ & $0.33060-014$ \\
\hline 22 & $0.15300+000$ & $0.55000-001$ & $0.50000+000$ & $0.33060-014$ \\
\hline 23 & $0.15300+000$ & $0.64000-001$ & $0.50000+000$ & $0.33060-014$ \\
\hline 24 & $0.15300+000$ & $0.45000-001$ & $0.50000+000$ & $0.33060-014$ \\
\hline 25 & $0.15300+000$ & $0.11000-001$ & $0.50000+000$ & $0.33060-014$ \\
\hline 26 & $0.15300+000$ & $0.20000-002$ & $0.50000+000$ & $0.33060-014$ \\
\hline 27 & $0.15300+000$ & $0.18000-001$ & $0.50000+000$ & $0.33060-014$ \\
\hline 28 & $0.15300+000$ & $0.17700+000$ & $0.50000+000$ & $0.33060-014$ \\
\hline 29 & $0.11800+000$ & $0.10800+000$ & $0.50000+000$ & $0.33060-014$ \\
\hline 30 & $0.11800+000$ & $0.88000-001$ & $0.50000+000$ & $0.33060-014$ \\
\hline 31 & $0.11800+000$ & $0.64000-001$ & $0.50000+000$ & $0.33060-014$ \\
\hline 32 & $0.11800+000$ & $0.55000-001$ & $0.50000+000$ & $0.33060-014$ \\
\hline
\end{tabular}




\begin{tabular}{|c|c|c|c|}
\hline $0.11800+000$ & $0.33000-00 \mathrm{~T}$ & $0.50000+000$ & $0.33060-014$ \\
\hline $0.11800+000$ & $0.24000-001$ & $0.50000+000$ & $0.33060-014$ \\
\hline $0.11800+000$ & $0.12200+000$ & $0.50000+000$ & $0.33060-014$ \\
\hline $0.16800+000$ & $0.55000-007$ & $0.50000+000$ & $0.33060-014$ \\
\hline $0.16800+000$ & $0.45000-001$ & $0.50000+000$ & $0.33060-014$ \\
\hline $0.16800+000$ & $0.24000-001$ & $0.50000+000$ & $0.33060-014$ \\
\hline $0.16800+000$ & $0.14000-001$ & $0.50000+000$ & $0.33060-014$ \\
\hline $0.16800+000$ & $0.13700+000$ & $0.50000+000$ & $0.33060-014$ \\
\hline $0.15300+000$ & $0.14000-001$ & $0.50000+000$ & $0.33060-014$ \\
\hline $0.15300+000$ & $0.60000-002$ & $0.50000+000$ & $0.33060-014$ \\
\hline $0.15300+000$ & $0.15600+000$ & $0.50000+000$ & $0.33060-014$ \\
\hline $0.15300+000$ & $0.13700+000$ & $0.50000+000$ & $0.33060-014$ \\
\hline $0.99000-001$ & $0.30000-002$ & $0.50000+000$ & $0.33060-014$ \\
\hline $0.99000-001$ & $0.24000-001$ & $0.50000+000$ & $0.33060-014$ \\
\hline $0.99000-001$ & $0.64000-001$ & $0.50000+000$ & $0.33060-014$ \\
\hline $0.99000-00\}$ & $0.15600+000$ & $0.50000+000$ & $0.33060-074$ \\
\hline $0.99000-001$ & $0.20800+000$ & $0.50000+000$ & $0.33060-014$ \\
\hline $0.99000-001$ & $0.33000-001$ & $0.50000+000$ & $0.33060-014$ \\
\hline $0.57000-001$ & $0.24000-001$ & $0.50000+000$ & $0.33060-014$ \\
\hline $0.57000-001$ & $0.64000-001$ & $0.50000+000$ & $0.33060-074$ \\
\hline $0.57000-001$ & $0.15600+000$ & $0.50000+000$ & $0.33060-014$ \\
\hline $0.57000-001$ & $0.34500+000$ & $0.50000+000$ & $0.33060-014$ \\
\hline $0.57000-001$ & $0.75000-001$ & $0.50000+000$ & $0.33060-014$ \\
\hline $0.60000-002$ & $0.75000-001$ & $0.50000+000$ & $0.33060-014$ \\
\hline $0.60000-002$ & $0.20800+000$ & $0.50000+000$ & $0.33060-014$ \\
\hline $0.60000-002$ & $0.49000+000$ & $0.50000+000$ & $0.33060-014$ \\
\hline $0.60000-002$ & $0.13700+000$ & $0.50000+000$ & $0.33060-074$ \\
\hline $0.15300+000$ & $0.75000-001$ & $0.90000+000$ & $0.33060-074$ \\
\hline $0.19100+000$ & $0.26800+000$ & $0.90000+000$ & $0.33060-014$ \\
\hline $0.19100+000$ & $0.20800+000$ & $0.90000+000$ & $0.33060-014$ \\
\hline $0.19100+000$ & $0.15600+000$ & $0.90000+000$ & $0.33060-014$ \\
\hline $0.19100+000$ & $0.18000-001$ & $0.90000+000$ & $0.33060-014$ \\
\hline $0.19100+000$ & $0.12200+000$ & $0.90000+000$ & $0.33060-014$ \\
\hline $0.19100+000$ & $0.88000-001$ & $0.90000+000$ & $0.33060-014$ \\
\hline $0.19100+000$ & $0.60000-002$ & $0.90000+000$ & $0.33060-014$ \\
\hline
\end{tabular}




\begin{tabular}{|c|c|c|c|c|}
\hline 68 & $0.11800+000$ & $0.20800+000$ & $0.90000+000$ & $0.33060-014$ \\
\hline 69 & $0.11800+000$ & $0.17700+000$ & $0.90000+000$ & $0.33060-014$ \\
\hline 70 & $0.11800+000$ & $0.15600+000$ & $0.90000+000$ & $0.33060-014$ \\
\hline 71 & $0.11800+000$ & $0.33000-001$ & $0.90000+000$ & $0.33060-014$ \\
\hline 72 & $0.11800+000$ & $0.13700+000$ & $0.90000+000$ & $0.33060-014$ \\
\hline 73 & $0.11800+000$ & $0.12800+000$ & $0.90000+000$ & $0.33060-014$ \\
\hline 74 & $0.11800+000$ & $0.90000-002$ & $0.90000+000$ & $0.33060-014$ \\
\hline 75 & $0.57000-001$ & $0.13700+000$ & $0.90000+000$ & $0.33060-014$ \\
\hline 76 & $0.57000-001$ & $0.45000-001$ & $0.90000+000$ & $0.33060-014$ \\
\hline 77 & $0.57000-001$ & $0.20800+000$ & $0.90000+000$ & $0.33060-014$ \\
\hline 78 & $0.57000-001$ & $0.17700+000$ & $0.90000+000$ & $0.33060-074$ \\
\hline 79 & $0.57000-001$ & $0.90000-002$ & $0.90000+000$ & $0.33060-014$ \\
\hline 80 & $0.70000-002$ & $0.88000-001$ & $0.90000+000$ & $0.33060-014$ \\
\hline 81 & $0.70000-002$ & $0.64000-001$ & $0.90000+000$ & $0.33060-014$ \\
\hline 82 & $0.70000-002$ & $0.17700+000$ & $0.90000+000$ & $0.33060-014$ \\
\hline 83 & $0.70000-002$ & $0.20800+000$ & $0.90000+000$ & $0.33060-014$ \\
\hline 84 & $0.70000-002$ & $0.33000-001$ & $0.90000+000$ & $0.33060-014$ \\
\hline 85 & $0.57000-001$ & $0.11000-001$ & $0.50000+000$ & $0.33060-014$ \\
\hline 86 & $0.57000-001$ & $0.55000-001$ & $0.50000+000$ & $0.33060-074$ \\
\hline 87 & $0.57000-001$ & $0.64000-001$ & $0.50000+000$ & $0.33060-014$ \\
\hline 88 & $0.57000-001$ & $0.88000-001$ & $0.50000+000$ & $0.33060-014$ \\
\hline 89 & $0.57000-001$ & $0.10600+000$ & $0.50000+000$ & $0.33060-014$ \\
\hline 90 & $0.57000-001$ & $0.12200+000$ & $0.50000+000$ & $0.33060-014$ \\
\hline 91 & $0.35000-001$ & $0.11000-001$ & $0.50000+000$ & $0.33060-014$ \\
\hline 92 & $0.35000-001$ & $0.45000-001$ & $0.50000+000$ & $0.33060-014$ \\
\hline 93 & $0.35000-001$ & $0.55000-001$ & $0.50000+000$ & $0.33060-014$ \\
\hline 94 & $0.35000-001$ & $0.64000-001$ & $0.50000+000$ & $0.33060-074$ \\
\hline 95 & $0.35000-001$ & $0.75000-001$ & $0.50000+000$ & $0.33060-014$ \\
\hline 96 & $0.35000-001$ & $0.88000-001$ & $0.50000+000$ & $0.33060-074$ \\
\hline 97 & $0.35000-001$ & $0.10800+000$ & $0.50000+000$ & $0.33060-014$ \\
\hline 98 & $0.35000-001$ & $0.13700+000$ & $0.50000+000$ & $0.33060-074$ \\
\hline 99 & $0.35000-001$ & $0.17700+000$ & $0.50000+000$ & $0.33060-014$ \\
\hline 100 & $0.35000-001$ & $0.29800+000$ & $0.50000+000$ & $0.33060-014$ \\
\hline 101 & $0.19000-001$ & $0.10000+001$ & $0.65000+000$ & $0.33060-014$ \\
\hline 102 & $0.60000-002$ & $0.10000+001$ & $0.65000+000$ & $0.33060-074$ \\
\hline
\end{tabular}




$\begin{array}{lllll}103 & 0.49000-001 & 0.10000+001 & 0.65000+000 & 0.33060-014 \\ 104 & 0.10000+000 & 0.10000+001 & 0.65000+000 & 0.33060-014 \\ 105 & 0.16000+000 & 0.10000+001 & 0.65000+000 & 0.33060-014 \\ 106 & 0.71000-001 & 0.10000+001 & 0.65000+000 & 0.33060-014 \\ 107 & 0.11500+000 & 0.10000+001 & 0.65000+000 & 0.33060-014 \\ 108 & 0.81000-001 & 0.10000+001 & 0.65000+000 & 0.33060-014 \\ 109 & 0.20000+000 & 0.10000+001 & 0.65000+000 & 0.33060-014 \\ 110 & 0.13400+000 & 0.10000+001 & 0.65000+000 & 0.33060-014 \\ 111 & 0.59000-001 & 0.10000+001 & 0.65000+000 & 0.33060-014 \\ 112 & 0.23000-001 & 0.10000+001 & 0.65000+000 & 0.33060-014 \\ 113 & 0.15000-001 & 0.10000+001 & 0.65000+000 & 0.33060-014 \\ 114 & 0.12000-001 & 0.10000+001 & 0.65000+000 & 0.33060-014 \\ 115 & 0.28000-001 & 0.10000+001 & 0.65000+000 & 0.33060-014 \\ 116 & 0.40000-001 & 0.10000+001 & 0.65000+000 & 0.33060-014 \\ 117 & 0.40000-002 & 0.10000+001 & 0.65000+000 & 0.33060-014 \\ 118 & 0.30000-002 & 0.10000+001 & 0.65000+000 & 0.33060-014 \\ 119 & 0.33000-001 & 0.10000+001 & 0.65000+000 & 0.33060-014\end{array}$




\section{APPENDIX C}

CALCULATIONS SUPPORTING THE ONE-DIMENSIONAL STEADY-STATE ANSYS TEMPERATURE PROFILE 
$80^{\circ} \mathrm{F} \mathrm{Air}$

$C_{3} C_{1}$

\section{RADIATION AND CONVECTION AT OUTER SURFACE}

\section{Convection}

$$
\begin{aligned}
& q_{c}=\frac{T_{1}-T_{\infty}}{\frac{1}{h A}}=\frac{T_{1}-T_{\infty}}{\frac{1}{3.4 \times 10^{-6}(2 \pi)(1.3125) 1}}=\frac{T_{1}-T_{\infty}}{35665} \quad \text { (Air) } \\
& q_{c}=\frac{T_{1}-T_{\infty}}{\frac{1}{h A}}=\frac{T_{1}-T_{\infty}}{\frac{1}{1.929 \times 10^{-4}(2 \pi)(1.3125) 1}}=\frac{T_{1}-T_{\infty}}{628.62} \quad \text { (Water) }
\end{aligned}
$$

Radiation Resistance

$$
\begin{aligned}
R_{R}= & \frac{1-\varepsilon_{1}}{\varepsilon_{2} A_{1}}+\frac{1}{F_{12} A_{1}}+\frac{1-\varepsilon_{2}}{\varepsilon_{2} A_{2}} \\
= & \frac{1-0.7}{0.7(2 \pi)(1.3125)(1)}+\frac{1}{2 \pi(1.3125)(1)(1)}+0=1.7323 \times 10^{-1} \\
& \frac{1.7323 \times 10^{-1}}{0.3306 \times 10^{-14}}=5.2399 \times 10^{13}
\end{aligned}
$$

$T_{1}^{A i r}=295^{\circ} \mathrm{F} \quad$ From attached program $\quad T_{1}^{\text {Water }}=76.6^{\circ} \mathrm{F}$

Concluction Through Outer Wall

$$
\begin{array}{rlrl}
Q_{\text {cond }} & =\frac{T_{1}-T_{2}}{\frac{\Delta x}{k A}}=\frac{T_{1}-T_{2}}{\frac{\ln \left(r_{2} / r_{1}\right)}{2 \pi k L}}=\frac{T_{1}-T_{2}}{\frac{1.3125}{1.1765}} \frac{1 \pi k}{2 \pi k L} \quad(L=1) \\
R & =\frac{1.741 \times 10^{-2}}{k} & R^{\text {Water }}=\frac{1.741 \times 10^{-2}}{1.8071 \times 10^{-4}}
\end{array}
$$




$$
\begin{aligned}
& R^{A}=87.0496 \\
q=1.06 \times 10^{-2}=\frac{T_{1}-T_{2}}{R} & \\
T_{1}=R 1.06 \times 10^{-2}+T_{2} & T_{1}^{W}=96.3418 \\
T_{1}^{A}=87.0496\left(1.06 \times 10^{-2}\right)+295 & T_{1}^{W}=77.6^{\circ} \mathrm{F} \\
T_{1}^{A}=295.9 &
\end{aligned}
$$

Thermal short - no change in temperature through wall.

\section{INNER GAP}

Conduction

$$
\begin{aligned}
& R_{\text {cond }}=\frac{\ln \frac{r_{0}}{r_{1}}}{2 \pi \mathrm{kL}}=\frac{\ln \frac{1.1765}{1.125}}{2 \pi \mathrm{kL}}=\frac{7.162 \times 10^{-3}}{k} \\
& \mathrm{R}_{\text {cond }}^{A}=\frac{7.162 \times 10^{-3}}{4.83 \times 10^{-7}}=14828 \quad \mathrm{R}_{\text {cond }}^{\mathrm{W}}=\frac{7.162 \times 10^{-3}}{3.74 \times 10^{-7}}=19133
\end{aligned}
$$

\section{Radiation Resistance}

$$
\begin{array}{rlrl}
R_{A D}= & \frac{1-0.5}{(0.5)(2 \pi)(1.125) 1}+\frac{1}{2 \pi(1.125) 1(7)}+\frac{1-0.5}{(0.5) 2 \pi(1.1765) 1}=0.41822 \\
& \frac{0.41822}{0.3306 \times 10^{-14}}=1.265 \times 10^{14} & \\
T_{2}= & 300^{\circ} \mathrm{F} & T_{2}=76.6^{\circ} \mathrm{F} \\
T_{1}= & 425^{\circ} \mathrm{F} \quad \text { From a ttached progrant } \quad T_{1}=253^{\circ} \mathrm{F}
\end{array}
$$

Profile in Fuel

$$
\begin{array}{rlrl}
\text { Air Storage } & \text { Water Storage } \\
T-425 & =\frac{3.4466 \times 10^{-3}}{4\left(6.3 \times 10^{-6}\right)}\left(0.989^{2}-r^{2}\right) & T-253 & =\frac{3.4466 \times 10^{-3}}{4\left(6.75 \times 10^{-6}\right)}\left(0.989^{2}-r^{2}\right) \\
T-425 & =135\left(0.989^{2}-r^{2}\right) & T-253 & =127.65\left(0.989^{2}-r^{2}\right) \\
T_{c} & =557^{\circ} \mathrm{F} & T_{c} & =378^{\circ} \mathrm{F}
\end{array}
$$




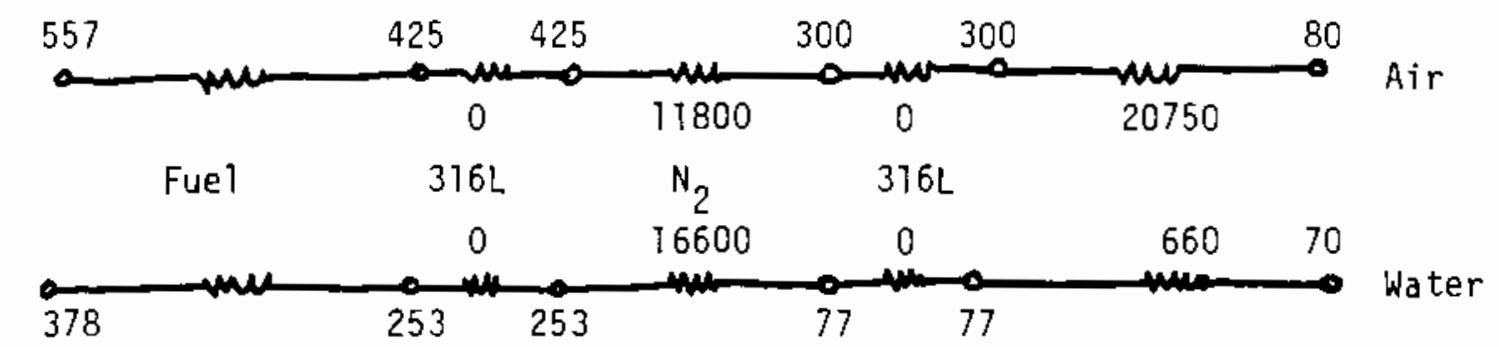

HP Program for Combined Radiation and Convection or Conduction

〈nown temperature... Store 2

ionvection or conduction resistance... Store 9

Radiation resistance... Store 7

Key in unknown temperature guess.

$\begin{array}{lcr}001 & \text { *LBLE } & 2 T 15 \\ 002 & \text { ENT } & -21 \\ 003 & \text { ST01 } & 3501 \\ 004 & \text { ZCL2 } & 3602 \\ 005 & - & -45 \\ 006 & \text { ST03 } & 3503 \\ 007 & \text { RCL1 } & 3601 \\ 008 & \text { RCL4 } & 3604 \\ 009 & + & -55 \\ 010 & X^{2} & 53 \\ 011 & \text { RCL2 } & 3602 \\ 012 & \text { RCL4 } & 3604 \\ 013 & + & -55 \\ 014 & X^{2} & 53 \\ 015 & + & -55 \\ 016 & \text { ST05 } & 3505 \\ 017 & \text { RCL1 } & 3601 \\ 018 & \text { RCL2 } & 3602 \\ 019 & + & -55 \\ 020 & \text { RCL6 } & 3606\end{array}$

\begin{tabular}{|c|c|c|}
\hline 021 & + & -55 \\
\hline 022 & RCL 5 & 3605 \\
\hline 023 & $x$ & -35 \\
\hline 024 & RCL 7 & 3607 \\
\hline 025 & $X \notin Y$ & -41 \\
\hline 026 & $\div$ & -24 \\
\hline 027 & ST08 & 350 \\
\hline 028 & RCL 9 & 3609 \\
\hline 029 & $x$ & -35 \\
\hline 030 & RCL9 & 3609 \\
\hline 031 & RCL8 & 3608 \\
\hline 032 & + & -5 \\
\hline 033 & 4 & -2 \\
\hline 034 & STOC & $35 \quad 13$ \\
\hline 035 & $\mathrm{RCL} 3$ & 3603 \\
\hline 036 & $x \neq y$ & $-4 I$ \\
\hline 037 & $\div$ & -2 \\
\hline 038 & STOB & 351 \\
\hline 039 & RCLA & 3611 \\
\hline 040 & - & 10 \\
\hline & $R / S$ & \\
\hline
\end{tabular}

C. 3 
, . 


\section{APPENDIX D}

STRESS INTENSITY FACTOR CALCULATIONS USING

THE DISPLACEMENT METHOD 
From Tada Handbook

$$
\begin{aligned}
& u=\frac{X_{I}}{G}[r /(2 \pi)]^{1 / 2} \cos \frac{\theta}{2}\left[1-2 v+\sin ^{2} \frac{\theta}{2}\right] \\
& \frac{\delta}{2}=v=\frac{K_{I}}{G}[r /(2 \pi)]^{1 / 2} \sin \frac{\theta}{2}\left[2-2 v+\cos ^{2} \frac{\theta}{2}\right] \\
& v=\text { crack opening } \\
& \theta=180^{\circ}
\end{aligned}
$$

$$
\begin{aligned}
\frac{\delta}{2} & =v=\frac{K_{I}}{G}(r /(2 \pi))^{T / 2}(2-2 v) \quad \text { (plane strain) } \\
K_{I} & =V G\left(\frac{2 \pi}{r}\right)^{1 / 2} \frac{1}{2(1-v)} \quad, G=\frac{E}{2(1+v)} \\
K_{I} & =V \frac{E}{2(1+v)} \frac{\sqrt{2 \pi}}{\sqrt{r}} \cdot \frac{1}{2(1-v)} \\
& =\frac{v}{\sqrt{r}} \frac{E \sqrt{2 \pi}}{4\left(1-v^{2}\right)}=\frac{\sqrt{2 \pi}}{4}\left(\frac{E}{1-v^{2}}\right) \frac{v}{\sqrt{r}} \\
K_{I} & =0.627\left(\frac{E}{1-v^{2}}\right) \frac{v}{\sqrt{r}}=0.313\left(\frac{E}{1-v^{2}}\right) \frac{\delta}{\sqrt{r}}
\end{aligned}
$$

$v=$ vertical displacement component from $\theta=180^{\circ}$ at nearest node to crack tip in opening

$\delta=$ total vertical travel of two nodes nearest crack tip

$E$ = temperature dependent elastic modulus

$v=$ temperature dependent Poisson's ratio

$r=$ distance (radial) from crack tip to nodes of interest

Extremes for Upper and Lower Weld

Upper Weld

$\begin{array}{lccr}\text { Quench } & 20 \mathrm{sec} & v=-8.4 \times 10^{-6} & \text { Temp } \simeq 133^{\circ} \mathrm{F} \\ \text { Air Heatup } & 400 \mathrm{sec} & v=1.75 \times 10^{-6} & \text { Temp } \simeq 96^{\circ} \mathrm{F} \\ \text { Temo }=96^{\circ} \mathrm{F} & v=0.26654 & E=28 \times 10^{6} \\ \text { Temp }=133^{\circ} \mathrm{F} & v=0.26813 & E=27.85 \times 10^{6}\end{array}$




$$
\begin{aligned}
& r=\left(x_{1}-x_{2}\right)=(1.2507-1.2566)=|0.0059| \quad \Delta \text { node coords. } \\
& K_{I}^{!}=0.627 \frac{28 \times 10^{6}}{1-(0.26654)^{2}} \frac{-8.4 \times 10^{-6}}{\sqrt{0.0059}} \\
& K_{I}^{1}=-2067 \\
& K_{I}^{2}=0.627 \frac{27.85 \times 10^{6}}{1-(0.26813)^{2}} \frac{1.75 \times 10^{-6}}{\sqrt{0.0059}} \\
& K_{I}^{2}=430 \quad \Delta K=430-(-2067) \approx 2500 \mathrm{psi} \sqrt{\mathrm{in} .} \\
& \Delta K=2.5 \mathrm{ksi} \sqrt{i \mathrm{n} .}
\end{aligned}
$$

Lower Weld

$$
\begin{aligned}
& \text { Quench } \quad 30 \mathrm{sec} \quad v=-2.5402 \times 10^{-5} \quad \text { Temp } \simeq 117^{\circ} \mathrm{F} \\
& \text { Air Heatup } 400 \mathrm{sec} \quad v=-1.432 \times 10^{-6} \quad \text { Temp }=96^{\circ} \mathrm{F} \\
& \text { Temp }=117^{\circ} \mathrm{F} \quad v=0.26744 \quad E=27.92 \times 10^{6} \quad r=(1.2249-1.2326)=0.0077 \\
& K_{I}^{l}=0.627 \frac{27.92 \times 10^{6}}{1-(0.26744)^{2}} \quad \frac{-2.5402 \times 10^{-5}}{\sqrt{0.0077}}=-5458 \\
& K_{I}^{2}=0.627 \frac{27.85 \times 10^{6}}{1-(0.26813)^{2}} \quad \frac{-1.432 \times 10^{-6}}{\sqrt{0.0077}}=-307 \\
& \Delta K=\left|K_{I}^{1}\right|-\left|K_{I}^{2}\right|=5151 \text { psi } \sqrt{i n} \text {. } \\
& \Delta K=5.15 \mathrm{ksi} \sqrt{\mathrm{in}} \text {. }
\end{aligned}
$$





\section{APPENDIX E}

STRESS INTENSITY FACTOR CALCULATIONS USING

THE CRACK CLOSURE WORK METHOD 
K ENERGY METHOD

ORIGINAL CRACK TIP DISP

20 sec Quench

$30 \mathrm{sec}$ Quench

Upper weld

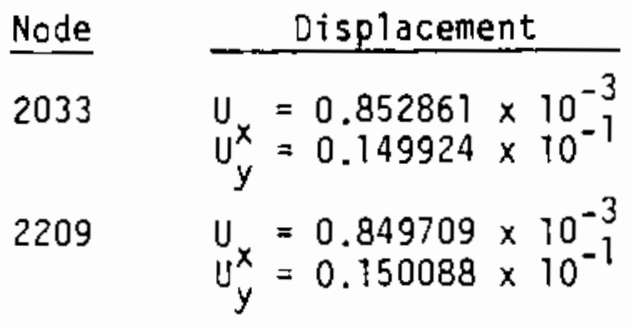

400 sec Heatup

Upper weld

Node

$\frac{\text { Displacement }}{U_{y}=0.255778 \times 10^{-3}}$

2033

2209

$$
\begin{aligned}
& U_{y}=0.256196 \times 10^{-3} \\
& U_{y}^{x}=0.128892 \times 10^{-1}
\end{aligned}
$$

Lower weld

Node

Displacement

2403

$U_{x}=0.134615 \times 10^{-2}$
$U_{y}=-0.402575 \times 10^{-3}$

2445

$$
\begin{aligned}
& U_{x}=0.135574 \times 10^{-2} \\
& U_{y}=-0.350449 \times 10^{-3}
\end{aligned}
$$

400 sec Hea tup

Lower weld

Node

Displacement

2403

$$
\begin{aligned}
U_{x} & =0.544617 \times 10^{-3} \\
U_{y} & =0.10404 \times 10^{-3}
\end{aligned}
$$

2445

$$
\begin{aligned}
& U_{y}=0.545147 \times 10^{-3} \\
& U_{y}=0.106978 \times 10^{-3}
\end{aligned}
$$

CORRESPONDING NODAL FORCES

20 Sex Quench

Upper weld

Node 2033
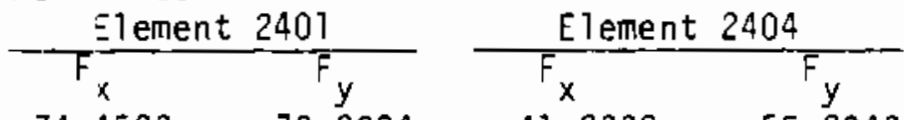

$74.4593 \quad-70.0324$

$-41.2338 \quad-55.2343$

Node 2209

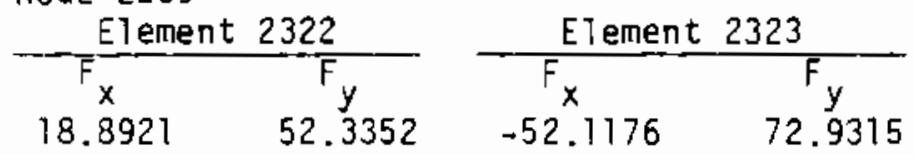

$30 \mathrm{sec}$ Quench

$$
\text { Lower weld }
$$

Node 2403

$\begin{array}{ccccc}F_{x} \frac{\text { Element }}{x} \frac{431}{F_{y}} & & \frac{\text { Element }}{F_{x}} & 432 \\ 50.8553 & -156.972 & -153.769 & -220.278\end{array}$


Node 2445

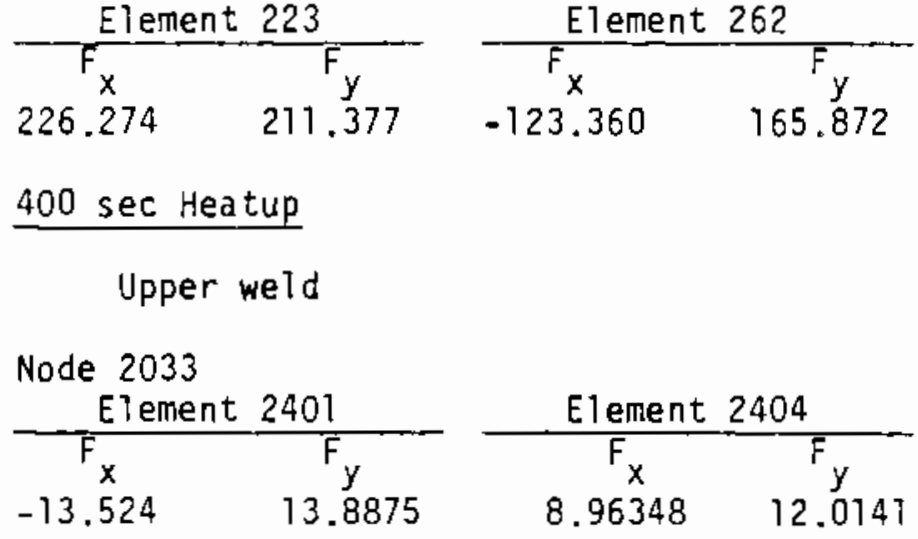

Node 2209

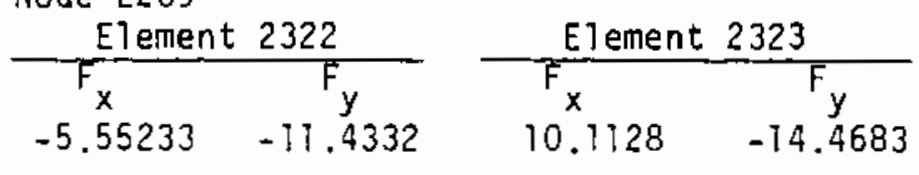

400 sec Heatup

Lower we1d

Node 2403

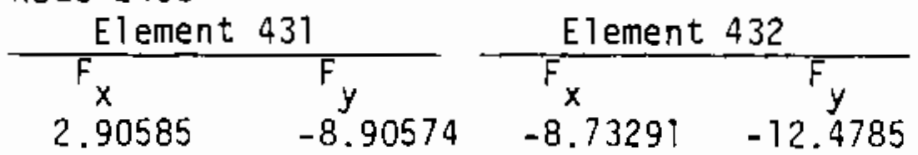

Node 2445

\begin{tabular}{ccccc}
$\frac{\text { Element 223 }}{F_{x}}$ & & \multicolumn{2}{c}{ Element 262 } \\
& $F_{y}$ & & $F_{x}$ & $F_{y}$ \\
11.9718 & & -7.07385 & 9.41248
\end{tabular}

\section{CRACK CLOSURE WORK METHOD}

Plane Strain

$$
E_{T}=\frac{I-v}{2 G} k_{I}^{2} \quad E_{T}=\frac{d w}{d a} \simeq \frac{\Delta w}{\Delta a}
$$

$$
\begin{aligned}
& \text { From Tada Mode I } \\
& \frac{\Delta w}{\Delta a}=\frac{1 / 2\left(F_{y} U_{y}+F_{x} U_{x}\right)}{R\left(a_{2}-a_{1}\right)} \\
& E_{T}=\text { total energy } \\
& v=\text { Poisson's ratio } \\
& G=\text { shear modulus, } E / 2(1+v)
\end{aligned}
$$$$
\text { Tota } 1 \text { work includes }
$$$$
\text { modes I and II }
$$ 


$$
\begin{aligned}
& k_{I}=\text { stress intensity factor } \\
& F_{y}=\text { nodal y force ( } \Sigma \text { a } 11 \text { element contributions) } \\
& J_{y}=\text { nodal y displ-relative } \\
& \bar{x}_{x}=\text { nodal } x \text { force }(\varepsilon \text { all element contributions) } \\
& { }^{11}{ }_{x}=\text { nodal dispi-relative } \\
& a_{1}=\text { original crack length } \\
& \mathrm{i}_{2}=\text { first unzipping } \\
& \mathrm{R}=\text { radius to unzipped nodes (released this time step) } \\
& \frac{\Delta w}{\Delta \mathrm{a}}=\frac{1-v}{2 \mathrm{G}} \mathrm{K}_{\mathrm{I}}^{2} \\
& \frac{\Delta w}{\Delta a} \quad \frac{2 G}{T-v}=K_{I}^{2} \\
& K_{I}=\sqrt{\frac{\Delta w}{\Delta a} \frac{2 G}{T-\nu}}=\sqrt{\frac{\Delta w}{\Delta a} \frac{2}{1-\nu} \frac{E}{2(T+v)}} \\
& K_{I}=\sqrt{\frac{\Delta w}{\Delta a}-\bar{E}} \\
& =\left[\frac{1 / 2\left(F_{y} U_{y}+F_{x} U_{x}\right)}{R\left(a_{2}-a_{1}\right)}\left(\frac{E}{1-v^{2}}\right)\right]^{1 / 2} \\
& =\left[\frac{E}{2\left(1-v^{2}\right)} \frac{\left(F_{y} U_{y}+F_{x} U_{x}\right)}{R\left(a_{2}-a_{1}\right)}\right]^{I / 2} \\
& =\left[\frac{E}{2 R\left(a_{2}-a_{1}\right)\left(1-v^{2}\right)}\left(F_{y} U_{y}+F_{x} U_{x}\right)\right]^{1 / 2} \\
& K_{I}=\left[\frac{E\left(F_{y} U_{y}+F_{x} U_{x}\right)}{2 R\left(a_{2}-a_{1}\right)\left(1-v^{2}\right)}\right]^{1 / 2}
\end{aligned}
$$

so for Mode I

$$
K_{I}=\left[\frac{E\left(F_{y} U_{y}\right)}{2 R\left(a_{2}-a_{p}\right)\left(1-v^{2}\right)}\right]^{1 / 2}
$$




\section{Upper Weld}

\begin{tabular}{|c|c|c|c|}
\hline Quench & $20 \mathrm{sec}$ & $v=0.26813$ & $E=27.85 \times 10^{6}$ \\
\hline Heatu & $400 \mathrm{sec}$ & $v=0.26654$ & $E=28 \times 10^{6}$ \\
\hline
\end{tabular}

Lower Weld

$\begin{array}{lrlrl}\text { Quench } \quad 30 \mathrm{sec} & v=0.26744 & E=27.92 \times 10^{6} \\ \text { Heatup } \quad 400 \mathrm{sec} & v=0.26654 & E=28 \times 10^{6} \\ \text { Quench (20 sec) (Upper) } & & \end{array}$

$\underline{N 2033}$

$K_{I}=\sqrt{\frac{27.85 \times 10^{6}(-55.2343+-70.0324)\left(0.149924 \times 10^{-1}-0.150088 \times 10^{-1}\right)}{\frac{2(1.2566+1.2624)(1.2087-1.2566)-(1.2087-1.2624)\left(1-0.26813^{2}\right)}{2}(1.2087-(1.256)}}$

$K_{I}=-2054$ psi $\sqrt{\text { in }} . \quad(-2067$ from Displacement Method $)$

Heatup (400 sec)

$K_{I}=\sqrt{\frac{28 \times 10^{6}(13.887+12.0141)\left(0.128926 \times 10^{-1}-0.128892 \times 10^{-1}\right)}{\frac{2(1.2566+1.2624)}{2}\left(1.2624-1.2566\left(1-0.26654^{2}\right)\right.}}$

$K_{I}=426$ psi $\sqrt{i n}$ (430 from Displacement Method)

$\Delta K_{I}=426-(-2054)=2.48 \mathrm{ksi} \sqrt{\overline{i n}}$. (2.5 from Displacement Method)

Same growth rate for upper weld.

Lower weld

$$
X_{I}=\frac{E F_{y} U_{y}}{2 R\left(a_{2}-a_{1}\right)\left(1-v^{2}\right)}
$$

Quench $(30 \mathrm{sec})$

N2445

$$
\begin{aligned}
& K_{I}=\frac{\sqrt{\frac{27.92 \times 10^{6}(211.377+165.872)\left(0.350449 \times 10^{-3}-0.402575 \times 10^{-3}\right)}{2(1.2326+1.2403)(1.2403-1.2326)-\left(1-0.25744^{2}\right)}}}{K_{I}=-5573 \text { psi } \sqrt{i n .} \quad(-5458 \text { from Displacement Method })}
\end{aligned}
$$


Heat쏘 $(400$ sec)

N2445

$K_{I}=\sqrt{\frac{\left(28 \times 10^{6}\right)(11.9718+9.41248)\left(0.10404 \times 10^{-3}-0.106978 \times 10^{-3}\right)}{(1.2326+1.2403)(1.2403-1.2326)\left(1-0.26744^{2}\right)}}$

$k_{1}=-375$ psi $\sqrt{i n} . \quad(-307$ from Displacement Method)

$\Delta K=-3 i 5-5573=5258 \mathrm{ksi} \sqrt{\mathrm{in}} . \quad$ (5.15 from Displacement Method)

Virtsally no difference between results of displacement and energy method.

Displacement Method $K$

Upper weld

$$
-2067 \text { psi } \sqrt{\text { in }} \text {. }
$$$$
\Delta K=\frac{430}{2497}
$$

Lower weld

$$
\Delta K=\frac{-5458 \text { psi } \sqrt{i n .}}{5151}
$$

Energy Method K

$$
\begin{aligned}
\Delta K= & \begin{array}{r}
-2054 \text { psi } \sqrt{i n .} \\
2486
\end{array} \\
& -5573 \text { psi } \sqrt{i n .} \\
\Delta K= & \frac{-375}{5258}
\end{aligned}
$$




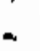

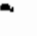




\section{DISTRIBUTION}

No. of

Copies

OFFSITE

30 DOE Technical Information Center

3 DOE Office of Defense Waste \& Byproducts Washington, DC 20545

ATNN: 0 . B. LeClaire, OP-12

J. J. Jicha, Jr.

W. C. Remini

2 DCE Office of Terminal Waste 0isposal \& Remedial Action Washington, OC 20545

ATTN: J. A. Coleman, $N E-25$

W. R. Voigt, $N E-20$

]. Ayer

U.S. Nuclear Regulatory Commission Mail Stop SS-396

Washington, OC 20555

M. J. Bell

Division of Nuclear Materials Safety \& Safeguards

Mail Station 881-SS

U.S. Nuclear Regulatory Commission Washington, DC 20555

\section{A. T. Clark}

Division of Fuel Material Safety

U.S. Nuclear Regulatory Commission

Washington, DC 20555

2 Evvironmental Protection Agency

Office of Radiation Programs

4)1 M Street, S.W.

Washington, DC 20460

ATTN: D. Egan

G. L. Sjoblam
No. of

Copies

3 OOE Albuquerque Operations office P.0. Box 5400

A1buquerque, NM 87185

ATTN: R. Y. Lowrey

J. McGough

W. H. McMulien

G. K. Oertel

DOE Savannah River Operations Dffice

P.0. Box A

Aiken, SC 29801

B. Rawles

Battelle Menorial Institute

$505 \mathrm{King}$ Avenue

Columbus, $\mathrm{OH} 43201$

3 Oak Ridge National Laboratory

P.0. Box $X$

Oak Ridge, TN 37830

ATTN: K. W. Haff

E. Lamb

F. J. Schultz

W. R. McDonne 11

E. I. du Pont de Nemours Company

Savannah River Laboratory

Aiken, SC 29801

R. G. Post

College of Engineering

Univerity of Arizona

Tucson, AZ 85721

D. J. Sasmor

Sandia National Laboratories

Division 6453

Albuquerque, NM 87185 
No. of

Copies

ONSITE

7 DOE Richland Dperations Office

E. A. Bracken

M. Dayan $i$

C. R. Delannoy

J. J. Krupar Jr.

M. J. Plahuta

J. L. Rhoades

M. W. Shupe

J. D. White

5 Rockwell Han ford Operations

K. A. Gasper

M. W. Gibson

I. E. Reep

R. H. Riech

R. L. Salley
No. of

Copies

50 Pacific Northwest Laboratory

M. C. C. Bampton

G. H. Bryan

D. E. Eakin

S. K. Edler

W. J. Gray

C. R. Hann

P. E. Hart

R. F. Hazel ton

J. H. Jarrett

G. A. Jensen

Y. B. Katayama

H. E. Kjarmo

J. M. Latkovjch

R. C. Liikala

J. L. McEl roy

R. E. Nightingale

A. M. Platt

R. J. Shippell

G. L. Tingey (25)

R. P. Turcotte

E. J. Wheelwright

Publishing Coordination (2)

Technical Information (5) 